NBER WORKING PAPER SERIES

\title{
CONNECTING TO POWER: \\ POLITICAL CONNECTIONS, INNOVATION, AND FIRM DYNAMICS
}

\author{
Ufuk Akcigit \\ Salomé Baslandze \\ Francesca Lotti \\ Working Paper 25136 \\ http://www.nber.org/papers/w25136
}

\author{
NATIONAL BUREAU OF ECONOMIC RESEARCH \\ 1050 Massachusetts Avenue \\ Cambridge, MA 02138 \\ October 2018
}

We thank Marco Chiurato, Salvatore Di Novo, and Marta Prato for excellent research assistance and our discussants Stefania Albanesi, Serdar Dinc, Stuart Graham, and Matteo Maggiori, for very constructive comments. We thank seminar and conference participants at the University of Chicago, MIT, Harvard, Penn State, NYU, ASSA Meetings, Richmond Fed, Georgetown University, Institute for Fiscal Studies, Harvard Business School, World Bank, Brandeis University, Tufts University, University College London, University of Maryland, EIEF, Bank of Italy, SKEMA Business School, CEPR Symposium, Philadelphia Fed, College de France, Banque de France, Turkish Central Bank, IESE, St. Louis Fed, University of Toronto Rotman, New York Fed, Atlanta Fed, INSEAD, University of Zurich, Munich Summer Institute, SED Mexico, INPS, NBER Entrepreneurship meeting, NBER Political Economy meeting, NBER Productivity lunch meeting for very helpful feedback and discussions. For providing invaluable support with the data access, we thank the research division of the Social Security Institute of Italy (INPS), especially Massimo Antichi, Mariella Cozzolino, Edoardo Di Porto, and Paolo Naticchioni. The views expressed by the authors do not necessarily reflect those of the Bank of Italy, INPS, the Federal Reserve System, or the National Bureau of Economic Research.

NBER working papers are circulated for discussion and comment purposes. They have not been peerreviewed or been subject to the review by the NBER Board of Directors that accompanies official NBER publications.

(C) 2018 by Ufuk Akcigit, Salomé Baslandze, and Francesca Lotti. All rights reserved. Short sections of text, not to exceed two paragraphs, may be quoted without explicit permission provided that full credit, including $\odot$ notice, is given to the source. 
Connecting to Power: Political Connections, Innovation, and Firm Dynamics

Ufuk Akcigit, Salomé Baslandze, and Francesca Lotti

NBER Working Paper No. 25136

October 2018, Revised April 2020

JEL No. D70,O3,O4

\begin{abstract}
$\underline{\text { ABSTRACT }}$
How do political connections affect firm dynamics, innovation, and creative destruction? To answer this question, we build a firm dynamics model, where we allow firms to invest in innovation and/or political connection to advance their productivity and to overcome certain market frictions. Our model generates a number of theoretical testable predictions and highlights a new interaction between static gains and dynamic losses from rent-seeking in aggregate productivity. We test the predictions of our model using a brand-new dataset on Italian firms and their workers, spanning the period from 1993 to 2014, where we merge: (i) firm-level balance sheet data; (ii) social security data on the universe of workers; (iii) patent data from the European Patent Office; (iv) the national registry of local politicians; and (v) detailed data on local elections in Italy. We find that firm-level political connections are widespread, especially among large firms, and that industries with a larger share of politically connected firms feature worse firm dynamics. We identify a leadership paradox: when compared to their competitors, market leaders are much more likely to be politically connected, but much less likely to innovate. In addition, political connections relate to a higher rate of survival, as well as growth in employment and revenue, but not in productivity - a result that we also confirm using a regression discontinuity design.
\end{abstract}

Ufuk Akcigit

Department of Economics

University of Chicago

1126 East 59th Street

Saieh Hall, Office 403

Chicago, IL 60637

and NBER

uakcigit@uchicago.edu

Salomé Baslandze

Einaudi Institue for Economics and Finance (EIEF)

Via Sallustiana 62

Rome 00187

Italy

salome.baslandze@eief.it
Francesca Lotti

Structural Economic Analysis Department

Bank of Italy

via Nazionale 91, 00184 Rome (IT)

francesca.lotti@bancaditalia.it 
"There are public officials who, instead of serving the interests of the community, put themselves at the service of private individuals. It's a devastating situation: those firms that have political and administrative support, thanks to the "good" friend, manage to obtain illicit benefits, while honest companies look astonished at what happens."

Carmelo Zuccaro, Chief Prosecutor of Catania ${ }^{1}$

La Sicilia, May 3rd, 2018

\section{Introduction}

In May 2018, Mr. Carmelo Zuccaro, the chief prosecutor of the Sicilian port city of Catania, uttered the above quote during his press conference on the "Black Job" operation against the misconduct of local politicians. This quote succinctly demonstrates how some firms can secure preferential treatment in the market, thanks in no small part to their connections to local politicians. How widespread are such connections to local politicians, and how do they affect firm dynamics, market competition, innovation, and the overall productivity process in the economy? This paper studies these questions, both theoretically and empirically.

A growing body of literature argues that factor reallocation from less productive to more productive firms is an important source of productivity growth (e.g., Bartelsman and Doms, 2000; Foster et al., 2001, 2006). Similarly, innovation-based endogenous growth models (e.g., Grossman and Helpman, 1991; Aghion and Howitt, 1992) assert that the process of creative destruction, whereby unproductive incumbents are replaced by innovative new entrants, is the key ingredient for economic growth. These models assume that it is sufficient for an entrepreneur to innovate the most superior product or production technology to seamlessly replace an incumbent firm, and thus become the new market leader. However, many examples, such as the one in the opening paragraph, illustrate that there might be more to it than that. Political connections can help some firms dominate a market, even if they do not necessarily introduce a more superior product or process.

Our analysis begins with a theoretical investigation of how political connections could influence an economy's business dynamism, new firm creation, factor reallocation, and innovation. To organize our thoughts, we build an illustrative Schumpeterian creative destruction model where firms face regulatory burdens. ${ }^{2}$ As in Restuccia and Rogerson (2008); Hsieh and Klenow (2009); Garicano et al. (2016), we model these regulatory burdens as wedges in the production process of a firm that may be alleviated by connecting with politicians, but those connections are costly. The static problem implies a threshold rule of firm size, above which firms find it profitable to incur the cost of connections to lower the burden of regulations - hence larger firms (market leaders) are more likely to be politically connected. We also discover that firms that become connected enjoy temporarily higher employment and sales growth but have lower labor productivity growth. However, in a dynamic perspective, industries that have politically connected incumbents face lower entry by new firms. Intuitively, new firms need to compete with incumbents not only in productivity, but they also need to overcome the regulatory or bureaucratic burden, to which the connected incumbent is

\footnotetext{
${ }^{1}$ https://www.lasicilia.it/news/cronaca/157854/il-procuratore-zuccaro-ci-sono-funzionari-pubblici-al-servizio-di-privati.html

${ }^{2}$ For an extensive evidence on high regulatory/bureaucratic burden and political connections in Italy, see Section 4.2.
} 
already immune. An additional amplification comes from the fact that incumbents anticipate this dynamic effect and strategically choose to become politically connected to preempt competition.

The model highlights the important contrasting facets of firm-level connections for the aggregate economy. Statically, connections may be beneficial in overcoming certain market frictions; however, they may also bring dynamic losses, since the incumbents' connections give them an unfair advantage over other market participants. In this way, while political connections might be desirable for static considerations, they distort competition and firm dynamics, resulting in markets that are dominated by older and larger firms with low innovation and productivity growth. This interplay is at the heart of both our empirical and theoretical constructs.

The second part of the paper is devoted to the study of these theoretical ideas using a brand-new micro-level confidential data, focusing on Italian firms and politicians from 1993 to 2014. There are three main reasons for this. First, as hinted by our opening story, there is ample anecdotal evidence for the link between political power and the corporate sector in Italy. Perhaps the largest manifestation of this presumption is the historical episode of Mani Pulite ("Clean Hands") - an investigation into a huge political scandal, which eventually uncovered a dense network of corruption and bribery throughout Italy in the early 1990s.

Second, to rigorously study all the channels through which political connections affect firm dynamics, we need a very detailed, large-scale micro dataset on firms and their political connections. To this end, we construct a new dataset for the Italian economy, spanning the entire period of 19932014, wherein we merge: (i) firm-level balance sheet data; (ii) social security data on the universe of workers; (iii) patent data from the European Patent Office; (iv) the national registry of local politicians; and (v) detailed data on local elections in Italy. We define a firm as being politically connected at time $t$ if the firm employs at least one local politician at time $t$. The nature of this data allows us to exploit rich heterogeneity in the type of connection - based on the level or rank of a position, or the party affiliation of a politician employed. Our unique, five-way data match allows us to examine at the micro level how firms change their competition strategy as they gain market power, or what firm-level outcomes are associated with (or implied by) political connections. In addition, we study how factor reallocation among incumbents and new firms is affected by the presence of political connections.

Third, the Italian economy has been performing poorly, particularly in terms of productivity growth, since the 1990s (see, for instance, Bugamelli and Lotti, 2018). While many reasons could be at play for low and stalling aggregate productivity, we try to shed some light on the aggregate implications of firm-level political connections through their effect on firm dynamics, innovation incentives, and competition.

The focus on local politicians - at the municipal, provincial, and regional level - is also a distinctive feature of our analysis relative to most of the empirical literature that looks at high-profile connections. Indeed, local-level connections are much more pervasive and usually harder to identify. In addition, local politicians hold extensive power: among other duties, they have authority over and responsibility for the provision of local public goods and services; administrative authority over the issuing of various permits and licenses; and are responsible for the majority of the 
administrative burden faced by private firms in Italy. ${ }^{3}$

We find that firm-level political connections are widespread, especially among large and old firms. While the average share of connected firms by industries is $4.5 \%$, connected firms account for one third of employment across industries. Our analysis uncovers the following important findings that are consistent with our theory:

Fact 1 More connected industries face lower firm entry, but conditional on entry, entrants are more likely to be connected than in other industries.

Fact 2 Industries with a higher share of politically connected firms have a lower share of young firms and exhibit lower growth and productivity.

As our model highlights, market competition comes with a certain level of tension between the market leader and its competitors. While followers try to leapfrog the leader with new products or technological innovation, the leader may often rely on various defensive strategies to maintain its market position. These defensive strategies could include the establishment of political connections. In our empirical analysis, we identify some strong evidence to support this leadership paradox:

Fact 3 Market leaders are the most politician-intensive but the least innovation-intensive, relative to their direct competitors.

In addition, we find:

Fact 4 Politically connected firms are more likely to survive, and their survival probability increases in the political power of the politicians they employ.

Fact 5 At the firm level, political connections are associated with higher employment and revenue growth but not with productivity growth.

We also exploit a quasi-random discontinuity caused by local elections decided on a thin margin in order to gauge causality in our firm-level results (Lee, 2008). We collect new data on all local elections in Italy and, based on vote allocation, identify elections that have been decided on a thin margin. Our regression discontinuity (RD) design compares firms that have been connected right before a marginally contested election with a politician from marginally losing versus marginally winning parties. Since the results of closely contested elections can be considered as pure chance (breaking news, weather shock, etc.), discontinuity in outcomes between marginally winning and losing firms after the election can be attributed to the causal effect of majority-level connections on the firms' outcomes. We find that differences in post-election outcomes between marginally winning and marginally losing firms are large: firms on the winning side grow much more in terms of size but not in productivity.

Finally, given the nature of our social security data, we can also observe the compensation levels of politicians inside the companies and give a back-of-the-envelope estimate for the rent (static surplus) sharing between firms and their worker-politicians. As a result, we find that:

Fact 6 Worker-politicians earn significant wage premiums relative to their co-workers. This premium increases with the political rank of a worker.

\footnotetext{
${ }^{3}$ See Section 4.2 .1 for more details.
} 


\section{Related Literature}

The process of creative destruction is at the center of most of the endogenous growth models (Aghion and Howitt, 1992; Grossman and Helpman, 1991; Klette and Kortum, 2004; Lentz and Mortensen, 2008; Aghion et al., 2014; Acemoglu et al., 2018; Akcigit and Kerr, 2018; Jones and Kim, 2018, among many others). ${ }^{4}$ Likewise, a growing body of empirical literature shows that creative destruction and factor reallocation are important contributors to aggregate productivity growth (Bartelsman and Doms, 2000; Foster et al., 2001, 2006). Less is known, however, about what factors are significant impediments to such reallocation. While addressing this question, our study brings out the interaction of two separate strands of literature: the literature on idiosyncratic distortions and implied static misallocation (Restuccia and Rogerson, 2008; Hsieh and Klenow, 2009), and the literature on dynamic creative destruction discussed above. We show that the existence of political connections that alleviate certain market frictions can lead to an asymmetric distribution of distortions between incumbents and entrants - impeding creative destruction and growth.

Our study provides micro evidence on how political connections could influence market power and business dynamism through their impact on entry deterrence, factor reallocation, creative destruction, and firm dynamics. In that regard, our paper contributes to a recently growing macroeconomics literature on market power and declining business dynamism. Syverson (2019) explains in detail why the macroeconomic discussion on market power should rely more on microeconomic foundations. In a recent work, Gutiérrez and Philippon (2019) focus on the political economy of business dynamism and argue that the existence of supranational regulators could adopt policies that would hurt competition and business dynamism. Andrews et al. (2019) document a widening productivity gap between market leaders and followers, and Akcigit and Ates (2019a,b) and Argente et al. (2020) argue that the declining knowledge diffusion from market leaders to followers due to defensive and strategic use of patenting would prevent rivals from leapfrogging the market leaders. One way to act strategically and defend the market could be to connect to the political system through politicians as shown in the current paper. Cooper et al. (2019) argue that changing adjustment costs might cause a decline in responsiveness of firms to firm-level shocks and hence lower the business dynamism. Several other papers, such as Gutiérrez and Philippon (2016, 2017), Aghion et al. (2019) show that an increase in market power is related to the decline in investments in the U.S. Similarly, in this paper, we demonstrate that an increase in firm power through political connections potentially creates dynamic costs by lowering firms investments in innovation and growth.

On the other hand, our study contributes, both empirically and theoretically, to a separate body of literature on firm-level political connections and their implications. Politicians and entrepreneurs have often found themselves along the road in the pursuit of power. Recent empirical evidence shows that political connection is a widespread phenomenon; politically connected firms have been observed both in developed and developing countries, including the US, the UK, France, Italy, Turkey, China, Malaysia, Indonesia, Korea, Thailand, and Singapore (Fisman, 2001; Johnson and Mitton, 2003; Khwaja and Mian, 2005; Leuz and Oberholzer-Gee, 2006; Fan et al., 2007; Cingano and

\footnotetext{
${ }^{4}$ Some prominent examples of endogenous growth models without creative destruction are Romer (1990); Jones (1995); Acemoglu (2002); Lucas and Moll (2014); and Perla and Tonetti (2014).
} 
Pinotti, 2013; Schoenherr, 2015).

The reasons that might lead a private company to pursue political connections are most certainly linked to profit maximization; surely, then, expected benefits must exceed the costs of establishing said connections, but the channels through which this is realized are manifold. The range of benefits provided by governments to favored firms include preferential access to credit (Joh and Chiu, 2004; Cull and Xu, 2005; Johnson and Mitton, 2003; Khwaja and Mian, 2005); preferential treatment by government-owned enterprises (Backman, 2001; Dinc, 2005) and for procurement (Goldman et al., 2013); relaxed regulatory oversight of the company in question or stiffer regulatory oversight of its rivals (Kroszner and Stratmann, 1998); lighter taxation (De Soto, 1989; Arayavechkit et al., 2017); allocation of public subsidies to R\&D (Fang et al., 2018); and government bailouts of financially distressed firms (Faccio and Parsley, 2006). While political connections increase equity returns and are valued positively in the stock market (Faccio and Parsley, 2006; Akey, 2015; Acemoglu et al., 2017), they become especially valuable wherever there are high levels of regulation, corruption, and population concentration - like in many capital cities, for instance.

There are different views on the social costs stemming from corruption and rent-seeking. On the one hand, if connections are aimed at reducing the burden of bureaucracy and administrative regulation, they do not necessarily imply a negative effect on welfare. This mechanism, known also as the greasing wheels hypothesis (Kaufmann and Wei, 1999), is expected to have a positive effect on welfare, since it increases efficiency through a relief of the burden of regulation (Shleifer and Vishny, 1994). On the contrary, if a connected firm exerts a rent seeking behavior, for example by diverting public demand (Goldman et al., 2013), the entailed social cost may be high. This second effect, named the grabbing hand hypothesis (Shleifer and Vishny, 2002), is consistent with the results provided by Cingano and Pinotti (2013) on political connections in Italy. Focusing on a small sample of Italian manufacturing firms surveyed by the Bank of Italy, representative of those with at least 50 employees, matched with data on politicians appointed at the local level, they find that firms experience revenue premium from connections mainly coming from public demand shift towards politically connected firms.

We contribute to the empirical literature on political connections by analyzing a newly constructed, large-scale dataset based on multiple administrative datasets for the universe of firms and workers from Italy. This allows us to provide a detailed analysis of the effect of connections on firm outcomes, including a causal RD design, as well as the effect on the entire firm and industry dynamics in the economy - aggregate aspects that have received less attention in the literature so far. Specifically, we bring new evidence on the relationship between political connections and firms' innovation, survival, and industry entry and competition. ${ }^{5}$ In addition, we provide some new facts on how politically connected firms are compensating their worker-politicians - another unique feature of our analysis.

On the theory side, surprisingly little has been done to understand social costs of rent-seeking through its impact on business dynamics, innovation, and aggregate productivity growth - aspects that are the focus of this article. Two exceptions are Krusell and Rios-Rull (1996) and Mukoyama

\footnotetext{
${ }^{5}$ An interesting new evidence coming from historical data from the Venetian Republic shows that politically connected craft guilds patented less (Comino et al., 2017) - possibly, indicating that guilds were substituting formal intellectual property protection with political protection.
} 
and Popov (2014), where the authors study the models with tensions between new and old technologies/incumbents and entrants in the environments where firms can influence entry policies. Relatedly, Comin and Hobijn (2009) show that lobbying dampens technology adoption when new technologies have close predecessors in the adopting country. In his seminal paper, Baumol (1990) maintained that large growth differences between or within countries should, to a great extent, be driven by differences in the allocation of entrepreneurial talent between productive and growthenhancing entrepreneurship or unproductive and destructive entrepreneurship, such as rent seeking or organized crime. Countries' institutions, policies, and social reward schemes drive the allocation of entrepreneurial talent between those activities. Relatedly, seminal works by Murphy et al. (1991) and Shleifer and Vishny (2002) focus on the problem of occupational choice between highproductivity sectors (entrepreneurs, engineers, etc.) and low-productivity sectors that are centered on rent-seeking and intermediation (law, financial services, etc.). In societies that reward rentseeking activities more, a lower pace of growth is observed. While those papers focus on the allocation of talent and discuss potential consequences for growth, more recent papers by Arayavechkit et al. (2017) and Garcia-Santana et al. (2016) point out static capital misallocation across different firms, resulting from preferential treatment by the various governments.

Our theory takes a different approach to understanding potential benefits and social costs associated with political connections. Our focus is on the effect of connections on innovation, creative destruction, and firm dynamics. We show that in an environment with high market frictions (such as regulations or bureaucracy) - where a firm's route to success often runs through the political system - political connections may impede growth by lowering innovation and reallocation.

The paper is organized as follows. Section 3 provides a theoretical framework and a list of testable implications. Section 4 provides an overview of the data and variable construction, provides some insights on the institutional background, and discusses relevant industry-level facts and summary statistics. Section 5 shows the firm-level analysis at the micro level. Section 6 describes the regression discontinuity design. Section 7 then explores politicians' compensation, while Section 8 concludes.

\section{Theoretical Model}

In this section, we build a simple model of a firm's innovation and political connections. The model illustrates that, even if political connections may be beneficial to alleviate certain types of market frictions for the firms, dynamically, they may induce important social costs through lower reallocation and growth.

How to model political connections? Political connections might affect firms through various channels. As was exemplified in the opening paragraph of the paper, political connections might help firms overcome regulatory or bureaucratic burden and get around existing "red tape". To understand if the data supports this channel, in Section 4.2 we examine the patterns of political connection in more heavily versus less heavily regulated industries. We observe a strong relationship between the amount of regulations or bureaucracy that an industry faces and the share of firms 
relying on political connections.

That bureaucratic and regulatory burden is pervasive and represents a common obstacle for businesses is also reflected in the recent report by the Ministry for Simplification and Public Administration of Italy. ${ }^{6}$ The estimated administrative burden faced by private firms in Italy is a staggering 31 billion Euros per year (representing $1.7 \%$ of the Italian $\mathrm{GDP}^{7}$ ). ${ }^{8}$ Perhaps not surprisingly, based on Doing Business Indicators by the World Bank, Italy ranks among the worst in the friendliness of business regulations across developed countries. ${ }^{9}$ An interesting new study by Gratton et al. (2017) provides extensive evidence that after the First Republic, the bureaucratic efficiency in Italy has collapsed. Hence, in the period of our analysis, the importance of political connections to relieve red tape seems even more relevant.

Motivated by the above evidence, we build a model where political connections help to overcome particular market frictions - bureaucracy and regulations. We follow the literature (e.g., Restuccia and Rogerson, 2008; Hsieh and Klenow, 2009; Garicano et al., 2016) and model these market frictions as wedges in the production process of a firm. A priori, the model gives a chance to political connections to have a positive impact by reducing existing regulations. As we will see, however, even in this model, connections will imply dynamic costs by lowering entry and reallocation.

\subsection{Static Environment}

Consider a narrowly defined sector with a sectoral output produced as

$$
Y=\frac{1}{1-\beta}\left[\sum_{m=1}^{M} q_{m}^{\frac{\beta}{1-\beta}} y_{m}\right]^{1-\beta}
$$

Sectoral output producers are perfectly competitive, and we normalize the price of sectoral good to one. In this production function, $y_{m}$ denotes the output of a producer of vintage $m$. Different vintages differ by their qualities $q_{m}$. Different vintages are perfect substitutes after adjusting for their qualities. Among the implemented $M$ vintages, the latest vintage $M$ has the highest quality. Note that in this model, some of the new vintages by potential new entrepreneurs, even though they have superior quality when compared to the current incumbent's quality, might not be implemented in equilibrium, due to the incumbent's political connections, as we describe in Section 3.2.

Production function (1) implies that the demand faced by vintage- $m$ producer is given by:

$$
p_{m}=q_{m}^{\frac{\beta}{1-\beta}}\left[\sum_{m=1}^{M} q_{m}^{\frac{\beta}{1-\beta}} y_{m}\right]^{-\beta}
$$

Producers of different vintages compete in prices to capture the full market. In equilibrium, the firm with the best cost-adjusted quality will serve the market. Moreover, Assumption 1 below

\footnotetext{
${ }^{6}$ The so called "Burden Measurement Program".

${ }^{7}$ In fact, this compares unfavorably to the aggregate private R\&D spending by firms of $0.6 \%$ (National Institute of Statistics).

${ }^{8}$ These estimates of administrative burden include costs of procedures related to labor and social security, building, environment, safety, revenue agency, privacy, fire prevention, procurement, and landscape and heritage.

${ }^{9}$ Doing Business Indicator, The World Bank, 2017.
} 
will ensure that the producing firm will also charge the monopoly price. Hence, we will study the monopolist's problem throughout this section.

Assumption 1 Producers of different-quality vintages play a two-stage pricing game. In the first stage, producers choose to pay a fee $\varepsilon$ (which we assume to be arbitrarily small, i.e., $\varepsilon \approx 0$ ) to enter a price competition in the second stage. In the second stage, all firms that already paid the fee bid prices.

This assumption ensures that only the firm with the highest cost-adjusted quality pays the fee and goes to the second stage where price is determined. Therefore, the producing firm charges the unconstrained monopoly price. ${ }^{10}$

Production technology for each intermediate goods producer is one-for-one in labor:

$$
y=l
$$

The wage rate of the worker is given by $w$. Hence, in the absence of any regulatory burden, the marginal cost of production is simply $w$.

Politically Non-Connected Firms. A sector is characterized by regulatory or bureaucratic burden, which we capture by a wedge $\tau \geq 0$ that increases marginal cost of production from $w$ to $(1+\tau) w$, as in Hsieh and Klenow (2009). Therefore, a monopolist maximizes its profit, subject to the demand function it faces, as follows:

$$
\begin{aligned}
& \pi^{n}=\max _{l}\{p y-(1+\tau) w l\} \\
& \text { s.t. } \quad p=q^{\beta} y^{-\beta} \text { and (3) }
\end{aligned}
$$

This maximization delivers the following equilibrium labor $\left(l^{n}\right)$, output $\left(y^{n}\right)$, revenue $\left(\operatorname{Rev} v^{n}\right)$, profits $\left(\pi^{n}\right)$, and labor productivity $\left(L P^{n}\right)$ for non-connected firms that face regulatory burden:

$y^{n}=l^{n}=\left(\frac{1-\beta}{(1+\tau) w}\right)^{\frac{1}{\beta}} q, \quad \operatorname{Rev}^{n}=\left(\frac{1-\beta}{(1+\tau) w}\right)^{\frac{1-\beta}{\beta}} q, \quad \pi^{n}=\beta\left(\frac{1-\beta}{(1+\tau) w}\right)^{\frac{1-\beta}{\beta}} q, \quad L P^{n}=\frac{w(1+\tau)}{1-\beta}$.

Political Connections. Firms can escape regulation and bureaucracy costs by getting politically connected. If a firm gets politically connected, it can avoid paying the wedge $\tau$, yet it has to incur a cost of political connection $w^{p}$, which we take for now as exogenous and endogenize it later in Online Appendix A through the Nash bargaining between a firm and a politician. We can think of $w^{p}$ as a compensation to the politicians or as search or other type of cost that a firm incurs to maintain its political connection. However, in order to be able to acquire political connection, a firm has to become familiar with the network of politicians. We capture the ability to become politically connected by assuming that firms can be in two states, $s \in\{0,1\}$. In particular, $s=0$ indicates that the firm is not yet familiar with the political network, whereas $s=1$ implies that firms are already familiar with the network and can acquire political connections, "if they want to".

\footnotetext{
${ }^{10}$ This structure also gives us theoretical tractability, since we do not have to worry about limit pricing.
} 
If a firm is in state $s=1$ and is politically connected, then it solves the following maximization problem:

$$
\begin{aligned}
& \pi^{p}=\max _{l}\left(p y-w l-w^{p}\right) \\
& \text { s.t. } \quad p=q^{\beta} y^{-\beta} \text { and (3) }
\end{aligned}
$$

This maximization delivers the following equilibrium labor $\left(l^{p}\right)$, output $\left(y^{p}\right)$, revenue $\left.(\operatorname{Rev})^{p}\right)$, profits $\left(\pi^{p}\right)$, and labor productivity $\left(L P^{p}\right)$ for connected firms that face regulatory burden:

$$
y^{p}=l^{p}=\left(\frac{1-\beta}{w}\right)^{\frac{1}{\beta}} q, \quad \operatorname{Rev} v^{p}=\left(\frac{1-\beta}{w}\right)^{\frac{1-\beta}{\beta}} q, \quad \pi^{p}=\beta\left(\frac{1-\beta}{w}\right)^{\frac{1-\beta}{\beta}} q-w^{p}, \quad L P^{p}=\frac{w}{1-\beta} .
$$

Table 1 compares the optimal decisions of connected versus non-connected firms. The last column points out the direction of change in the relevant moments when a non-connected firm becomes

\begin{tabular}{|c|c|c|c|c|}
\hline & Non-connected Firms & & Connected Firms & Change \\
\hline Labor: & {$\left[\frac{(1-\beta)}{(1+\tau) w}\right]^{\frac{1}{\beta}} q$} & vs & {$\left[\frac{(1-\beta)}{w}\right]^{\frac{1}{\beta}} q$} & 介 \\
\hline Revenue: & {$\left[\frac{(1-\beta)}{(1+\tau) w}\right]^{\frac{1-\beta}{\beta}} q$} & vs & {$\left[\frac{(1-\beta)}{w}\right]^{\frac{1-\beta}{\beta}} q$} & $\Uparrow$ \\
\hline Labor Productivity: & $\frac{(1+\tau) w}{(1-\beta)}$ & vs & $\frac{w}{(1-\beta)}$ & $\Downarrow$ \\
\hline
\end{tabular}
connected.

Table 1: The Impact of Political Connection on Static Moments

The important result here is that the connected firms eliminate the regulatory burden and therefore grow more in labor and revenue - even though they do not necessarily grow in productivity. Hence, political connections are associated with higher employment and revenue growth, but not with labor productivity growth.

When do firms decide to get connected? Figure 1 provides a graphical illustration of the answer. Panel (a) plots the profits of connected and non-connected firms as a function of the quality levels of their product. Panel (b), on the other hand, plots the equilibrium connection decision and indicates the resulting static return - the outer envelope (i.e., the maximum) of the two lines.

Firms that have the option of being connected (i.e., $s=1$ ) choose to do so if $\pi^{p}(q)>\pi^{n}(q)$. Since both profits are linear in $q$, the static equilibrium is such that firms follow a cut-off rule $\left(\hat{q}^{s}\right)$ and get connected if and only if $q>\hat{q}^{s}$, where

$$
\hat{q}^{s} \equiv \frac{w^{p}}{\pi\left(1-(1+\tau)^{-\frac{1-\beta}{\beta}}\right)}
$$


Figure 1: Connection Decision in a Static Environment

(a) Profits of Connected and Non-connected Firms

(b) Static Connection Decision
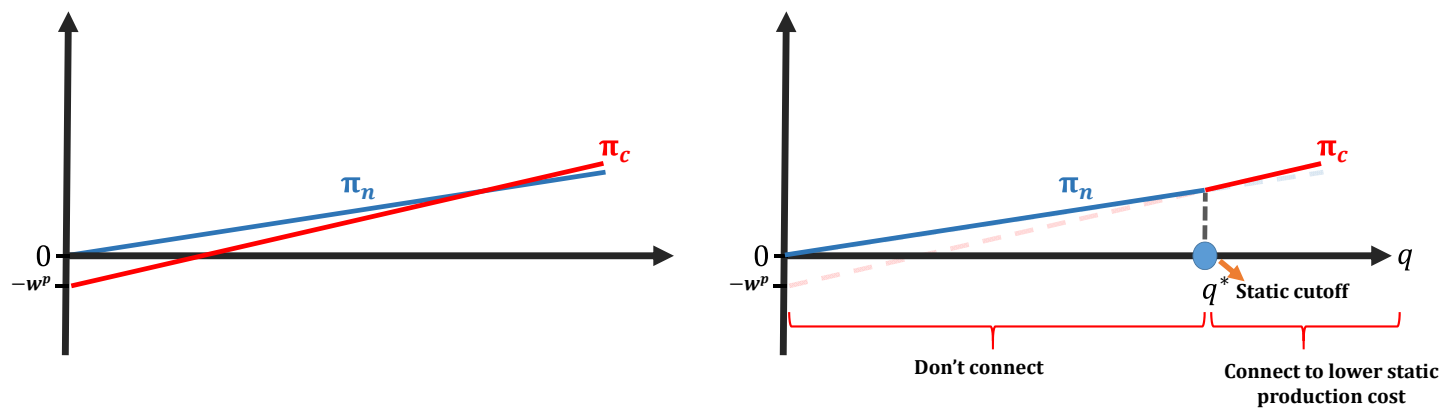

and $\pi \equiv \beta\left(\frac{1-\beta}{w}\right)^{\frac{1-\beta}{\beta}}$. Hence, larger firms find it optimal to become connected in order to remove regulatory burden. In what follows, for simplicity, we assume $\beta=0.5$ and we rewrite this static threshold as

$$
\hat{q}^{s}=\frac{w^{p}}{\pi} \frac{1+\tau}{\tau}
$$

Note that the threshold declines in the regulatory burden $\tau$, implying that firms are more likely to be connected in more regulated industries. We will come back to this threshold in the next section, after discussing a firm's dynamic problem.

\subsection{Dynamics}

Accessing a network of politicians takes time. We assume that $\alpha$ share of entrants start with $s=1$, and $1-\alpha$ start with $s=0$. Firms switch from state $s=0$ to $s=1$ at the Poisson arrival rate $\zeta$. We assume that state $s=1$ is an absorbing state. Note that consistent with the empirical evidence we provide below, these assumptions imply that connected firms are older, even after controlling for firm size.

At each point in time, there is a potential entrant who receives a new innovative idea with Poisson arrival rate $p$ and can produce a new vintage. A new idea of quality $\lambda$ improves the latest vintage quality $q_{M}$ according to the following law of motion

$$
q_{M+1}=(1+\lambda) q_{M}
$$

where $\lambda \sim F(0, \infty)$ is the realization of the innovation quality that is distributed according to some distribution $F(\cdot)$.

Importantly, not all entrants that have a better-quality product will be able to replace existing incumbents. ${ }^{11}$ For an entrant to replace the incumbent, its quality-adjusted cost should be lower

\footnotetext{
${ }^{11}$ If a higher-quality vintage is not able to enter the market, we assume that the vintage is lost. Hence, ideas are implemented right away or are lost.
} 
than that of an incumbent. When there is an asymmetry in connections between an entrant and incumbent, the quality advantage of an entrant has to be very high in order to overcome the cost advantage of an incumbent, who is immune to the regulatory costs. To see this, consider the following three cases.

\section{Case 1 Incumbent is not connected.}

If incumbent is not connected, any quality improvement $\lambda>0$ by an entrant will lead to creative destruction. Hence, creative destruction rate is simply equal to entry rate $p$. This case is a standard Schumpeterian case as in Aghion and Howitt (1992), for instance.

Case 2 Incumbent is connected, entrant is connected.

This case is equivalent to Case 1: any quality improvement by $\lambda>0$ will lead to creative destruction at the rate $p$.

Case 3 Incumbent is connected, entrant is not connected.

In this asymmetric case, when the incumbent is connected and the entrant is not connected, creative destruction is lower. This is because an entrant should not only produce a superior technology, but it should also overcome the regulatory burden that the incumbent is not subject to. In the rest of this subsection, we will show this formally.

Let us first start with the price competition between an entrant and the incumbent. Let us denote the current incumbent by $M$ and the new entrant by $M+1$. The demand for each vintage is given by (2). As a result, for an entrant to win the pricing game, the quality per price has to be greater:

$$
\frac{q_{M+1}}{p_{M+1}}>\frac{q_{M}}{p_{M}} .
$$

Now we can look for a threshold innovation quality $\lambda^{*}$ that can ensure that entrant will produce in equilibrium. In the price competition, the lowest price that the incumbent can charge is $w$, whereas the lowest possible price for the entrant's vintage is $(1+\tau) w$. Since the entrant's quality is $q_{M+1}=(1+\lambda) q_{M}$, the condition in (5) gives us the innovation quality threshold $\lambda^{*}$, above which entrants successfully replace incumbents:

$$
\lambda>\lambda^{*} \equiv \tau
$$

This result in intuitive. Since the incumbent has a cost advantage thanks to its political connection, the entrant has to produce a sufficiently large innovation that can overcome the cost advantage. This threshold is exactly equal to the regulatory advantage of the incumbents, which is $\tau$.

This leads us to a key question: when do incumbents decide to become connected in this dynamic environment? To answer this question, we first need to express the value functions of incumbents. We will pose that the firms will follow a cutoff rule such that firms with $q>\hat{q}^{d}$ will decide to connect in this dynamic model. We will ultimately solve for this dynamic threshold $\hat{q}^{d}$. 
First, consider a firm with $q<\hat{q}^{d}$ and denote its value by $V_{-1}$. Then

$$
r V_{-1}(q)=\pi(1+\tau)^{-1} q-p V_{-1}
$$

where $r>0$ is the exogenous interest rate. This value function simply equates the safe return $r V_{-1}(q)$ to the risky return on the right-hand side. Firms collect their instantaneous profits $\pi^{n}(q)=$ $\pi(1+\tau)^{-1} q$ and get replaced at the rate $p$, in which case they exit. Rearranging this value function implies

$$
V_{-1}(q)=\frac{\pi(1+\tau)^{-1}}{r+p} q
$$

Intuitively, firm value decreases in the regulatory burden $\tau$ and rate of creative destruction $p$.

Now, we can solve for the value of a firm that has a quality that is above the threshold $q \geq \hat{q}^{d}$, but is not yet exposed to the political network (i.e., $s=0$ ). Denoting this value by $V_{0}$, we can express it as:

$$
r V_{0}(q)=\pi(1+\tau)^{-1} q-p V_{0}+\zeta\left(V_{1}-V_{0}\right)
$$

This value function is very similar to (6), with the exception that firms that are not exposed to the political network will get exposed to it at the rate $\zeta$. In this case, their state switches from $s=0$ to $s=1$, and we denote the value of the latter case as $V_{1}$.

For a firm in state $s=1$ with $q \geq \hat{q}^{d}$, the value function can be expressed as:

$$
r V_{1}(q)=\pi q-w^{p}-p[\underbrace{\alpha}_{\text {connected }}+\underbrace{(1-\alpha) \operatorname{Pr}\left(\lambda>\lambda^{*}\right)}_{\text {non-connected but major innovation }}] V_{1} .
$$

This time, the value function contains some additional terms that affect the rate at which the incumbent is replaced by an entrant. If the entrant is already exposed to the political network (with probability $\alpha$ ), any innovation is sufficient to replace the incumbent. If the entrant is not yet exposed to the political network (with probability $1-\alpha$ ), the entrant cannot get around the regulatory burden and, therefore, is at disadvantage compared to the incumbent. In this case, the entrant has to come up with a large enough innovation $\left(\lambda>\lambda^{*}\right)$ to make-up for the regulatory disadvantage, which can happen with probability $\operatorname{Pr}\left(\lambda>\lambda^{*}\right)$.

Rearranging (7) delivers:

$$
V_{1}(q)=\frac{\pi q-w^{p}}{r+p\left[\alpha+(1-\alpha) \operatorname{Pr}\left(\lambda>\lambda^{*}\right)\right]}
$$

Firms connect to politicians if and only if the value of connection is bigger than of non-connection:

$$
V_{1}(q)>V_{-1}(q)
$$

Using (6) and (8), this condition holds if and only if the quality level is above the dynamic threshold $\hat{q}^{d}$ :

$$
q>\hat{q}^{d} \equiv \frac{w^{p}}{\pi\left[1-\frac{r+\tilde{p}}{r+p} \frac{1}{1+\tau}\right]}
$$


where $\tilde{p} \equiv p\left[\alpha+(1-\alpha) \operatorname{Pr}\left(\lambda>\lambda^{*}\right)\right]$. This result shows again the importance of the level of regulation and firm size for political connection.

First, the dynamic cut-off, just like the static cut-off, is decreasing in $\tau$. This implies that in more regulated industries, firms are more likely to get politically connected. This follows from the fact that more regulation imposes larger costs on firms. Hence, eliminating these burdens through political connections becomes more profitable when the regulations are heavier.

Second, (9) shows that large firms are more likely to be connected. The key difference of this result from the earlier result on connections and firm size highlighted in Table 1 is the direction of causality. Our model predicts a two-way relationship between political connections and firm size: as firms grow in size, they find it worthwhile to incur the connection cost to eliminate the regulatory burden. Hence, larger firms are more likely to be connected. In addition, when they obtain political connections and remove the regulatory burden, they can grow even further (Table 1).

Preemptive Motive. Now we can compare the static cut-off in (4) and the dynamic cut-off in (9): ${ }^{12}$

$$
\left.\hat{q}^{s} \equiv \frac{w^{p}}{\pi\left[1-\frac{1}{1+\tau}\right]}>\hat{q}^{d} \equiv \frac{w^{p}}{\pi[1-\underbrace{\frac{r+\tilde{p}}{r+p}}_{\text {preemptive motive }}} \frac{1}{1+\tau}\right] .
$$

An important insight emerges from the comparison between the static and dynamic cutoffs. We see that $\hat{q}^{d}<\hat{q}^{s}$, as illustrated in Figure 2. In the region with $q \in\left[\hat{q}^{d}, \hat{q}^{s}\right]$, there is an additional preemptive motive to acquire political connections. Incumbents anticipate that, by getting connected, they discourage entry and survive longer, hence they optimally choose to seek a connection earlier. Notice that the difference between the two cutoffs in (4) and (9) disappears if $\alpha \rightarrow 1$, i.e., if all entrants are able to get connected. Likewise, if there is no regulatory burden $(\tau=0)$, the static and dynamic thresholds collapse to the same value, $\hat{q}^{d}=\hat{q}^{s}$. In those two extreme cases, there is no room for strategic entry deterrence. Hence, strategic motive becomes more apparent when the industry is heavily regulated (i.e., $\tau \uparrow$ ) or when the social asymmetry between incumbents and entrants is big (i.e., $\alpha \downarrow$ ).

Note that the entry rate is:

$$
\text { Entry rate }=\left\{\begin{array}{l}
p \text { if incumbent is not connected } \\
\tilde{p} \text { if incumbent is connected }
\end{array}\right.
$$

In other words, in connected industries, entry rate is lower, hence connected incumbents are less likely to exit. The intuition for this result comes from the fact that, since an entrant is relatively disadvantaged in getting connected, it must come up with a larger (more radical) innovation in order to overcome the effective advantage of the incumbent due to its political connections. Since the probability of a larger innovation is lower, this also lowers the entry probability and the probability that the incumbent gets displaced. Notice that if $\alpha=1$ so that all entrants are able to get connected,

\footnotetext{
${ }^{12}$ Note that $\pi^{p}>0$ when $q>\hat{q}^{d}$. Hence, connected firms never make any static loss in equilibrium.
} 
Figure 2: Connection Decision in a Dynamic Environment

(a) Values of Connected and Non-connected Firms

(b) Dynamic Connection Decision
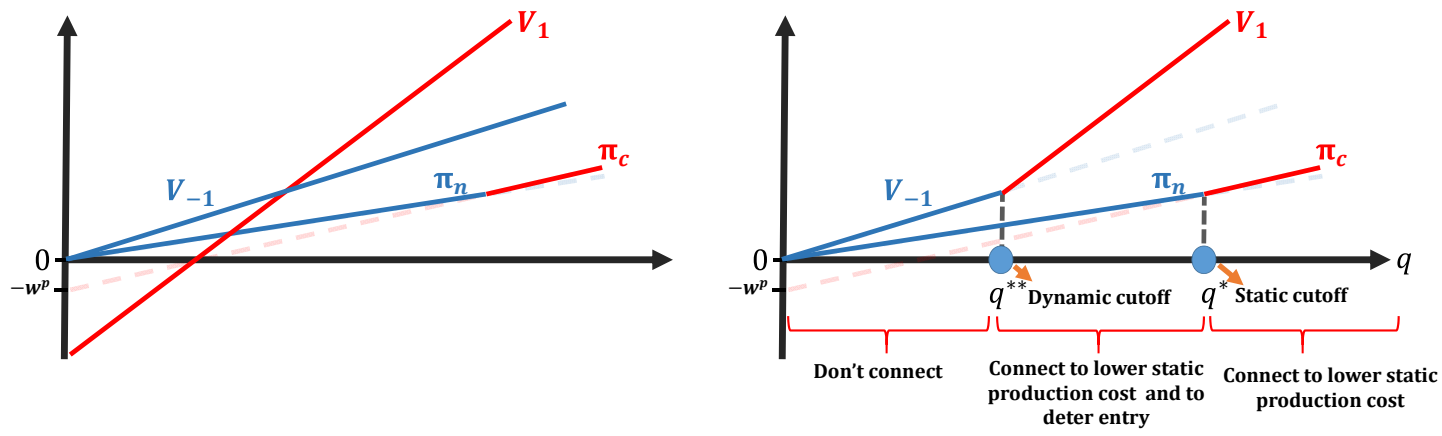

creative destruction is equal to entry rate $p$. In fact, politically connected incumbents are more likely to be replaced by connected entrants. ${ }^{13}$ Hence, the co-existence of red tape $(\tau)$ and the asymmetry in connections $(\alpha<1)$ are the factors that generate lower creative destruction.

The model generates additional intuitive predictions when we allow the compensation $w^{p}$ to be endogenously determined. To save space, we delegate this extension to Online Appendix A. We consider a model extension, wherein politicians are heterogeneous in their political power and compensation is determined through Nash bargaining between the firm and the politician. The model implies that: 1) compensation increases with political power of a politician; and 2) the greater the political power of the politician, the higher the rate of survival for the connected incumbent.

\subsection{Taking Stock}

The distinction between static and dynamic effects of political connections is important: statically, connections reduce frictions, but dynamically, the model implies lower entry and reallocation, resulting in markets that are dominated by older and larger firms with low innovation and productivity growth.

Notice that the negative effect of connections on firm entry and competition is not hard-wired in our model. To the contrary, we considered the positive side of political connections by assuming that political connections help remove red tape in the input market. However, an interesting result of our model is that firms use these connections also to prevent dynamic entry. Reduction in entry is an endogenous response of the economy to the market conditions, where the ability to get connected is distributed unequally between entrants and incumbents. This response arises only dynamically; in a static environment, political connections are socially beneficial and represent the second best, given the market frictions. Hence, starting with the "well-intended" nature of political connections, without imposing any direct negative effect from them, a simple glimpse into dynamic effects from misallocation uncovers important aggregate costs. This intuitive model provides some

\footnotetext{
${ }^{13}$ If an incumbent is not connected, its probability of getting replaced by a connected entrant, conditional on an innovation is 1 . In the case of a connected incumbent, this probability is: $\alpha+(1-\alpha) \operatorname{Pr}\left(\lambda>\lambda^{*}\right)<1$.
} 
new theoretical insights into understanding the social costs of political connections.

Below we summarize the implications of the model we discussed above:

Implication 1: In industries where incumbents are politically connected, creative destruction is lower. Connected incumbents are more likely to be replaced by connected entrants.

Implication 2: Industries with politically connected firms have older firms and lower productivity growth.

Implication 3: Large firms are more likely to be connected, but entrants are more innovative.

Implication 4: Connected firms are less likely to exit, especially if the firms are connected with politicians with higher political power $\phi$.

Implication 5: Political connections are associated with higher employment and revenue growth for a firm, but not with higher labor productivity growth.

Implication 6: Politician's compensation $\bar{w}^{p}(\phi)$ increases in his/her political power $\phi$.

\subsection{Alternative Mechanisms}

Our model that emphasizes the role of political connection in removing red tape (wedges) has sharp implications about i) who optimally chooses to get connected, ii) firm-level growth in productivity and size, and iii) aggregate implications for entry and reallocation. In this section, we briefly discuss other potential mechanisms through which political connections could affect firms and the implications thereof.

First, firms may rely on connections in order to help their new technologies or services penetrate the market. In this sense, connections may be catalyzers for incumbents' innovation, by reducing its effective cost. This mechanism would imply that 1) at the firm level, connections and innovation should go hand-in-hand and that 2) firms should grow both in size and productivity as a result of connections. These implications are in contrast to the implications from out model. By empirically exploring the relationship between political connections and innovation as well as firm growth, we will be able to differentiate between these alternative theories.

Second, one could imagine a completely negative scenario where incumbents use their connections to directly block entry by competitors. While this may be plausible, we do not have direct evidence for this mechanism and, if anything, it would strengthen the negative results from the model.

Finally, we believe alternative channels, including such elements as preferential bank lending or procurement contract allocation to connected firms, could also be empirically relevant. ${ }^{14}$ However, in both cases - similar to the current model - these alternative channels could generate asymmetric wedges in the effective cost of capital and in the demand shifter, respectively. This would lead to similar implications to the current model. Exploring the quantitative importance of these various channels is an important question that we do not tackle in this paper. Instead, the purpose of our

\footnotetext{
${ }^{14}$ Unlike a strong correlation between industry' intensity of political connections and the industry's degree of bureaucracy and regulatory burden, we do not find a significant correlation of connections intensity with industry's government dependence that proxies, for example, for firms' reliance on procurement contracts (see Section 4.2).
} 
illustrative model is to uncover a new tradeoff between static benefits and dynamic losses from lower reallocation and innovation.

Using a new large-scale dataset from Italy, in the next sections, we will focus on a set of empirical facts that speak to the implications of our model. We organize these facts to line up with the list of model implications above.

\section{Data and Aggregate Statistics}

We tap on data from multiple administrative sources to build a comprehensive dataset on firms, workers, and local politicians in Italy for the period of 1993-2014. The core of this data construction is the newly available individual-level data from the Italian Social Security Administration (INPS). ${ }^{15}$ We combined the rich Social Security (SS) data with administrative data on firms' balance sheets (Cerved) to obtain a detailed matched employer-employee dataset for Italy. On the firms' side, the data is further augmented with information on firm-level innovation activities derived from patent records in PATSTAT. Crucially, on the workers' side, we combine SS data with individual records on the universe of local politicians from the Italian Registry of Local Politicians (RLP). This allows us to track whether a politician works in the private sector while holding office. The literature has coined the term "moonlighting politicians" to refer to such politicians: it is exactly the existence of moonlighting politicians that helps us to identify political connections at the firm level. Finally, we also construct new data on all local elections in Italy held between 1993-2014. Together, RLP and elections data allow us to define various attributes of an individual's political career, such as type of political position, rank, party affiliation, and participation in marginally contested elections.

Below, we provide an overview of the data and main steps undertaken during the data construction, while we delegate a more detailed discussion of data cleaning and variable construction to Online Appendix B. Table 2 gives a summary of the data sources.

\subsection{Data Sources}

\section{Dataset \#1: Social Security Data (INPS)}

We access the Italian SS data at the Italian National Institute of Social Security within the VisitINPS Scholars program. INPS data covers the universe of private sector workers, whose employers make social security contributions in Italy. Part-time workers, as well as temporary-contract workers, are part of the INPS data, while self-employed, public employees, agriculture workers, or contractors are not. This data provides us with information about both workers and firms.

On the workers' side, the SS data provides complete information on employment histories. Among other things, we obtain information on the identities of firms where workers are employed, job start and separation dates, gross labor income (including bonuses and overtime), number of months/weeks worked in a year, type of contract (e.g., full-time or part-time, permanent or temporary), and broadly defined occupation description (from which we create white-collar and bluecollar classification). In addition, the data provides individual demographic information on the

\footnotetext{
${ }^{15}$ Data became available through the VisitINPS Scholars program initiated in 2016.
} 
Table 2: Data Sources

\begin{tabular}{|c|c|c|c|c|}
\hline Data & Source & Content & Time Span & Variables \\
\hline \multirow[t]{2}{*}{ 1. Social Security } & INPS & $\begin{array}{l}\text { Individual-level: } \\
\text { Universe of private } \\
\text { sector employees } \\
\text { (except contractors \& } \\
\text { agriculture) }\end{array}$ & $1985-2014$ & $\begin{array}{l}\text { Employment history, labor income, job } \\
\text { characteristics, demographics. }\end{array}$ \\
\hline & INPS & $\begin{array}{l}\text { Firm-level: Universe } \\
\text { of firms with at least } \\
\text { one paid employee } \\
\text { (except agriculture) }\end{array}$ & 1985-2014 & $\begin{array}{l}\text { Entry, exit, size, workforce characteristics, } \\
\text { industry, location. }\end{array}$ \\
\hline 2. Firm Financials & Cerved & $\begin{array}{l}\text { Universe of limited } \\
\text { companies }\end{array}$ & 1993-2014 & Balance sheets, income statements. \\
\hline 3. Patent Data & PATSTAT & $\begin{array}{l}\text { All EPO patents filed } \\
\text { by Italian firms }\end{array}$ & 1990-2014 & $\begin{array}{l}\text { Patent grant status, patent families, tech- } \\
\text { nology classification, citations, claims. }\end{array}$ \\
\hline $\begin{array}{l}\text { 4. Registry of } \\
\text { Local Politicians }\end{array}$ & $\begin{array}{l}\text { Ministry } \\
\text { of Interior }\end{array}$ & $\begin{array}{l}\text { Universe of local } \\
\text { politicians (regional, } \\
\text { province, municipal- } \\
\text { ity) }\end{array}$ & $1985-2014$ & $\begin{array}{l}\text { Political position attributes, party affilia- } \\
\text { tion, demographics. }\end{array}$ \\
\hline 5. Elections Data & $\begin{array}{l}\text { Ministry } \\
\text { of Interior } \\
\text { and own } \\
\text { collection }\end{array}$ & $\begin{array}{l}\text { Regional, province, } \\
\text { municipality election } \\
\text { outcomes }\end{array}$ & 1993-2014 & $\begin{array}{l}\text { Candidates, parties, coalitions, vote shares, } \\
\text { seats. }\end{array}$ \\
\hline
\end{tabular}

workers.

On the firms' side, we have information on all workers they employ and the corresponding characteristics of those workers described above. This lets us construct a reliable variable on firm size, average wages paid, or various work-force composition variables. Importantly, we also have complete demographic data on the firms - firm industry classification (ATECO 2007), location, entry and exit dates. ${ }^{16}$ For our purposes, this data is essential since this firm-level data on the universe of private-sector firms allows us to construct aggregate moments on firm entry, exit and turnover across industries, location, and time.

\section{Dataset \#2: Firm Financials Data (Cerved)}

We use proprietary firm-level data from Cerved, administered by Cerved Group. ${ }^{17}$ The data provides balance sheets and income statements for all incorporated firms in Italy for the 1993-2014 period. Firms not covered are mainly small firms - sole proprietorship or small household producers. We make use of standard company accounts variables such as assets, intangible assets, value added $(V A)$, and profits. We compute a firm's labor productivity, $L P$, as value added per worker. Total factor productivity, TFP, is calculated as the residual $z$ from a standard Cobb-Douglas

\footnotetext{
${ }^{16}$ It is hard to identify establishments using this data, hence our unit of analysis is a firm. However, in Italy the average number of establishment per firm is just 1.07 (Istat, Census 2011 data).

${ }^{17}$ This data gives rise to the Italian segment in ORBIS (Aida).
} 
specification $Y=z K^{\alpha} L^{1-\alpha}$, where $Y$ is measured as value added, $K$ is measured as total assets, $L$ is employment, and labor share $(1-\alpha)$ is equal to the average industry-level labor share from the data.

\section{Dataset \#3: Patent Data (PATSTAT)}

Our patent data source is the European Patent Office Worldwide Patent Statistical Database (EPO PATSTAT) ${ }^{18}$ PATSTAT provides coverage of all patents published (granted or not) at the EPO up to the spring 2016. This amounts to nearly 60 million patent applications from 1978 to 2014. We use this data to understand the patenting activity of firms in Italy. For this purpose, we match patent records to firms in Cerved, identifying 13,904 Italian companies that had filed for patents.

For all patents, we extract information on their patent families, technology classification, application date, grant status, number of claims, and backward and forward citations. This data allows us to construct various patent-based innovation measures for firms. In particular, we focus on: (i) yearly patent counts by firms; (ii) citations-adjusted patent counts to reflect quality heterogeneity across patents; and (iii) family-size-adjusted patent counts. Patent family size can serve as another proxy for patent quality as it may indicate the extent of geographical protection an applicant is seeking. We report the details of the PATSTAT matching, as well as summary statistics of these measures, in Online Appendix B.3.

\section{Dataset \#4: Registry of Local Politicians (RLP)}

We obtain administrative data on local politicians (RLP) from the website of the Ministry of the Interior. RLP contains information on all local politicians at the municipal (8,110 municipalities), provincial (103 provinces) and regional (20 regions) levels from 1985 to 2014. For each individual, we have his/her detailed demographic information, location, position (e.g., council member, mayor, regional president, vice-president, etc.), and appointment date. The data contains information on 515,201 unique politicians during our benchmark period of 1993-2014.

In order to link individual politicians to the Social Security data on private-sector employees, we recover social security numbers from the demographic information on politicians. Next, we define an individual's majority affiliation - whether a politician is a member of a majority party (or a coalition) at the local level. Finally, based on politician's position attributes, we identify a politician's regional rank (e.g., municipality, province, or region). Similarly, we identify his/her hierarchical rank (i.e., mayor, president, vice-president, etc.). Online Appendix B.3.1 reports the details on data cleaning and variable construction in RLP.

Table 3 reports some summary statistics on local politicians. In our data, most of the politicians (96.6\%) work at the municipal level. Around 11.3\% of the politicians have high-rank positions (e.g., mayor, president, vice-mayor or vice-president) and an additional 19.6\% have executive roles ("assessore"). Finally, 73\% of the politicians are part of the majority party or coalition. Characteristics on politicians that are employed in the firms are shown in Table A.3. Almost $10 \%$ of politicians hold top- or middle-management positions, while 55\% perform other white-collar jobs.

\footnotetext{
18 “EPO Worldwide Patent Statistical Database - 2016 Spring Edition".
} 
Table 3: Statistics on Local Politicians

\begin{tabular}{lcc}
\hline \hline CATEGORY & POSITION & SHARE \\
\hline Regional Rank: & Region & $0.8 \%$ \\
& Province & $2.6 \%$ \\
& Municipality & $96.6 \%$ \\
\hline \multirow{2}{*}{ Hierarchical Rank: } & Mayor, President, Vice-mayor, Vice-president & $11.3 \%$ \\
& Executive councilor & $19.6 \%$ \\
& Council member & $69.1 \%$ \\
\hline Majority Affiliation: & Majority & $73 \%$ \\
\hline \hline
\end{tabular}

Notes: Summary statistics on the distribution of politicians across regional rank, hierarchical rank, and their local majority affiliation from the Registry of Local Politicians (RLP). Statistics are from the period between 1993 and 2014 with 2,888,480 observations on 515,201 distinct politicians.

\section{Dataset \#5: Elections Data}

We derive data on elections at the regional, province, and municipality level from the Ministry of Interior and complement it with our own data collection from various sources online (online election archives, Wikipedia). The final data covers all local elections during the period 1993-2014. We have information on the identities of all the candidates (names and demographics); parties/coalitions participating in the elections and candidates that they support; votes obtained (for candidates or parties) in each election round, if multiple; and the allocation of seats in the councils.

This data serves two purposes. First, it helps complement majority party/coalition identification from RLP (and hence to define politician's majority affiliation more accurately as described in details in Online Appendix B.3.2 and B.3.3). Second, and more importantly, we identify marginally contested elections and party affiliations of marginally winning and losing parties/coalitions, as discussed in Section 6.1.

\subsection{Descriptive Statistics}

In this section, we provide some descriptive statistics of the final matched data. We first start with the main variable definitions.

We label a firm as being "connected at time $t$ " if at least one politician is working in that firm in the same year $t$. Notice that our definition, more conservatively, is based on the contemporaneous employment relations. ${ }^{19}$ The main political connection indicators we use throughout the paper are:

- Connection $_{i t}:=1$ if at least one politician is working in firm $i$ at time $t$.

- Connection high - $\operatorname{rank}_{i t}:=1$ if at least one high-rank politician, defined as either mayor, region or province president, vice-mayor or vice-president, or a (vice-)president of a council, is working in firm $i$ at time $t$.

\footnotetext{
${ }^{19}$ Interestingly, looking at the first time that a firm becomes connected, we observe that in the majority of the cases (63\%) the firm becomes connected through a worker already employed in the firm, while in the remaining cases the politician gets hired by the firm (either moving from another firm, being a "professional politician", or a self-employed/professional not enrolled in INPS.)
} 
Table 4: Summary Statistics of the Matched Firm-Level Data

PANEL A: Number of Observations

\begin{tabular}{|c|c|c|c|c|c|c|}
\hline & \multicolumn{3}{|c|}{ All FIRMS } & \multicolumn{3}{|c|}{ — With BALANCE SHEET } \\
\hline & \multicolumn{3}{|c|}{ 1993-2014 } & \multicolumn{3}{|c|}{ 1993-2014 } \\
\hline & \multicolumn{3}{|c|}{$32,776,800$} & \multicolumn{3}{|c|}{$7,292,069$} \\
\hline $\begin{array}{l}\text { Observations (firms } \times \text { year) } \\
\text { Unique firms }\end{array}$ & \multicolumn{3}{|c|}{$4,432,111$} & \multicolumn{3}{|c|}{$1,028,063$} \\
\hline Observations (firms $\times$ year), connected firms & \multicolumn{3}{|c|}{449,236} & \multicolumn{3}{|c|}{270,843} \\
\hline Unique firms ever-connected & \multicolumn{3}{|c|}{112,333} & \multicolumn{3}{|c|}{64,612} \\
\hline Variable & Mean & Median & St dev & Mean & Median & St dev \\
\hline \multicolumn{7}{|c|}{ PANEL B: Variables from INPS (Data \#1) } \\
\hline Employment & 7.223 & 2.000 & 129.005 & 18.481 & 5.000 & 213.193 \\
\hline Average weekly pay, thous. $€$ & 0.357 & 0.346 & 3.545 & 0.440 & 0.415 & 0.388 \\
\hline Employment growth & 0.125 & 0.000 & 0.782 & 0.069 & 0.000 & 0.633 \\
\hline \multicolumn{7}{|c|}{ PANEL C: Variables from Cerved (Data \#2) } \\
\hline Assets, thous. $€$ & - & - & & 3198.352 & 768.080 & 8171.213 \\
\hline VA growth & - & - & - & 0.167 & 0.016 & 0.800 \\
\hline LP growth & - & - & & 0.098 & -0.018 & 0.686 \\
\hline TFP growth & - & - & - & 0.064 & -0.020 & 0.554 \\
\hline \multicolumn{7}{|c|}{ PANEL D: Variables from PATSTAT (Data \#3) } \\
\hline Num. patents (yearly) & 2.113 & 1.000 & 5.028 & 2.114 & 1.000 & 5.042 \\
\hline Num. family-size-adj. patents (yearly) & 11.304 & 5.000 & 28.183 & 11.361 & 5.000 & 27.979 \\
\hline Num. citations-adj. patents (yearly) & 4.286 & 1.000 & 21.657 & 4.229 & 1.000 & 20.606 \\
\hline \multicolumn{7}{|c|}{ PANEL E: Variables from the Registry of Local Politicians (Data \#4) } \\
\hline Connection & 0.014 & 0.000 & 0.119 & 0.035 & 0.000 & 0.183 \\
\hline Connection high-rank & 0.002 & 0.000 & 0.040 & 0.004 & 0.000 & 0.059 \\
\hline Connection majority & 0.008 & 0.000 & 0.090 & 0.020 & 0.000 & 0.138 \\
\hline Num. politicians (cond on employing) & 1.759 & 1.000 & 6.841 & 1.780 & 1.000 & 6.947 \\
\hline Num. majority-politicians (cond on employing) & 0.896 & 1.000 & 3.517 & 0.892 & 1.000 & 3.623 \\
\hline Num. high-rank politicians (cond on employing) & 0.152 & 0.000 & 0.882 & 0.132 & 0.000 & 0.860 \\
\hline
\end{tabular}

Notes: Summary statistics of the matched data at the firm $\times$ year level. The columns under "All firms" report statistics for all firms at INPS that are in our largest baseline sample. The columns "With balance sheet" present statistics for all observations where balance sheet information is not missing (observations matched to Cerved). All nominal variables are expressed in thousands of 2014 Euros. Employment is defined based on the number of employees in March. Employment growth is defined as in (14). The "All firms" sample includes also firms that report zero employment in a particular year but still appear in INPS data. Number of observations with nonzero employment is $27,982,454$ (employment growth excluding zero-employment observations is significantly lower, so a bulk of positive growth comes from entry years). Average weekly pay is the average gross weekly pay of all workers employed in March. Patent-related variables are defined in Section 4.1. The statistics on number of patents are given conditional on patenting. Definitions of Connection, Connection high-rank, and Connection majority are given in Section 4.2. The statistics on number of politicians employed are given conditional on having a connection. Standard balance sheet variables are defined in Section 4.1.

- Connection majority it $:=1$ if at least one politician from the majority party/coalition at local level is working in firm $i$ at time $t$.

Main summary statistics of the final matched dataset are reported in Table 4, Panel A. In total, we have about 32 million observations at the firm level, with 4 million unique firms in 1993-2014. Among these, 1 million firms match to Cerved, hence, report their financial data. Firm-level connections are a widespread phenomenon. In total, 112,333 unique firms, at some point in their existence, can be identified as connected. Conditional on being connected, the average number of politicians employed per year is 1.7.

Although the average share of connected firms by industries is around $4.5 \%$, connected firms 
account for $33.6 \%$ of employment across industries. Hence, connections are particularly common among large firms. As Figure 3 shows, larger firms are disproportionately more likely to be connected: $45 \%$ of firms with more than 100 workers are connected with politicians. This relationship could arise mechanically since larger firms employ more workers and hence are more likely to be defined as politically connected. However, Section 5.1 shows that even conditional on firm size, larger firms are more likely to employ politicians. Figure 3 also shows that, holding size fixed, age matters as well: older firms are significantly more likely to have political connections than younger firms.

Figure 3: Share of Connected Firms by Size and Age

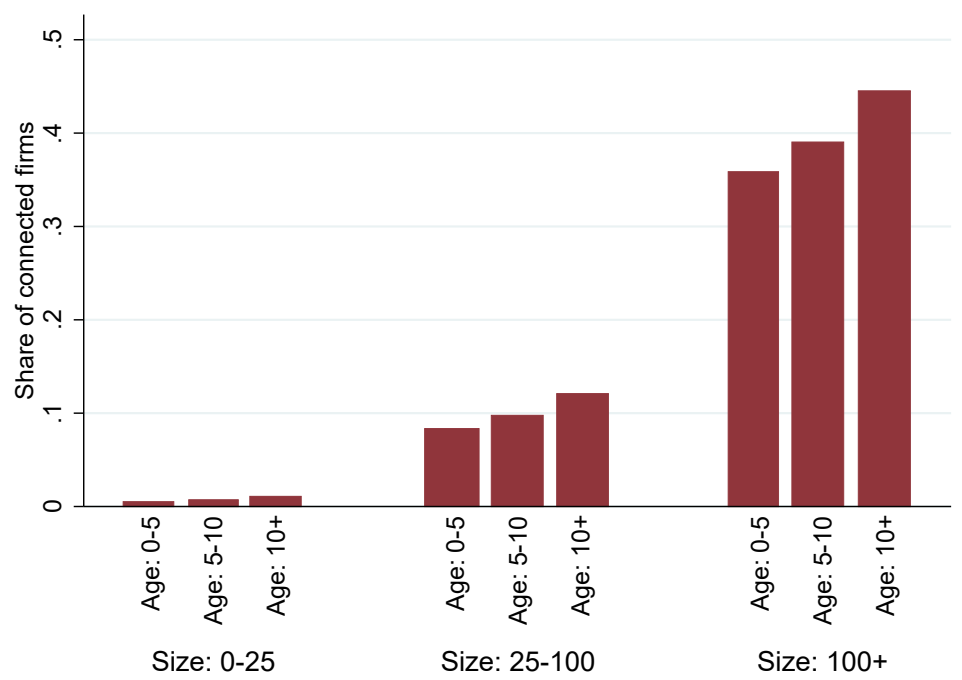

Notes: The figure shows share of connected firms by age and size bins.

Some of the sectors with the highest shares of connected firms are utilities, pharmaceuticals, banking, waste disposal, and telecommunications, among others. On the opposite side, industries with the lowest shares of connected firms are in personal services, bars, restaurants, retail management, restoration, and others. We examine the patterns of political connections across various industry characteristics. We build the industry-level Bureaucracy Index that measures the level of regulatory and bureaucratic burden, based on texts of newspaper articles. This index is simply the share of newspaper articles about a sector that have certain keywords that are related to bureaucracy/regulation. ${ }^{20}$ Using the sectoral input-output table for Italy, we also construct the standard Government Dependence Index that measures the share of an industry's output that is demanded by public sector. We identify that the strongest correlate of the presence of political connections across industries is the amount of regulations and bureaucracy that the industry faces. However, we do not find a significant correlation between connection intensity of the industry and standard measures of industry's government dependence. ${ }^{21}$ Online Appendix B.5 provides more details on the

\footnotetext{
${ }^{20}$ Some of these keywords are "regulation", "bureaucracy", "paperwork", "red tape", and "license". See Online Appendix B.5 for more details.

${ }^{21}$ Indeed, if we look at a regression of the share of connected firms in an industry as a function of an industry's Bureaucracy and Government Dependence Indices jointly, we find that one standard deviation increase in the Bureaucracy Index is associated with $44 \%$ increase in the share of connected firms from the mean. To the contrary, a coefficient on the
} 
construction of these indices and their correlations with political connections.

\subsubsection{The Role of Local Politicians in Italy: Institutional Background}

We provide a short excursus of two decades of Italian history to understand the roots of local political power and how, after a series of events, this power has increased.

In February 1992, the investigation into the biggest corruption scandal, known as Mani Pulite ("Clean Hands"), started in Milan with the arrest of Mario Chiesa, a socialist manager of a public hospice, and subsequently widened to the entire country and saw a huge increase in the number of involved politicians, bureaucrats, and entrepreneurs. Mani Pulite uncovered a dense network of corruption and bribery throughout Italy (Vannucci, 2009). As a result, Italian parties were completely disrupted, leading to a big change in the political arena. The radical change in the political class following the "Mani Pulite" scandal, in fact, delineated the transition from the First (1946-1993) to the Second Republic (since 1993). ${ }^{22}$ One of the peculiarities of the transition to the Second Republic was the replacement in the political arena of the so-called "professional politicians" with political newcomers, most of whom came from the business sector (Mattozzi and Merlo, 2008). ${ }^{23}$ At the same time, high-rank politicians - including mayors, presidents, vice-mayors, and vice-presidents acquired greater decision-making power, and hence, could be considered more valuable for firms. In fact, since the 1990s, a few reforms were enacted to shift towards a federal government, in which spending and decision-making centers would move from the highest levels, the central state, to the more local ones, with the idea of "getting closer" to the citizens.

A change in the electoral rule towards a majority system in 1993 pledged the emergence of an effective alternation in government of competing coalitions and the almost direct electoral investiture of the Prime Minister. Since 1997, a series of reforms have conferred more functions and more autonomy to the regions, provinces, and municipalities, so as to culminate in a reform of the Constitution in 2001. According to the Article 114 of the Italian Constitution, modified in 2001, "The [Italian] Republic is made up of Municipalities, Provinces, Metropolitan Cities, Regions, and the State. Municipalities, Provinces, Metropolitan Cities, and Regions are autonomous entities with their own statutes, powers and functions".

In this system, in addition to the central government (two houses of parliament, the central government, and the prime minister), each geographical entity (8,110 municipalities, 103 provinces, and 20 regions) has its own local government with both a legislative and an executive branch, as well as the executive head (mayor, president of province, and president of region, respectively). The regions were given financial autonomy to decide freely how to spend their money and organizational autonomy to decide how many councilors to have and how much to pay them. ${ }^{24}$ Each of these different

\footnotetext{
Government Dependence Index is statistically insignificant and indistinguishable from zero.

${ }^{22}$ In 1993, there was a popular referendum that led to the abolition of the proportional electoral system that characterized the First Republic and to its substitution by a quasi-majoritarian system.

${ }^{23}$ In March 1994, national elections were held: those elections saw a major turnover in the new parliament, with 452 out of 630 deputies and 213 out of 315 senators elected for the first time.

${ }^{24}$ Although the 1948 Constitution directly granted even the non-Special Statute Regions legislative powers for limited matters, such as agriculture, public works, tourism and urban planning, the regions were a little more than paper entities (Del Duca and Del Duca, 2006). In other words, the regions had no power to impose taxes, and they depended only on the State revenue sharing.
} 
levels of government has authority over, and responsibility for, the provision of local public goods and services, administrative authority over the issuing of permits and licenses, and some power to set up rates for certain categories of taxes. Hence, the majority of bureaucratic procedures firms face in their day-to-day operations is administered by local authorities, showing the importance of local politicians for firms.

This short discussion of the institutional background underlines that the links between entrepreneurs and local politicians have evolved and possibly strengthened over time in Italy. ${ }^{25}$

\subsubsection{Firm-Level Political Connections and Industry Dynamics}

As highlighted by our theory, political connections might have important implications for the aggregate industry dynamics. If political connections slow down competition, industries with connected firms may feature lower business dynamism, face lower firm entry and reallocation, be dominated by larger or older firms and, as a result, might have lower productivity and growth. In this section, we provide descriptive statistics at the industry and regional level consistent with these conjectures.

First, we explore empirically if markets with higher political presence show lower signs of business dynamism. We define market at the industry $\times$ region $\times$ year level and for each market, we compute the share of connected firms, firm entry rates, and total employment growth (to the next period) series. We then regress entry and growth rates on the share of connected firms, controlling for year, industry, and region fixed effects. Figure 4 plots binscatters from these regressions, where each dot represents outcome variables adjusted for fixed effects. Regressions are weighted by number of firms in each market. The results show that markets with higher political presence, on average, have lower entry of new firms - Panel (a), and grow less - Panel (b).

We quantify these relationships in Table 5 and, in addition, consider other measures for business dynamism: productivity, share of young firms, and share of small firms. We find that more politically connected markets are less productive, have a lower share of young firms, and are dominated by large firms - a clear signal of a lower degree of creative destruction. Interestingly, conditional on entry, in those markets that are more populated by connected firms, new firms tend to start off with connections, as evident from the last column of the table. In connected markets, in order to compete with incumbents, entrants might need to seek protection before entering the market. However, we cannot exclude that other time-variant factors at the market level that led incumbents to resort to political connections could also make entrants do the same.

Even if these relationships cannot be interpreted as being causal, our results show a strong and negative correlation between our measures of connections and business dynamism in Italy. We summarize our results in the following stylized facts that are in line with Implication \#1 and Implication \#2 from the model:

\footnotetext{
${ }^{25}$ Even if the core of our analysis is based on the 1993-2014 period, data on local politicians is available back to 1985 - allowing us to look at the evolution of firm-level political connections in Italy over time. Interestingly, we observe a permanent increase in the level of high-rank connections around mid-1990s - the time that delineated the transition to the Second Republic (see Online Appendix Figure A.1). We interpret this trend as a smoking gun for a regime shift from a more "under the table" relationship between firms and politicians involving corruption and bribes towards a more formal "moonlighting" relationship.
} 
Figure 4: Political Connections, Entry, AND Growth

(a) Entry Rate

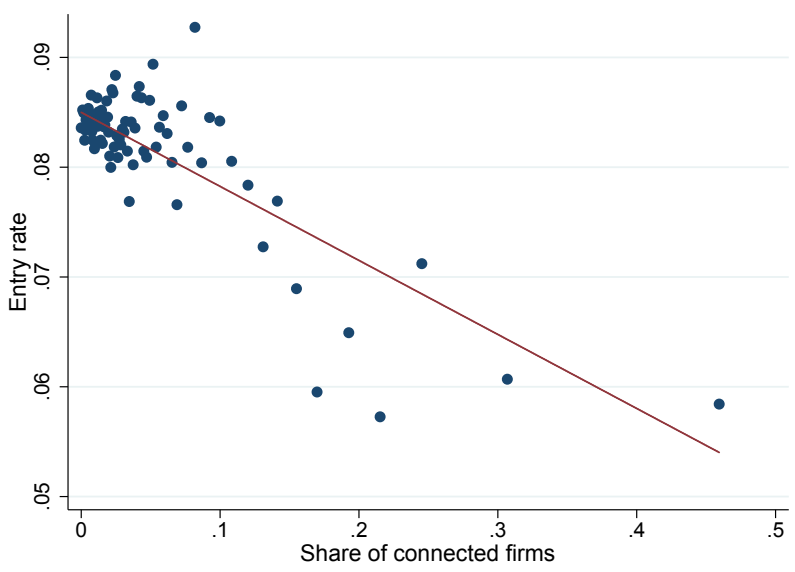

(b) Employment Growth

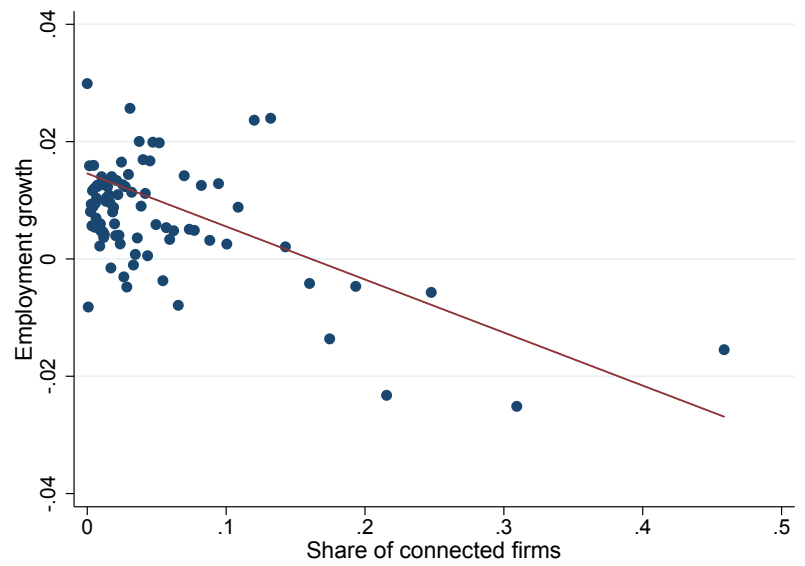

Notes: Each outcome variable at the industry $\times$ region $\times$ year level is regressed on the share of connected firms, controlling for industry, year, and region fixed effects. Each dot represents the adjusted outcome variable, namely the outcome from which we subtract all covariates (except the share of connected firms) times their estimated coefficients. Regression lines are depicted in each panel. Regressions are weighted by number of firms in each industry $\times$ region $\times$ year. The $x$-axis is divided into 20 quantile bins and each dot represents average value within that bin. In Panel (a), the outcome is entry rate of new firms. Panel (b) considers aggregate employment growth to the next period.

Fact 1. More connected markets face lower firm entry, but conditional on entry, entrants are more likely to be connected than in other industries.

Fact 2. Markets with a higher share of politically connected firms have a lower share of young firms and exhibit lower employment growth and productivity.

Table 5: Political Connections and Industry Dynamics

Growth Log LP Share young Share small Entry rate Share conn. entry

\begin{tabular}{lcccccc}
\hline Share of & $-0.0980^{* * *}$ & $-1.243^{* * *}$ & $-0.290^{* * *}$ & $-0.992^{* * *}$ & $-0.0309^{* * *}$ & $0.234^{* * *}$ \\
connected firms & $(0.0289)$ & $(0.114)$ & $(0.0215)$ & $(0.0180)$ & $(0.0114)$ & $(0.00900)$ \\
\hline Year FE & YES & YES & YES & YES & YES & YES \\
Region FE & YES & YES & YES & YES & YES & YES \\
Industry FE & YES & YES & YES & YES & YES & YES \\
Observations & 34214 & 33569 & 36049 & 36049 & 35857 & 30411 \\
\hline
\end{tabular}

Notes: Table reports the coefficients from OLS regressions at the industry $\times$ region $\times$ year level of various industry moments on the share of connected firms (share of connected incumbents in the case of columns 5 and 6). Columns list various outcome variables: 1) industry growth; 2) industry productivity; 3) share of firms younger than 5 years old; 4) share of small firms (<5 workers); 5) entry rate of new firms; and 6) share of connected firms among entrants. Regressions include year, region, and industry fixed effects. Regressions are weighted by number of firms in each industry $\times$ region $\times$ year to weight more representative markets more heavily. Standard errors are in parentheses. ${ }^{*} p<0.1,{ }^{* *} p<0.05,{ }^{* * *} p<0.01$ 


\section{Firm-Level Empirical Analysis}

In this section, we present results from the micro analysis at the firm level.

\subsection{Leadership Paradox: Market Rank, Political Connections, and Innovation}

How does market leadership influence a firm's growth strategy? One possibility is for market leaders to become even more innovative and extend their lead by pushing the technology frontier forward. An alternative possibility is to follow some anti-competitive strategies to defend their lead against their competitors. Our theory implies that market leaders are likely to follow the latter strategy and rely on political connections to preempt competition and creative destruction. We now examine this relationship empirically.

We rank each firm based on its employment share in a market, where market is defined at the (6-digit) industry $\times$ region $\times$ year level. ${ }^{26}$ We then zoom in on the top 20 firms across markets and plot various measures of political connections and of innovation over firm's market rank.

Figure 5 shows the relationship between politician intensity and innovation intensity over a firm's market rank. We measure politician intensity (blue triangles) as the number of politicians employed in a firm, normalized by 100 white-collar employees. ${ }^{27}$ We measure innovation intensity (red squares) as the number of patent applications in a year, normalized again by 100 white-collar employees. Both outcome variables are adjusted for industry, region, and year fixed effects. The blue and red lines depict regression lines from regressing politician intensity and innovation intensity, respectively, on market rank, controlling for industry, region, and year fixed effects. We observe that market leaders - the largest firms - are the most politician-intensive, but also the least patentintensive.

This "leadership paradox" is robust to alternative specifications. Online Appendix Figure B.1 presents a similar figure, but with alternative measures of politician and innovation intensities. There, we measure politician intensity as the number of majority-party politicians employed in a firm, normalized by 100 white-collar employees, and innovation intensity as intangible assets over a firm's value added. Again, politician and innovation intensities go in the opposite direction with market rank.

For visibility, Figures 5 and B.1 zoom in on the top 20 firms, however, we show that this relationship is preserved in the total sample of firms. Online Appendix Table B.1 shows coefficients from OLS regressions of various measures of connection and innovation intensity on market rank dummies, conditional on year, industry, and region fixed effects. Innovation intensity monotonically declines, while politician intensity monotonically increases with market rank. Age turns out to be a crucial factor, too: older firms are less innovation intensive, but more politician intensive. In the Appendix, we show that the observed relationship between innovation and connection intensity over market rank is robust to alternative definition of market share. Online Appendix Figure B.2 plots similar figures over market rank, based on value added. In addition, Online Appendix Figure

\footnotetext{
${ }^{26}$ Defining market by industry, excluding regional dimension leads to similar results.

${ }^{27}$ Since politicians are mostly employed in white-collar positions, a more relevant normalization is the number of white-collar workers in a firm. However, normalizing by total employment does not alter results significantly.
} 
Figure 5: Leadership Paradox: Market Rank, Innovation, and Political Connection

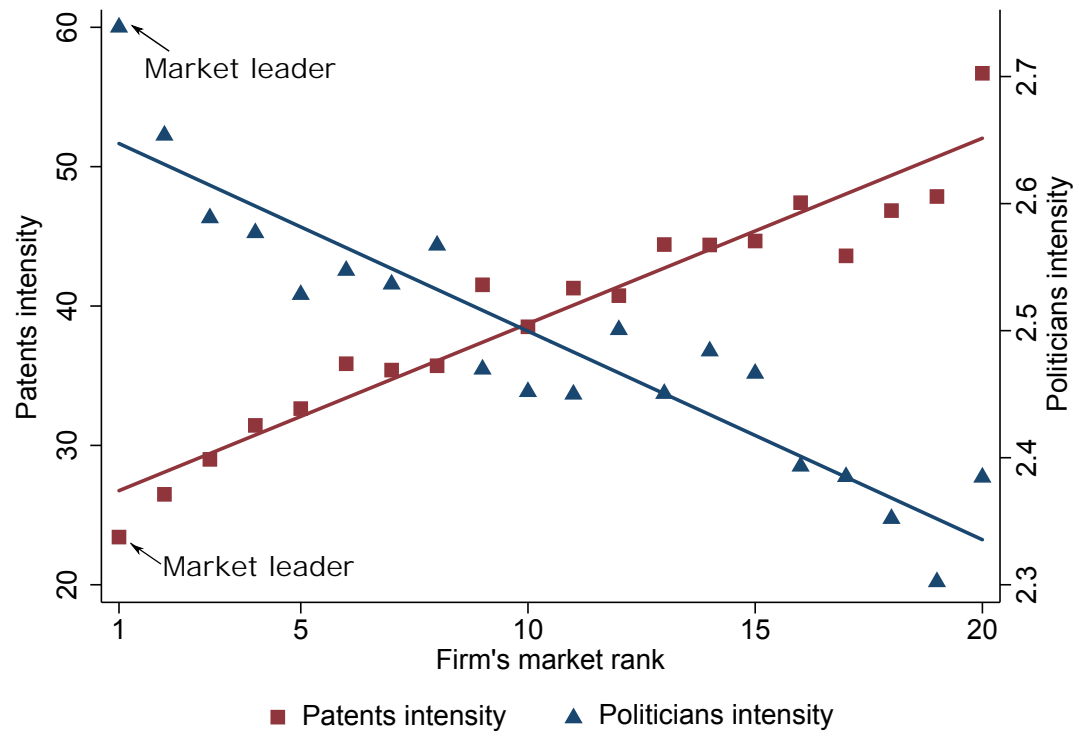

Notes: Figure plots politician intensity and innovation intensity over firm's market rank for top 20 firms in the markets. Market is defined at (6-digit) industry $\times$ region $\times$ year level. Markets in which top 1 firm holds less than $10 \%$ share are excluded. Politician intensity (blue triangles) is the number of politicians employed in a firm normalized by 100 white-collar employees. Innovation intensity (red squares) is the number of patent applications in a year normalized by 100 white-collar employees (conditional on patenting). Both outcome variables are adjusted for industry, region, and year fixed effects. The blue and red lines depict regression lines from regressing politician intensity and innovation intensity, respectively, on market rank, controlling for industry, region, and year fixed effects.

B.3 illustrates that negative relationship between innovation intensity and market rank is also robust, if we consider quality-adjusted patents, where quality is measured by 5-year patent citations or patent family size. Interestingly, this means that a reduction in the quantity of innovation by market leaders is not offset by a better quality of innovation.

These results on innovation are consistent with earlier findings on U.S. firms: using U.S. Census data, Akcigit and Kerr (2018) show that larger firms are less innovation-intensive and come up with less impactful innovation. Likewise, Argente et al. (2020) show that larger firms in the consumer goods sector introduce new products at a declining pace, and their products are less novel. Hence, an observation that large firms and market leaders are less innovative is perhaps less surprising, but what characterizes these firms is that they rely more on political connections.

Fact 3. Market leaders are the most politician-intensive but the least innovation-intensive, relative to their direct competitors.

This fact is in line with Implication \#3 of our theory. The theory shows that larger firms have higher incentives to be politically connected both because of static returns from removing market frictions and dynamic motives to preempt competitors. Hence, Fact 3 corroborates our theoretical intuition. 


\subsection{Political Connections and Firm Survival}

The fourth implication of the model predicted that politically connected firms enjoy higher survival probabilities. This section explores this prediction empirically.

In the data, differences in survival probabilities of firms with different connection statuses are large. To illustrate this, Figure 6 presents Kaplan-Meyer survival estimates splitting the sample of firms based on their connection status over the lifecycle. Different curves plot cumulative survival probabilities of firms that have never been connected; that have been connected, but never with a majority-level or a high-rank politician; that have at some point been connected with a majoritylevel politician but never one with a high-rank; and that have been connected with both a majoritylevel and high-rank politician at some point in their life. We see that these survival probabilities monotonically increase with the strength of connections that firm has established.

Figure 6: Survival Estimates by Connection Status

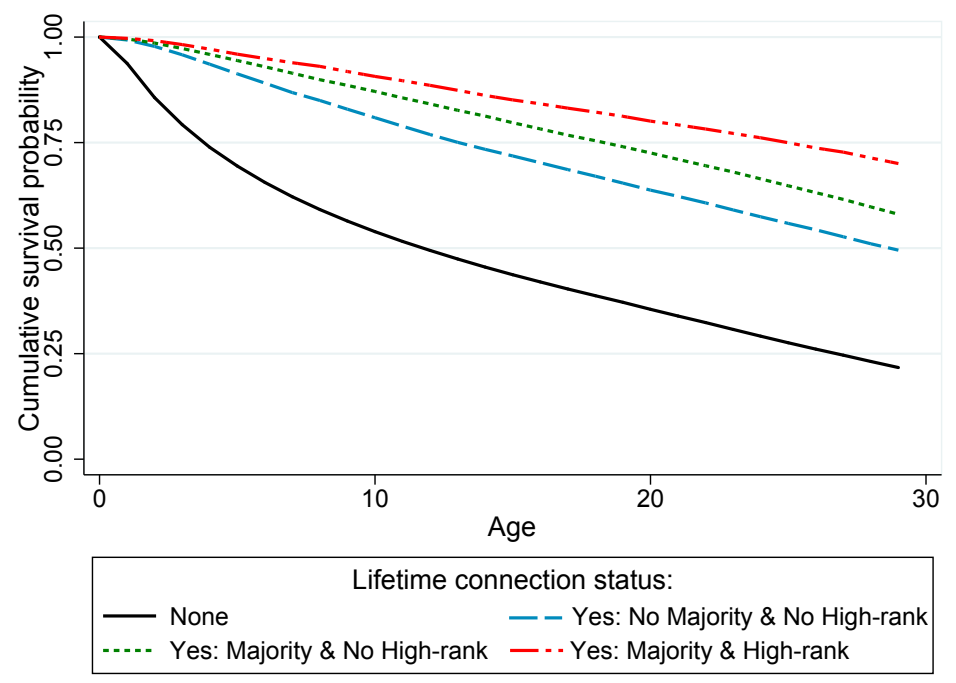

Notes: Kaplan-Meyer Survival estimates by maximum level of connections over the lifetime of a firm. Black curve denotes firms that have never been connected with a politician; blue curve - firms that have been connected but never with a politician from a majority party or a high-rank politician; green curve - firms that have been connected with a politician from a majority party but never with a high-rank politician; red curve - firms that have been connected with a high-rank politician. See Section 4.2 for the definitions of high-rank and majority politicians.

These differences might be driven by the fact that connected firms are also larger, and large firms are both more likely to be connected and more likely to survive. To address this concern, we conduct a parametric Cox survival analysis on all firms in our sample. Table 6 reports the results. The main explanatory variables for a firm's survival are connection dummy (column 1), majoritylevel dummy (column 2), and high-rank connection dummy (column 3). The model also controls for firm size, a firm's market share, and year and industry dummies.

Conditional on observables, firms that are connected have lower hazard and therefore they survive longer. Survival time increases even further if a firm is connected with a majority-level or a high-rank politician. Relative to non-connected firms, firms that are connected with high-rank politicians experience a 0.275 decline in yearly log hazard rate, while connections with a majoritylevel politician is associated with a 0.109 decline in yearly log hazard rate. This brings us to our 
Table 6: Cox Survival Analysis

\begin{tabular}{lccc}
\hline \hline & Exit & Exit & Exit \\
\hline Connection & $-0.088^{* * *}$ & $-0.059^{* * *}$ & $-0.067^{* * *}$ \\
& $(0.009)$ & $(0.013)$ & $(0.010)$ \\
Connection major & & $-0.050^{* * *}$ & \\
& & $(0.019)$ & $-0.208^{* * *}$ \\
Connection high-rank & & & $(0.033)$ \\
& & $-0.413^{* * *}$ & $-0.415^{* * *}$ \\
Log Size & $-0.415^{* * *}$ & $(0.001)$ & $(0.001)$ \\
& $(0.001)$ & $-0.024^{* * *}$ & $-0.024^{* * *}$ \\
Log market share & $-0.024^{* * *}$ & $(0.0008)$ & $(0.0008)$ \\
& $(0.0008)$ & YES & YES \\
Year FE & YES & YES & YES \\
Industry FE & YES & $25,842,288$ & $25,773,082$ \\
Observations & $25,773,082$ & & \\
\hline \hline
\end{tabular}

Notes: Cox proportional hazard model of firm survival as a function of connection status at a point in time. Definitions of Connection, Connection major and Connection high-rank are given in Section 4.2. Other controls are Log Size, Market Share - defined as share of a firm's employment in industry $\times$ region $\times$ year - and year and industry dummies. Efron method for tied failures is used. ${ }^{*} p<0.1,{ }^{* *} p<0.05,{ }^{* * *} p<0.01$

next stylized fact, consistent with the theoretical Implication 3.

Fact 4. Politically connected firms are more likely to survive, and their survival probability increases in the political power of the politicians they employ.

\subsection{Political Connections and Firm Growth}

Do political connections help firms grow? Do firms use their political connections to push the technology frontier? The answers to these questions could shed some light on the two alternative hypothesis that connections are useful for or detrimental to technological progress. If firms use their connections to push the frontier, employment growth should be coupled with productivity growth. Alternatively, if political connections are used to gain certain types of preferential treatment (as it was in our theoretical model) or to directly eliminate competition, the freed-up workers from competitors would be reallocated to the connected firms. However, such growth in employment would be detached from growth in productivity.

In Tables 7, we estimate the following regressions:

$$
y_{i t}=\beta_{0}+\beta_{1} \text { Connection }_{i t}+\beta_{2} \text { Connection majority }_{i t}+\zeta \mathbf{x}_{i t}+\eta \mathbf{x}_{t}+\gamma \mathbf{x}_{i}+\varepsilon_{i t}
$$

where $y_{i t}$ is a firm $i^{\prime}$ s growth from $t$ to $t+1$. The main explanatory variables Connection ${ }_{i t}$ and Connection majority $y_{i t}$ are dummy variables defined in Section 4.2. $\mathbf{x}_{i t}$ includes time-varying firmlevel controls - log total assets, log size (employment), and age. $\mathbf{x}_{t}$ includes time dummies, while $\mathbf{x}_{i}$ includes a firm's region and industry dummies for columns $1,3,5$, and 7 , and firm fixed effects for columns $2,4,6$, and 8 . 
Table 7: Political Connections and Various Measures of Firm Growth

\begin{tabular}{|c|c|c|c|c|c|c|c|c|}
\hline & $\begin{array}{l}\text { 1. Empl } \\
\text { (OLS) }\end{array}$ & $\begin{array}{l}\text { 2. Empl } \\
\text { (FE) }\end{array}$ & $\begin{array}{l}\text { 3. VA } \\
\text { (OLS) }\end{array}$ & $\begin{array}{l}\text { 4. VA } \\
\text { (FE) }\end{array}$ & $\begin{array}{l}5 . \mathrm{LP} \\
\text { (OLS) }\end{array}$ & $\begin{array}{l}\text { 6. LP } \\
\text { (FE) }\end{array}$ & $\begin{array}{l}\text { 7. TFP } \\
\text { (OLS) }\end{array}$ & $\begin{array}{l}\text { 8. TFP } \\
(\mathrm{FE})\end{array}$ \\
\hline \multirow[t]{2}{*}{ Connection } & $0.032^{* * *}$ & $0.040^{* * *}$ & $0.039^{* * *}$ & $0.014^{* * *}$ & $-0.014^{* * *}$ & $-0.028^{* * *}$ & $-0.008^{* * *}$ & $-0.019^{* * *}$ \\
\hline & $(0.001)$ & $(0.002)$ & $(0.002)$ & $(0.002)$ & $(0.002)$ & $(0.002)$ & $(0.001)$ & $(0.002)$ \\
\hline \multirow[t]{2}{*}{ Connection major } & $0.003^{*}$ & $0.007^{* * *}$ & $0.010^{* * *}$ & 0.002 & -0.001 & -0.004 & 0.000 & -0.003 \\
\hline & $(0.001)$ & $(0.002)$ & $(0.002)$ & $(0.002)$ & $(0.002)$ & $(0.003)$ & $(0.002)$ & $(0.002)$ \\
\hline Year FE & YES & YES & YES & YES & YES & YES & YES & YES \\
\hline Region FE & YES & $\mathrm{NO}$ & YES & $\mathrm{NO}$ & YES & $\mathrm{NO}$ & YES & $\mathrm{NO}$ \\
\hline Industry FE & YES & $\mathrm{NO}$ & YES & $\mathrm{NO}$ & YES & $\mathrm{NO}$ & YES & $\mathrm{NO}$ \\
\hline Firm FE & $\mathrm{NO}$ & YES & $\mathrm{NO}$ & YES & $\mathrm{NO}$ & YES & $\mathrm{NO}$ & YES \\
\hline Observations & $6,545,131$ & $6,585,740$ & $5,684,519$ & $5,710,338$ & $5,598,367$ & $5,623,077$ & $5,271,002$ & $5,291,979$ \\
\hline
\end{tabular}

Notes: Firm-level regressions described in equation (10). Dependent variables are growth in employment (columns 1 and 2), value added (columns 3 and 4), labor productivity (columns 5 and 6), and TFP (columns 7 and 8 ) from time $t$ to time $t+1$. TFP is calculated using Cobb-Douglas specification where capital is measured as total assets, labor is given by employment level from INPS, and labor share is taken equal to average industry-level labor share from the data. Main control vaiables are Connection - a dummy variable equal to one if the firm is connected with a politician, and Connection major - a dummy equal to one if the firm is connected with a majority-member politician at time $t$. The regressions, in addition, control for a firm's log assets, log size, age, as well as year, region, and industry fixed effects in columns 13,5 , and 7; and for year dummies and firm fixed effects in columns 2, 4, 6, and 8. Robust standard errors clustered at firm level reported in parentheses. ${ }^{*} p<0.1{ }^{* *} p<0.05,{ }^{* * *} p<0.01$.

Column 1 of Table 7 reports employment growth regression, controlling for a firm's assets, size, and age, as well as year, region, and industry fixed effects. The results show that connected firms grow 3 percentage points faster, on average. Being connected to a majority party is associated with an additional 0.3 percentage point employment growth. Column 2 shows similar coefficients using identification within firms, including firm fixed effects. Columns 3 and 4 show that connected firms grow 1 to 4 percentage point faster in value added.

These results indicate that firms that are getting connected expand in terms of size and revenue. However, this growth is not accompanied by a corresponding growth in these firms' productivities. Columns 5 and 6 of Table 7 show similar regressions, but for the growth of labor productivity. Columns 7 and 8 repeat the same analysis for total factor productivity growth. We see that connections are associated with a weak decline in productivity growth, while connections with majority-level politicians are not significant.

Overall, these results tell us that political connections are associated with positive growth in size, but not in productivity. Online Appendix Table B.2 summarizes these opposing results but extends the analysis to other dependent variables. Panel A looks at growth in size - employment, white-collar employment, value added, and profits. Connections are positively associated with all these outcomes. On the other hand, in Panel B, connections are associated negatively with future growth in productivity measures - labor productivity, TFP, intangibles intensity, or patents growth.

A major concern with these regressions is a potential endogeneity of the political connections. Therefore, we perform a regression discontinuity analysis in the next section. We conclude this section by summarizing our findings:

Fact 5. At the firm level, political connections are associated with higher employment and revenue growth, but not with productivity growth.

This empirical fact is in line with Implication \#5 of our model. Taken together, Fact 3 and Fact 
5 suggest that the primary role of political connections is to help firms alleviate certain market frictions and obtain preferential treatment that they do not necessarily use to innovate and advance their productivities.

\section{Causal Inference}

In the spirit of Lee (2008), we exploit a quasi-random discontinuity caused by local elections decided on a thin margin to gauge the causality of our firm-level growth results. The idea behind this method is to compare the post-election performance of two different firms that were politically connected to different competing parties right before a marginally-contested election. Since the outcomes of closely contested elections can be considered as pure chance, discontinuity in outcomes between marginally winning and losing firms after the election can be attributed to a causal effect of majoritylevel connections on firms' outcomes. Before we go into the details of the methodology, it is useful to describe the institutional setting of the Italian local elections and the identification of closely contested elections in our data.

\subsection{Institutional details on elections.}

Elections at the municipal level. Local elections are typically held every five years, and voters are asked to choose a mayor and members of the local council. There are around 8,100 municipalities in Italy, with populations ranging from 100 inhabitants to 3 million inhabitants. Electoral law could have some size-dependent nuances across municipalities.

Elections generally take place through the "one-shot" voting mechanism with a majoritarian system for both the mayor and the council members. Votes are cast both for mayor candidates and the parties that support those candidates. ${ }^{28}$ In large municipalities (population $>15,000$ ), if no candidate gets an absolute majority, i.e., more than $50 \%$, then the election goes to the second round. Votes cast for the candidates not only determine the identity of a mayor, but also determine the allocation of seats to parties with the candidates. Importantly, the winning candidate gets a majority premium, and hence his/her party/coalition is guaranteed to have a majority of the seats on the council. ${ }^{29}$ After determining the total allocation of seats to a winning coalition, the further allocation of seats within a winning coalition or outside of it is determined by the votes cast for each party.

Elections at the provincial level. Elections are normally held every 5 years, and voters choose the president of the province and the council composition. Electoral rules for province-level elections are very similar to the ones for large municipalities (population $>15,000$ ) as described above. ${ }^{30}$

\footnotetext{
${ }^{28}$ In general, separate voting is not allowed, so that voters cannot pick candidates and parties from competing tickets, except in large municipalities.

${ }^{29}$ Specifically, $2 / 3$ of the seats in smaller municipalities and at least $60 \%$ in larger municipalities.

${ }^{30}$ Major reform concerning province-level elections was enacted around 2014. The reform in essence removed provincelevel elections. The Budget Law for 2012 (L214/2011: Disposizioni urgenti per la crescita, l'equitáe il consolidamento dei conti pubblici) has laid the foundations for a provincial reform in Italy that came to an end in 2014 with the so-called Delrio Law (L56/2014). In the transitory regime, elections in the provinces of Como, Belluno, Vicenza, Genova, La Spezia, Ancona, and Caltanissetta e Ragusa were not held. As a result, in the transition period (2012-2014), many provinces did not hold scheduled elections. Instead, they extended the mandate of the incumbent politicians. Hence, in those cases, we impute results from the previous elections by extending the results to more than 5 years.
} 
Elections at the regional level. Regional elections are generally held every 5 years in the twenty regions of Italy. Before 1995, voters did not directly choose a regional president. Instead, they cast votes for parties/coalitions that formed a council. Allocation of seats between parties was based on a proportional system. However, since 1995, it is possible to cast votes for a presidential candidate, as well as for parties/coalitions forming a government (with lists running at district or regional level). There is no possibility of runoff. The coalition associated with a winning president is generally assured a majority of the seats in the government (at least 55\%). The rest of the seats are determined by the number of votes cast for each party. ${ }^{31}$

Identifying marginally contested elections. Our detailed data allows us to identify elections that have been contested on a thin margin. As described above, votes cast for the candidates (not for parties) determine the margin of victory and the identity of a majority party/coalition in a particular election. ${ }^{32}$ In most cases, the minimum threshold of votes is $50 \%$, and if that threshold is not reached by anyone, a runoff is expected. Important exceptions to the $50 \%$-threshold are elections in small municipalities with a population below 15,000 inhabitants, as well as in regional elections. In such cases, a second round is never held and the winner is the one who receives the largest share of votes in the first round.

We identify the marginal elections as follows: let $p_{1}$ denote the share of votes obtained by a winner and $p_{2}$ the share of votes held by a runner-up. We define a margin of victory as the difference between the share of votes of the highest-share candidate $\left(p_{1}\right)$ and of the second-highest share candidate $\left(p_{2}\right)$ in a decisive round. Hence, margin of victory $\equiv p_{1}-p_{2}$.

There were 36,513 municipal elections during the 1993-2014 period. Out of those, 19,589 were decided within a 20\% margin, 5,879 within a 5\% margin, and 2,395 within a very narrow $2 \%$ margin. At the provincial level, 846 out of 1,162 elections were decided within a 20\% margin, and 266 and 62 - within $5 \%$ and $2 \%$ margins, respectively. ${ }^{33}$ This provides us with a large sample for our regression discontinuity analysis. ${ }^{34}$ Online Appendix Figure B.4 shows that the distribution of victory margins in our sample period is smooth, while B.5 shows that marginal elections are geographically scattered all over Italy with no particular geographic concentration.

Random outcomes of marginal elections. Our identification strategy relies on the randomness of election outcomes when the margin of victory is close to zero. A threat to this randomness could come from incumbency advantage - incumbent politicians may have higher chances of reelection even in tight contests. We examine this possibility by looking at the re-election probability of incumbent parties. If the outcomes of close elections cannot be anticipated, then the odds of winning for an incumbent party/coalition should be the same as odds of non-incumbents. Figure 7

\footnotetext{
${ }^{31}$ Parties may decide to compete within district or regional lists, and this will have an effect on how the seats are allocated. However, in our data, we have information on the allocation of final seats, hence we do not need to work out all these details to determine how many seats a party/coalition got.

${ }^{32}$ We cannot define marginal elections for regional elections before 1995, as presidents were not chosen directly and seats were allocated proportionally based on votes for parties.

${ }^{33}$ At the regional level, 62 out of 266 elections were decided within a $20 \%$ margin and 21 were decided within a $5 \%$ margin, and just 10 elections were decided within a $2 \%$ margin.

${ }^{34}$ For example, even for elections within $4 \%$ victory margin (for example, an election with $48 \%-52 \%$ outcome), we have more than 20,000 RLP politicians for whom we have detailed party affiliation and social security information from INPS.
} 
plots the probability of re-election - the share of elections won by an incumbent party as a function of the margin of victory. The sample contains all those elections (within the $20 \%$ margin) where an incumbent party/coalition is either a winner or a runner-up. We see that elections with a wide victory margin feature a large incumbency advantage in terms of re-election. However, closer to the zero margin of victory, the outcome of an election resembles a coin flip - an incumbent is exactly as likely to win as the other candidate.

Figure 7: Probability of Re-election against the Margin of Victory

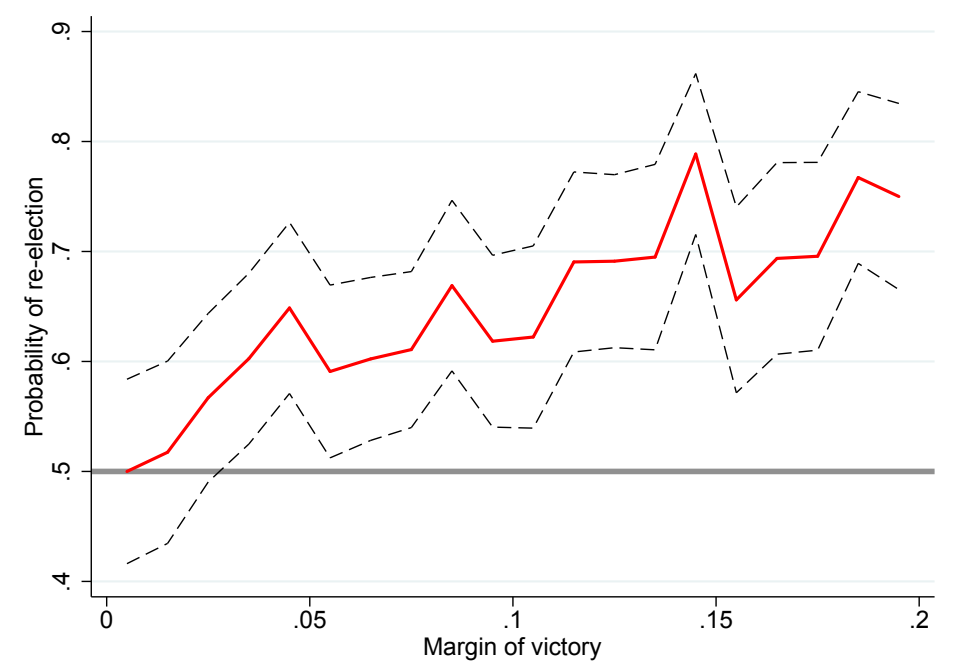

Notes: Share of elections won by an incumbent party against the margin of victory in those elections. Re-election is equal to one if a winning party is the same (or shares at least one common party, in the case of coalitions) as an incumbent party/coalition that won the last election. Margin of victory is equal to the difference between share of votes received by a winning candidate minus the share of votes by a runner-up. The sample focuses on all the elections, where margin of victory is less than 0.2 and an incumbent party/coalition is either a winner or a runner-up.

Another potential concern could be that our identification of treated and control groups in RD could be noisy if, in anticipation of a closely contested election, firms employ politicians from both competing parties. We check for this possibility in Figure 8, where, across firms, we plot the distribution of the share of winning politicians at firm $i$ in the election held at time $t$. Share of winning politicians is defined as

$$
\text { Share of winning politicians } \text { wit }=\frac{\text { Winning-party members }_{i t-1}}{\left[\text { Winning-party } \text { members }_{i t-1}\right] \cup\left[\text { Losing-party }_{\text {members }} \text { m-1 }_{\text {- }}\right]}
$$

and is simply the number of workers employed in a company $i$ at $t-1$ who were members of the winning party/coalition of the election in $t$, divided by the total number of politicians employed in $i$ at $t-1$. An interesting finding here is that only $4 \%$ of firms employ politicians from both competing parties simultaneously. ${ }^{35}$ We see that firms almost always "bet" only on one side of an election. While $75 \%$ of the firms employ only from the winning party, $20 \%$ of the firms employ only from the losing party. ${ }^{36}$

\footnotetext{
${ }^{35}$ In the subsequent analysis, we drop those observations.

${ }^{36}$ Though it is tempting to infer from this figure that firms seem to anticipate election outcomes just because there is a
} 
Figure 8: Distribution of Share of Winning Politicians across Firms

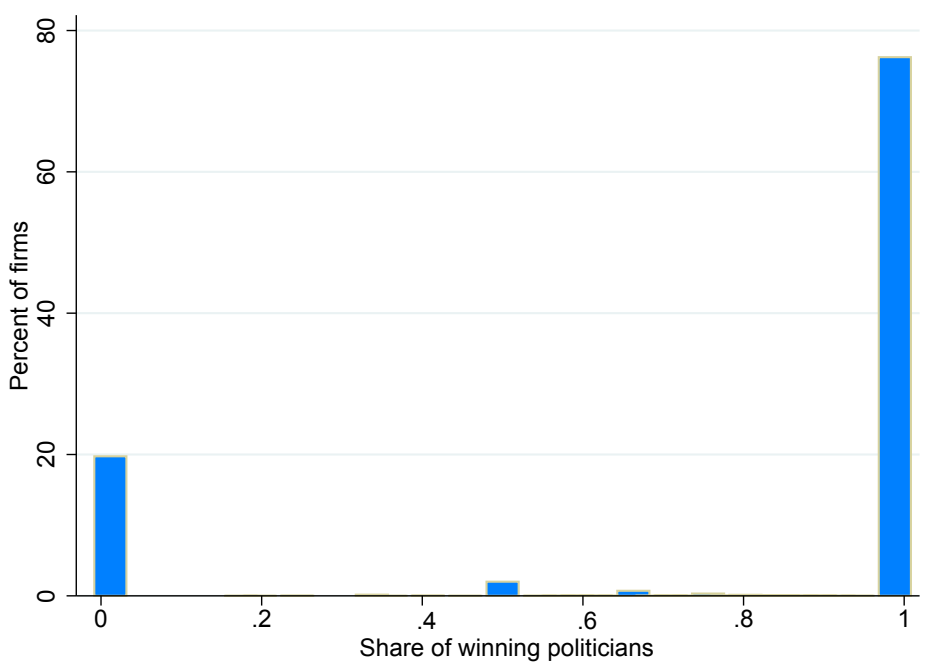

Notes: Figure shows distribution of firms over share of winning politicians in their companies in elections within $10 \%$ victory margin. We compute share of winning politicians in a company $i$ as the number of workers employed in the company $i$ at $t-1$ who were members of the winning party of the election in $t$, divided by the total number of politicians employed in $i$ at $t-1$. We see that firms usually "bet" on one side of an election, and the share of firms employing politicians from the competing parties is very low.

\subsection{Regression Specification}

Now we are ready to describe our econometric specification. Let $m$ denote an election that has been decided with a victory margin Victory $\operatorname{margin}_{m}, T(m)$ - the year in which it was held, $y_{i T(m)}$ - the outcome variable (e.g., firm $i$ 's employment or labor productivity growth from $T(m)$ to $T(m)+1$ ), winning dummy $\operatorname{Win}_{i T(m)-1}$ - a dummy equal to one if firm $i$ at time $T(m)-1$ employs a politician from a party that wins the election $m$. We ultimately estimate the following relationship:

$$
y_{i T(m)}=\alpha+\beta \operatorname{Win}_{i T(m)-1}+f\left(\text { Victory } \operatorname{margin}_{m}\right)+\delta_{1} X_{i T(m)}+\delta_{2} X_{m}+\delta_{3} X_{T}+v_{i T(m)},
$$

where $f$ (Victory $\left.\operatorname{margin}_{m}\right)$ is a polynomial function in margin of victory of election $m$ estimated on both sides of the threshold, $X_{i T(m)}$ are firm-level controls, such as the firm's age and size at time $T(m), X_{m}$ is a set of province dummies, $X_{T}$ is a year dummy, and $v_{i T(m)}$ is the error term. The parameter of interest $\beta$ identifies the causal effect of treatment (winning) at the threshold.

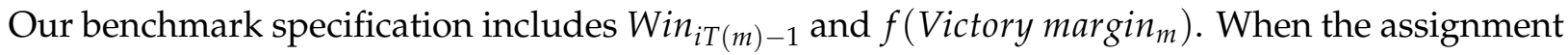
of treatment is random, our estimate of $\beta$ should be invariant to the inclusion of additional controls $X_{i T(m)}, X_{m}$ or $X_{T}$, since they should be orthogonal to treatment. We validate this assumption in Section 6.5 below and show our results with and without those additional controls. We follow the recent literature (see Imbens and Lemieux (2008) and Cattaneo et al. (2018) for an excellent review) and in our baseline results approximate the regression functions above and below the threshold with local linear polynomials, with weights implied by triangular kernel. Hence, our benchmark

larger mass at one than zero, as opposed to 50-50, this inference is not correct. Recall from Table 3 that Majority affiliation is equal to one for $73 \%$ of observations in RLP. If every firm had employed only one randomly-chosen politician, by construction, we would have observed $73 \%$ of the firms at 1 and $27 \%$ at 0 in Figure 8. 
$f\left(\right.$ Victory $\left._{\text {margin }_{m}}\right)$ is the first-order polynomial interacted with winning dummy. The benchmark bandwidth is chosen following the optimal bandwidth choice of Imbens and Kalyanaraman (2012). We demonstrate robustness to different choices of the order of a local polynomial, a weighting function, and a bandwidth in Section 6.4.

\subsection{Graphical Analysis}

We first illustrate a discontinuity at the threshold graphically in Panel (a) of Figure 9, where the outcome variable is firm-level employment growth. We plot a firm's growth from $T$ to $T+1$ against margin of victory at time $T$. Positive margins of victory denote firms that have been connected at time $T-1$ with a politician from a party that won an election at time $T$ with a corresponding margin of victory. Likewise, negative margins of victory depict firms that are connected with losing politicians. The figure focuses on all the elections that were decided with no more than a $10 \%$ margin. For visibility, we divide the $x$-axis into 0.01 -wide intervals of the margin of victory at time $T$. Each point denotes average growth of firms in that interval; the solid lines represent predicted flexible polynomial fits from a regression that includes third order polynomial in margin of victory, ${ }^{37}$ a win dummy $\operatorname{Win}_{i T-1}$, and an interaction of the dummy with the polynomial. As a robustness check, we repeat the same plot for the elections within 20\% victory margin in Online Appendix Figure B.6.

A large positive discontinuity at the zero victory margin threshold visible in Panel (a) identifies the existence of a positive causal effect of majority-level connections on the employment growth after elections. This confirms that the direction of causality in previous firm-level regressions does (also) run from political connections to growth. An interesting observation is that firms connected with barely losing politicians have lower post-election growth rates than firms connected with politicians whose parties lost by a wide margin. Since power of political connection for losing firms closer to the margin is presumably stronger than that of firms losing further away from the margin (as the latter belong to a party controlling fewer seats), one might expect connections to have a relatively stronger positive effect for firms closer to the threshold. However, note that for firms losing on a wide margin, election outcome was anticipated, while losing was a negative shock for firms at the threshold who now would need to downsize relative to their expectations (for example, expectation of a lucrative contract or the expectation of receiving a permit, or a speedy removal of certain bureaucratic burden, etc.). These anticipation and selection differences aside, one could still argue that firms connected with fierce competitors of barely winning candidates could be performing worst because, for example, of a strong competition for the same resources. In addition, marginal elections are quite different from standard elections: in tightly contested elections, connected firms on both sides may allocate significant financial resources before the elections, especially hurting post-election growth opportunities of losing firms.

RD plots also confirm a causal interpretation of firm-level results on labor productivity growth. Panel (b) of Figure 9 shows no positive effects of connections on productivity growth. As a robustness check, we again repeat the same plot for the elections within a $20 \%$ victory margin in Online Appendix Figure B.6.

\footnotetext{
${ }^{37}$ The fourth-order polynomial fits look very similar.
} 
Figure 9: Employment and Labor Productivity Growth after Election

(a) EMPLOYMENT GROWTH AFTER ELECTION $(T \rightarrow T+1)$

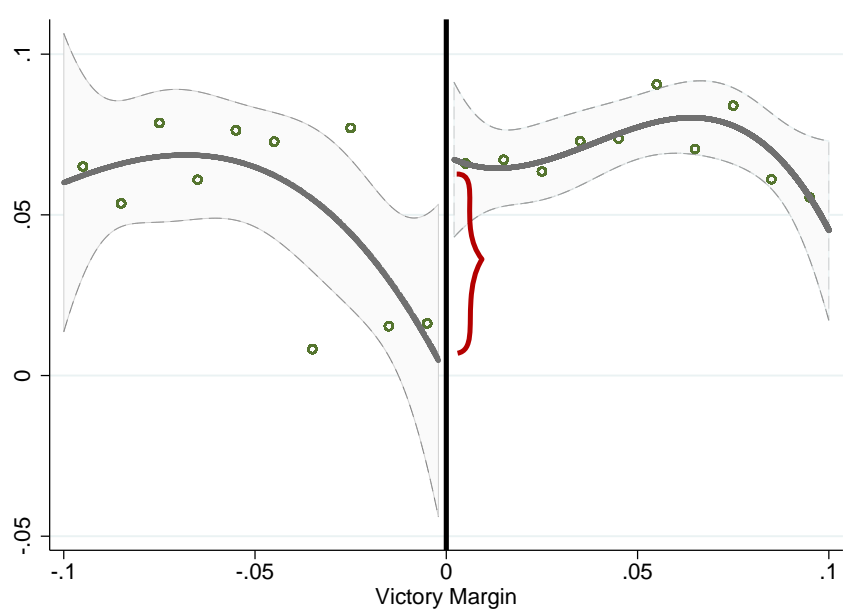

(b) LP GROWTH AFTER ELECTION $(T \rightarrow T+1)$

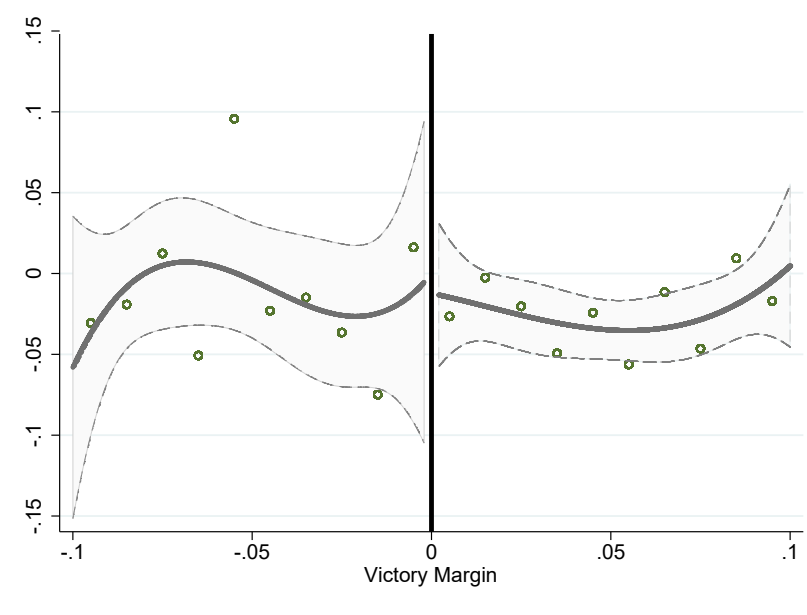

Notes: Figure plots a firm's growth from $T$ to $T+1$ against margin of victory at time $T$. Positive margins of victory denote firms that have been connected at time $T-1$ with a politician from a party that won an election at time $T$ with the corresponding margin of victory. Likewise, negative margins of victory depict firms that are connected with losing politicians. For visibility, we divide the $x$-axis into 0.01 -wide intervals of the margin of victory at time $T$, and each point denotes average outcome of firms in that interval. The solid lines represent predicted third order polynomial fits from the regression that includes third order polynomial in margin of victory, a dummy Win ${ }_{i t-1}$, and an interaction of the dummy with the polynomial. The dashed line represents $90 \%$ confidence intervals. Outcome variable in Panel (a) is employment growth, while in Panel (b) it is labor productivity growth. Figures are normalized such that outcome variables for marginal losers at the threshold are equal to zero.

\subsection{RD Estimates}

We now illustrate the estimates from the RD setup described in Section 6.2. Table 8 reports our benchmark results. Columns 1 and 3 correspond to the regression 11 including $W_{i n_{i T-1}}$ and $f$ (Victory margin), without additional controls. Coefficient on winning dummy is large and significant for employment growth, translating into a 4-percentage-point difference in growth rate, which is economically sizable. The effect on productivity growth is not statistically different from zero.

Table 9 illustrates robustness to the choice of kernel function for local polynomial regression, polynomial order, and bandwidths. Panel A repeats our benchmark results but uses uniform kernel weighting for the local linear regression; Panel B uses a second-order local polynomial approximation for $f$ (Victory margin); while Panels C and D report benchmark results on $20 \%$ and $10 \%$ bandwidths. Our results are robust to these variations.

\subsection{Tests for Quasi-Random Assignment}

Additional controls. Our identification strategy relies on the assumption of the random assignment of the winner in marginally contested elections. This implies that marginally winning and marginally losing firms are very comparable and should not show systematic differences in predetermined covariates. We provide some tests to support the quasi-random assignment in our RD 
Table 8: Employment and Productivity Growth after Election. RD Estimates.

\begin{tabular}{lcccc}
\hline \hline & $\begin{array}{c}\text { Empl } \\
\text { Growth }\end{array}$ & $\begin{array}{c}\text { Empl } \\
\text { Growth }\end{array}$ & $\begin{array}{c}\text { LP } \\
\text { Growth }\end{array}$ & $\begin{array}{c}\text { LP } \\
\text { Growth }\end{array}$ \\
\hline Win dummy & $0.0392^{* *}$ & $0.0408^{* *}$ & -0.0128 & -0.0141 \\
& $(0.0178)$ & $(0.0169)$ & $(0.0308)$ & $(0.0299)$ \\
Age & & -0.0000 & & -0.0005 \\
& & $(0.0003)$ & & $(0.0006)$ \\
Log Size & & 0.0018 & & -0.0106 \\
& & $(0.0033)$ & & $(0.0076)$ \\
\hline f(Victory margin) & YES & YES & YES & YES \\
Year FE & NO & YES & NO & YES \\
Province FE & NO & YES & NO & YES \\
\hline Observations & 19465 & 19362 & 10437 & 10422 \\
\hline \hline
\end{tabular}

Notes: RD estimates for employment growth (columns 1 and 2) and labor productivity growth (columns 3 and 4 ) based on regression specification 11. Growth rates are defined from $T$ to $T+1$. In the columns 1 and 3, regressions include win dummy, $W_{i T-1}$, and $f$ (Victory margin) - a linear polynomial interacted with win dummy. Columns 2 and 4 also include additional controls such as year and firm province fixed effects, log size, and age. The local linear regressions are estimated on the optimal Imbens and Kalyanaraman (2012) bandwidth and are weighted using a triangular kernel function. Robust standard errors reported in parentheses.

design. First, the inclusion of additional covariates in the regressions $\left(X_{i T(m)}, X_{m}, X_{T}\right.$ in equation 11) should not change the main effect of the treatment. Indeed, after including additional controls, such as year and province fixed effects, log size and age in columns 2 and 4 of Tables 8 and 9, we see that the magnitude of the main coefficients does not significantly change.

Pre-trends. Next, we examine the pre-trends in outcome variables. Figure 10 illustrates RD plots similar to the above plots, but for the employment growth and labor productivity growth at $T-1$, right before the elections. Panel (a) shows the result for employment growth and Panel (b) shows it for productivity growth. We see no significant difference in pre-elections growth rates at the threshold, which implies that the firms on the winning and losing sides do not show any systematic difference in main outcome variables prior to the election.

Balancing tests. Lastly, we show balancing tests for various pre-determined firm-level variables at time $T-1$. To analyze any discontinuity of pre-determined covariates at the zero margin threshold, we use the same techniques as in our benchmark RD setup. Specifically, for each covariate of interest, we employ a local linear estimation with an optimal bandwidth and triangular kernel. We report estimates of discontinuity for the before-election firm size, value added, assets, intangible capital, labor productivity, profits, previous-period growth in size and productivity, age, and geographic location in various columns of Table 10. These results show that the treatment and control groups are comparable around the threshold. The only statistically significant difference emerges in firm's age, however the magnitude of one year is economically small. 
Table 9: Employment and Productivity Growth after Election. RD Robustness

- Panel A. Uniform kernel function -

\begin{tabular}{lcccc} 
& $\begin{array}{c}\text { Empl } \\
\text { Growth }\end{array}$ & $\begin{array}{c}\text { Empl } \\
\text { Growth }\end{array}$ & $\begin{array}{c}\text { LP } \\
\text { Growth }\end{array}$ & $\begin{array}{c}\text { LP } \\
\text { Growth }\end{array}$ \\
\hline \hline Win dummy & $0.0329^{* *}$ & $0.0300^{* *}$ & -0.0153 & -0.0114 \\
& $(0.0154)$ & $(0.0146)$ & $(0.0279)$ & $(0.0272)$ \\
f(Victory margin) & Yes & Yes & Yes & Yes \\
Controls & No & Yes & No & Yes \\
\hline
\end{tabular}

- Panel B. Second-order local polynomial —

\begin{tabular}{lcccc} 
Win dummy & $0.0482^{*}$ & $0.0556^{* *}$ & 0.0057 & -0.0058 \\
& $(0.0278)$ & $(0.0262)$ & $(0.0491)$ & $(0.0487)$ \\
$\mathrm{f}($ Victory margin) & Yes & Yes & Yes & Yes \\
Controls & No & Yes & No & Yes \\
\hline \multirow{2}{*}{ Win dummy } & - Panel C. $20 \%$ victory & margin bandwidth - & \\
& $0.0360^{* *}$ & $0.0355^{* *}$ & -0.0099 & -0.0091 \\
f(Victory margin) & $(0.0163)$ & $(0.0155)$ & $(0.0285)$ & $(0.0277)$ \\
Controls & Yes & Yes & Yes & Yes \\
\hline & No & Yes & No & Yes \\
Win dummy & - Panel D. 10\% victory margin bandwidth- & \\
f(Victory margin) & $0.0451^{*}$ & $0.0513^{* *}$ & 0.0048 & -0.0049 \\
Controls & $(0.0243)$ & $(0.0229)$ & $(0.0421)$ & $(0.0416)$ \\
\hline \hline
\end{tabular}

Notes: Different panels illustrate robustness checks on the results reported in Table 8. Growth rates are defined from $T$ to $T+1$. In the columns 1 and 3, regressions include win dummy, Win $_{i T-1}$, and $f$ (Victory margin). Columns 2 and 4 also include additional controls such as year and firm province fixed effects, log size, and age. Panel A repeats the benchmark results but uses uniform kernel weighting for the local linear regression. Panel B employs a local polynomial regression of order 2. Panels C and D report benchmark results with $20 \%$ and $10 \%$ bandwidths.

\section{Politicians' Compensation}

In this section, we speak to the final model implication about the politicians' compensation and rent sharing between a politician and a firm. Thanks to the earnings information from the Social Security data, we can also provide some empirical estimates of the return to worker-politicians, measured by additional wage premium firms pay to their workers-politicians.

In the absence of any controls, we observe a $21 \%$ wage premium for politician-workers, relative to their co-workers in the same firm. Clearly, differences in worker characteristics and the types of jobs that they perform could account for this difference. We address this concern with two types of analysis: within-group and within-individual comparisons. 


\section{Figure 10: Pre-Trends in Employment and Labor Productivity Growth Before Election}

(a) EMPL GROWTH BEFORE ELECTION $(T-1 \rightarrow T)$

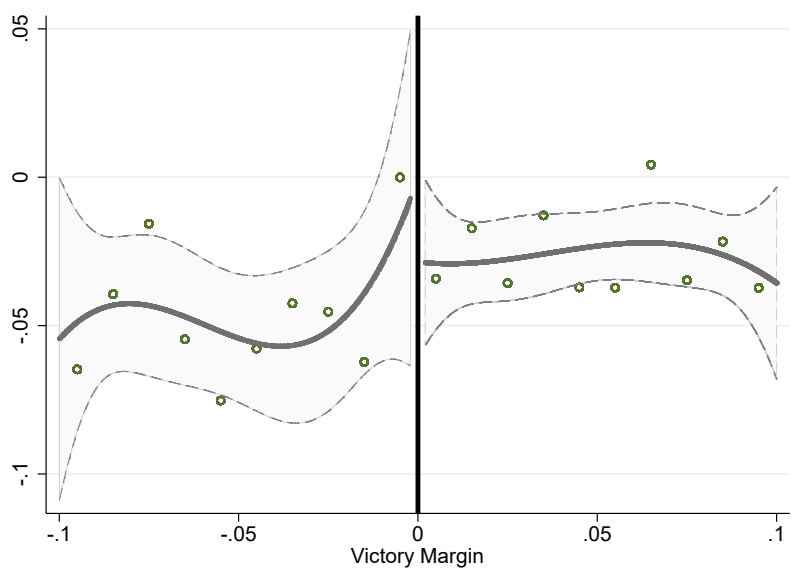

(b) LP GROWTH BEFORE ELECTION $(T-1 \rightarrow T)$

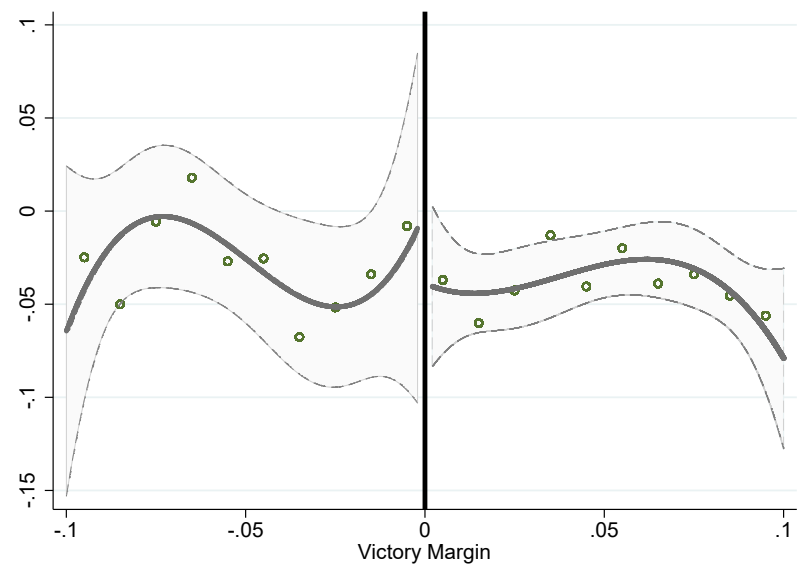

Notes: Figure plots a firm's growth from $T-1$ to $T$ against margin of victory at time $T$. Positive margins of victory denote firms that have been connected at time $T-1$ with a politician from a party that won an election at time $T$ with the corresponding margin of victory. Likewise, negative margins of victory depict firms that are connected with losing politicians. For visibility, we divide the $x$-axis into 0.01 -wide intervals of the margin of victory at time $T$, and each point denotes average outcome of firms in that interval. The solid lines represent predicted third order polynomial fits from the regression that includes third order polynomial in margin of victory, a dummy $W_{i T-1}$, and an interaction of the dummy with the polynomial. The dashed lines represent $90 \%$ confidence intervals. Outcome variable in panel (a) is employment growth, while panel (b) depicts labor productivity growth. Figures are normalized such that outcome variables for marginal losers at the threshold are equal to zero.

Table 10: Balancing Tests

\begin{tabular}{lcccccc}
\hline \hline $\begin{array}{l}\text { Dependent } \\
\text { variable: }\end{array}$ & Log Size & $\begin{array}{c}\text { Log Value } \\
\text { Added }\end{array}$ & $\begin{array}{c}\text { Log } \\
\text { Assets }\end{array}$ & $\begin{array}{c}\text { Log } \\
\text { Intangibles }\end{array}$ & $\begin{array}{c}\text { Log Labor } \\
\text { Productivity }\end{array}$ & Log Profits \\
\hline Win Dummy & 0.0472 & -0.0152 & -0.0344 & -0.0956 & -0.0342 & -0.0672 \\
& $(0.0656)$ & $(0.102)$ & $(0.108)$ & $(0.161)$ & $(0.0358)$ & $(0.124)$ \\
Yes & Yes & Yes & Yes & Yes & Yes \\
f(Victory margin) & Yes & 7666 & 8369 & 8005 & 12855 & 7680 \\
Observations & 12956 & & & & \\
Dependent & Empl growth & LP growth & Age & Center & North & \\
variable: & (last period) & (last period) & & & & \\
Win dummy & 0.0101 & 0.0001 & $-1.105^{* *}$ & -0.0129 & 0.0117 & \\
& $(0.0225)$ & $(0.0392)$ & $(0.556)$ & $(0.0203)$ & $(0.0181)$ & \\
f(Victory margin) & Yes & Yes & Yes & Yes & Yes & \\
Observations & 16063 & 7066 & 17164 & 11355 & 21197 & \\
\hline \hline
\end{tabular}

Notes: Table reports balancing tests for various pre-determined firm-level variables at time $T-1$ (before the election). Different columns report estimates of discontinuity for the before-election firm size, value added, assets, intangible capital, labor productivity, profits, growth in size, growth in productivity, age, and geographic location. For each covariate, we employ a local linear estimation with an optimal bandwidth and triangular kernel (similar to our benchmark RD design from specification 11). Robust standard errors are in parentheses. 
Within-group comparison. First, we compute wage premiums of politicians relative to their coworkers in the same groups, defined by type of job - white-collar or blue-collar, and gender (see Online Appendix Table B.3 for more details). Figure 11 reports these within-group wage premiums for white-collar politicians by political position's hierarchical rank and geographic level. Panel (a) shows that politicians obtain significant wage premiums, starting from $10 \%$ for any-rank politician, going up to $25 \%$ for high-rank female politicians. Panel (b) further shows that while municipalitylevel politicians secure, on average, about a $9 \%$ wage premium over similar co-workers, provincelevel and regional politicians earn premiums that are much higher and go up to a staggering $108 \%$ for white-collar male regional politicians.

Figure 11: Within-Firm Within-Group Wage Premium by Position Rank and Level

(a) By Position Rank (hierarchy) and Gender

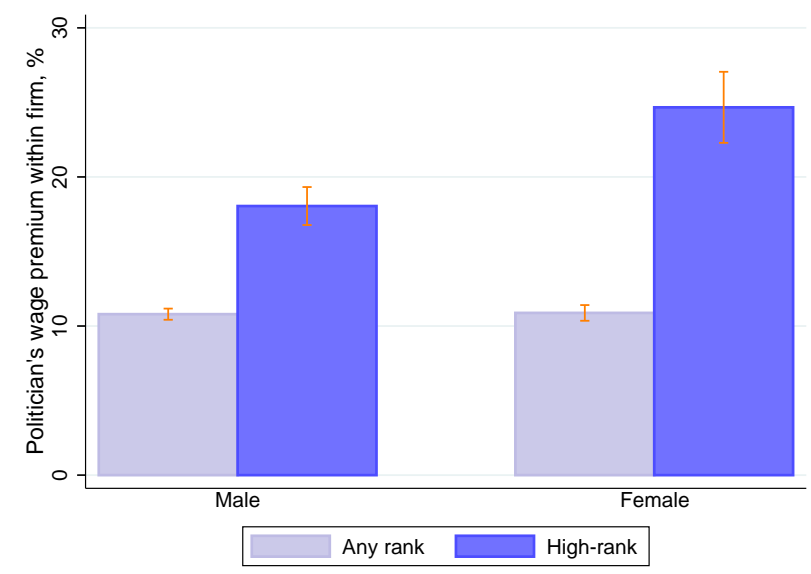

(b) By Position Level (geography) and Gender

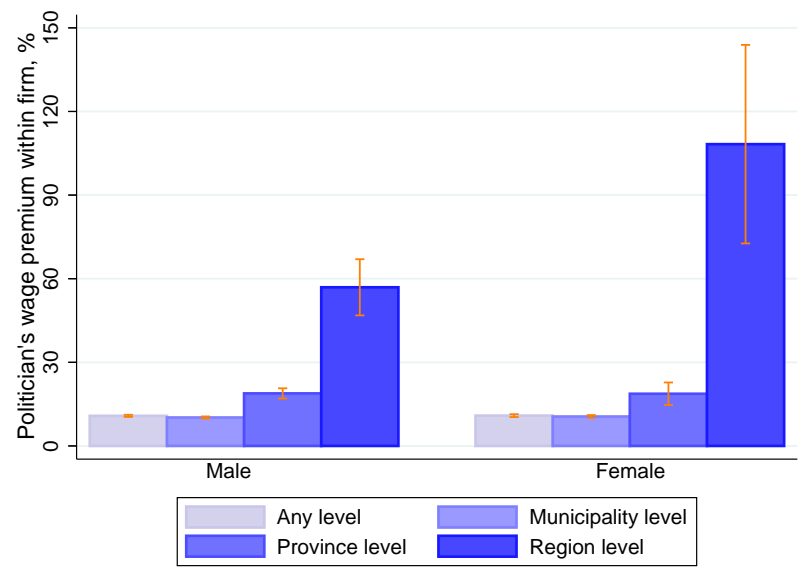

Notes: Wage premium - the percentage difference between politician's weekly wage and other co-workers' average weekly wage of the same job collar and gender in the same firm $\times$ year. Panel (a) reports the wage premium of white-collar politicians of any rank versus high-rank politicians. Panel (b) reports the wage premium of white-collar politicians at any level versus other levels (municipal, provincial, or regional - in the hierarchical order). Appendix Table B.3 also reports wage premiums for blue-collar politicians.

Within-individual comparison. Figure 11 might still reflect differences in other job and worker characteristics between politicians and non-politicians. To mitigate these concerns, in the second analysis, we take an event study approach. We focus on workers who become politicians while working in a firm and we look at the evolution of their wage premiums relative to co-workers in the same firm before and after becoming politicians. Specifically, denote by $t=0$ the year in which an individual becomes a politician for the first time. All years that the individual works in the same firm are indexed relative to that year. We consider a panel of individuals who become politicians while working in a firm and who work in the same firm at least a year before and after the event. We study the evolution of their wage premiums in the 10-year windows before and after the event, as a function of event time. Specifically, we estimate the following specification for the event study (Kleven et al., 2018): 


$$
y_{i s t}=\sum_{j \neq-1} \alpha_{j} I[j=t]+\sum_{k} \beta_{k} I\left[k=a g e_{s t}\right]+\sum_{y} \gamma_{y} I[y=s]+\varepsilon_{i s t},
$$

where $y_{\text {ist }}$ is the wage premium - the percentage difference between politician's weekly wage and other co-workers' average weekly wage - of individual $i$ in year $s$ at event time $t$. Hence, the regression includes time event dummies, full set of year dummies, and individual's age dummies.

Figure 12 plots the $\alpha_{j}$ coefficients on the event time dummies from this regression. ${ }^{38}$ Coefficient on $t=-1$ is normalized to zero. Since, in this exercise, all the fixed worker, firm, and colleague characteristics are conditioned on, a jump in the premium at zero can be attributed to the acquisition of political power by the worker. Not surprisingly, the jump at $t=0$ is gradual, as political appointments usually do not start in the first month of the year. This graph suggests that a worker might become more valuable to his/her firm after $\mathrm{s} /$ he enters politics. This result could also be driven by the fact that workers have a greater outside option after acquiring political power and hence can bargain higher wages. To the contrary, we do not find an evidence of a decline (neither of an increase) in politicians' wage premium after they lose their political seats but continue working in a firm.

Clearly, a change in the wage premium that we calculate is a lower bound for the total financial benefit of holding political office. First, workers that are also employed in a political job could reduce their private-sector working hours or level of effort. In the absence of detailed data on hours or level of effort, we underestimate the true change in wage premium. Second, the official private-sector wage premium should, presumably, be a small part of the total financial benefits. Non-wage benefits, like bribes, access to better financing, or other rent-seeking activities may largely contribute to the wealth accumulation of politicians during their term in office (Fisman et al., 2014). Nevertheless, we find it interesting that the monetary returns for being a politician show up even in the most transparent way - through private sector wages.

Rent sharing. The evidence above indicates that firms value their politician-workers and share the surplus with them. To get a sense of how the surplus is shared, we perform a back of the envelope calculation for the share of additional profits associated with political connections that are accounted by wage premiums paid to politicians. This is suggestive evidence for the amount of (static) rent sharing between a firm and politicians, the evidence of which is the first step in understanding the bargaining process between a firm and the political system.

Notes: Figure 12 depicts within-individual within-firm wage premium evolution before and after becoming a politician. Wage premium is the percentage difference between politician's weekly wage and other co-workers' average weekly wage. Red dots depict event time dummy coefficients from regression (12). Omitted dummy is at $t=-1$. The dashed grey lines denote $95 \%$ confidence intervals. Standard errors are clustered at the individual level. The vertical shaded area corresponds to the time around the event when a worker becomes a politician for the first time while working in a firm. The sample (700,622 observations) includes all the workers who at some point during their career in a firm become politicians and are observed in the firm for at least a year before and after the event. An increase in the wage premium is even higher if we calculate the premium only relative to stable co-workers from the previous period (instead of all co-workers). Figure 13 shows a back of the envelope calculation for the rent division between a firm and politicians. Total rent consists of firm's yearly profit gain from connections (blue area) and an additional income gain for worker-politicians estimated from the event study in 12 (orange area). See the main text for the details of the calculation.

\footnotetext{
${ }^{38}$ The estimated wage premium slightly increases if we look at the premium only relative to stable co-workers from the last year, instead of all co-workers. Hence, a potential change in the composition of co-workers does not play a role.
} 
Figure 12: Within-Firm Wage Premium Before ANd After Becoming a Politician

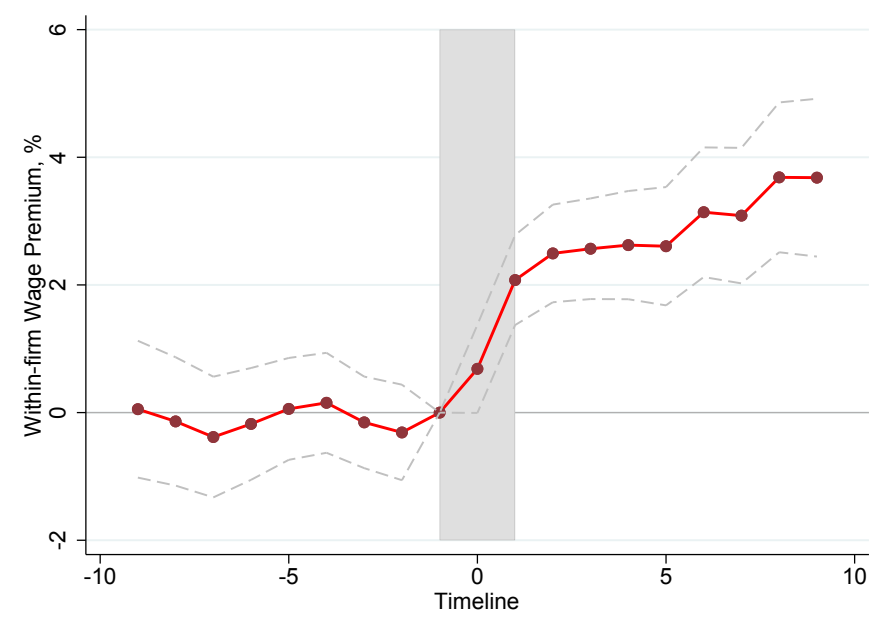

Figure 13: RENT SHARING BETWEeN Firm AND POLITICIANS

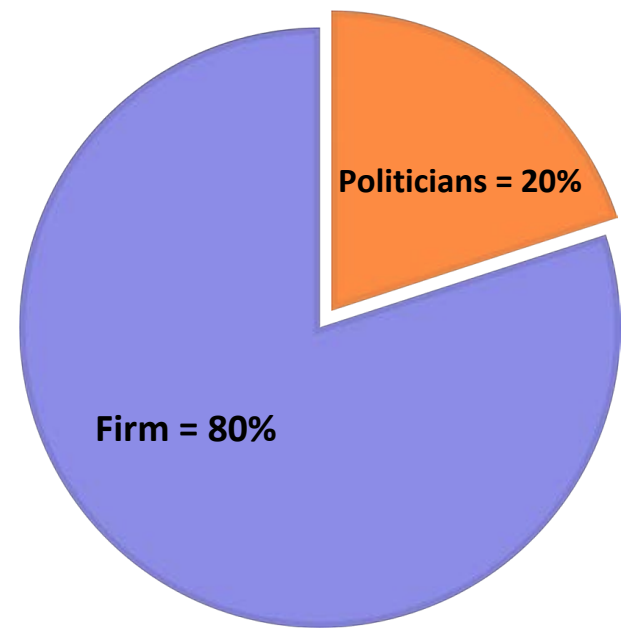

To calculate the nominal wage premium paid to politicians, we use an estimate of a change in wage premium after becoming a politician from equation (12). Since wage contracts adjust gradually, we take the average percentage change in the wage premium for several years after acquiring the connection - roughly 0.035 percentage points. Taking the average weekly pay of (non-politician) co-workers in a firm of 747 Euros, and given that on average firms employ 1.7 politician-workers conditional on being connected, we obtain an estimated yearly income gain of 2,311 Euros for politicians in a firm. To the extent that firms could anticipate the future political career of a worker, estimating the wage gain only from a change in the wage premium is a conservative measure of the rents paid by a firm to the politicians. To estimate gains in profits associated with political connections, we use estimates from the firm-level fixed effect regression of yearly profit growth on connection dummy (Table B.2), which amounts to 2.8 percentage points. Given the average value of profits in the sample, we obtain an estimated 9,037 Euros of static yearly profit gain for a firm. Then our back-of-the-envelope calculation indicates that an additional wage premium paid to politicians can account for $26 \%$ of the gains by the firm. In other words, politicians' gains as a percentage of the total surplus from the interaction of a firm and politicians is $20 \%(=26 \% /(100 \%+26 \%))$. Figure 13 depicts the division. As discussed above, because of anticipation and other potential monetary transfers from a firm not captured by the official private-sector wages, these calculations should be considered as a lower bound for a surplus captured by politicians.

Fact 6. Worker-politicians earn significant wage premiums relative to their co-workers. This premium increases with the political rank of a worker.

\section{Conclusion}

In this paper, we studied the link between political connections and firm dynamics, both theoretically and empirically, with Italy as our example. Our brand-new data, matching multiple administrative datasets together for the first time, enabled us to uncover new findings at the micro and 
macro levels. We showed that hiring/employing a local politician is a common practice, especially among large market leaders. Politician-workers earn significant wage premiums, relative to their coworkers, that are not explained by their individual characteristics. We also showed that politically connected firms grow in employment and revenues, survive longer in the market, but at the same time, have lower productivity growth. This finding is consistent with the view that political connections help firms remove particular market frictions or block competition, as opposed to help them push the productivity and technology frontiers. Our analysis also showed that firms lower their innovation efforts and increase their political connections as they become the market leaders. At the more aggregate level, political connections tend to be associated with worse industry dynamics lower entry, reallocation, growth, and productivity. This indicates that the effects of firm-level political connections go beyond the micro-level effects on connected firms, and may imply significant social costs.

A growing body of literature has argued that factor reallocation from low-productivity incumbents to high-productivity entrants is an important source of economic growth. Our results suggest that political connections might be an important impediment to such factor reallocation and productivity growth. While these connections might alleviate certain market frictions, such as regulatory barriers or bureaucratic burden, dynamically - by giving incumbents a powerful advantage over entrants - their detrimental impact on market competition and creative destruction might reverse the static benefits. Our results could also shed some light on the declining business dynamism in the U.S. and in Europe, where market concentration has increased and lobby spending has grown to record levels (Zingales, 2012; Decker et al., 2016; Loecker and Eeckhout, 2018). Future work should incorporate these opposing effects that have been highlighted in our model and assess their quantitative importance for aggregate growth and welfare in different countries.

\section{References}

Abrams, David, Ufuk Akcigit, and Jillian Popadak, "Patent Value and Citations: Creative Destruction or Strategic Disruption?," Working Paper 19647, National Bureau of Economic Research 2013.

Acemoglu, Daron, “Directed technical change," The Review of Economic Studies, 2002, 69 (4), 781-809.

— , Tarek A Hassan, and Ahmed Tahoun, "The Power of the Street: Evidence from Egypt's Arab Spring," Review of Financial Studies, 2017, 31 (1), 1-42.

— , Ufuk Akcigit, Harun Alp, Nicholas Bloom, and William Kerr, "Innovation, reallocation, and growth," American Economic Review, 2018, 108 (11), 3450-91.

Aghion, Philippe and Peter Howitt, “A Model of Growth through Creative Destruction," Econometrica, 1992,60 (2), 323-351.

— , Antonin Bergeaud, Timo Boppart, Peter J. Klenow, and Huiyu Li, "A Theory of Falling Growth and Rising Rents," 2019. mimeo.

— , Ufuk Akcigit, and Peter Howitt, "What do we learn from Schumpeterian growth theory?," in "Handbook of economic growth," Vol. 2, Elsevier, 2014, pp. 515-563.

Akcigit, Ufuk and Sina T. Ates, "Ten Facts on Declining Business Dynamism and Lessons from Endogenous Growth Theory," American Economic Journal: Macroeconomics, 2019. forthcoming.

_ and _ , "What Happened to U.S. Business Dynamism?," 2019. National Bureau of Economic Research Working Paper 25756.

_ and William R Kerr, "Growth through Heterogeneous Innovations," Journal of Political Economy, 2018, 126 (4), 13741443. 
Akey, Pat, "Valuing Changes in Political Networks: Evidence from Campaign Contributions to Close Congressional Elections," The Review of Financial Studies, 06 2015, 28 (11), 3188-3223.

Andrews, Dan, Chiara Criscuolo, and Peter N. Gal, “The Best versus the Rest: The Global Productivity Slowdown, Divergence across Firms and the Role of Public Policy," 2019. Center for Economic Performance Working Paper 1645.

Arayavechkit, Tanida, Felipe E. Saffie, and Minchul Shin, "Too Big to Pay: Tax Benefits and Corporate Lobbying," Working Paper, 2017.

Argente, David, Salome Baslandze, Douglas Hanley, and Sara Moreira, "Patents to Products: Product Innovation and Firm Dynamics," Working Paper 2020.

Backman, Michael, Asian Eclipse: Exposing the Dark Side of Business in Asia, Wiley, 2001.

Bartelsman, Eric J and Mark Doms, “Understanding Productivity: Lessons from Longitudinal Microdata," Journal of Economic Literature, 2000, pp. 569-594.

Baumol, William J., "Entrepreneurship: Productive, Unproductive, and Destructive," Journal of Political Economy, 1990, 98 (5, Part 1), 893-921.

Bugamelli, Matteo and Francesca Lotti, "Productivity Growth in Italy: a Tale of a Slow-motion Change," 2018. Bank of Italy, Occasional Papers n. 422.

Cattaneo, Matias D., Nicolas Idrobo, and Rocio Titiunik, "Monograph: A Practical Introduction to Regression Discontinuity Designs: Volume I," Cambridge Elements: Quantitative and Computational Methods for Social Science, Cambridge University Press, 2018.

Cingano, Federico and Paolo Pinotti, "Politicians at Work: The Private Returns and Social Costs of Political Connections," Journal of the European Economic Association, 2013, 11 (2), 433-465.

Comin, Diego and Bart Hobijn, "Lobbies and Technology Diffusion," The Review of Economics and Statistics, May 2009,91 (2), 229-244.

Comino, Stefano, Alberto Galasso, and Clara Graziano, “The Diffusion of New Institutions: Evidence from Renaissance Venice's Patent System," Working Paper 24118, National Bureau of Economic Research December 2017.

Cooper, Russell, John Haltiwanger, and Jonathan Willis, “Declining Dynamism at the Establishment Level: Sources and Productivity Implications," 2019. University of Maryland Working Paper.

Cull, Robert and Lixin Colin Xu, "Institutions, Ownership, and Finance: the Determinants of Profit Reinvestment among Chinese Firms," Journal of Financial Economics, 2005, 77 (1), 117-146.

Davis, Steven, John Haltiwanger, and Scott Schuh, Job Creation and Destruction, 1 ed., Vol. 1, The MIT Press, 1998.

Decker, Ryan A., John Haltiwanger, Ron S. Jarmin, and Javier Miranda, "Declining Business Dynamism: What We Know and the Way Forward," American Economic Review, May 2016, 106 (5), 203-07.

Dinc, I Serdar, "Politicians and Banks: Political Influences on Government-owned Banks in Emerging Markets," Journal of Financial Economics, 2005, 77 (2), 453-479.

Duca, Louis F. Del and Patrick Del Duca, "An Italian Federalism?: The State, Its Institutions and National Culture as Rule of Law Guarantor," The American Journal of Comparative Law, 2006, 54 (4), 799-841.

Faccio, Mara and David Parsley, "Sudden Deaths: Taking Stock of Political Connections," January 2006. CEPR Discussion Papers \#5460.

Fan, Joseph PH, Tak Jun Wong, and Tianyu Zhang, "Politically Connected CEOs, Corporate Governance, and Post-IPO Performance of China's Newly Partially Privatized Firms," Journal of Financial Economics, 2007, 84 (2), $330-357$.

Fang, Lily, Josh Lerner, Chaopeng Wu, and Qi Zhang, “Corruption, Government Subsidies, and Innovation: Evidence from China," Working paper, 2018.

Fisman, Raymond, "Estimating the Value of Political Connections," American Economic Review, 2001,91 (4), $1095-1102$.

— , Florian Schulz, and Vikrant Vig, "The Private Returns to Public Office," Journal of Political Economy, 2014,122 (4), 806-862.

Foster, Lucia, John C Haltiwanger, and Cornell John Krizan, “Aggregate Productivity Growth: Lessons from Microeconomic Evidence," in "New Developments in Productivity Analysis," University of Chicago Press, 2001, pp. 303-372.

_ , John Haltiwanger, and Cornell J Krizan, "Market Selection, Reallocation, and Restructuring in the US Retail Trade Sector in the 1990s," Review of Economics and Statistics, 2006, 88 (4), 748-758.

Garcia-Santana, Manuel, Josep Pijoan-Mas, Enrique Moral-Benito, and Roberto Ramos, “Growing like Spain: 19952007," Working Papers 1609, Banco de Espana, Working Papers May 2016.

Garicano, Luis, Claire Lelarge, and John Van Reenen, “Firm Size Distortions and the Productivity Distribution: Evidence from France," American Economic Review, November 2016, 106 (11), 3439-79. 
Goldman, Eitan, Jörg Rocholl, and Jongil So, "Politically Connected Boards of Directors and The Allocation of Procurement Contracts," Review of Finance, 2013, 17 (5), 1617-1648.

Gratton, Gabriele, Luigi Guiso, Claudio Michelacci, and Massimo Morelli, "From Weber to Kafka: Political Instability and the Rise of an Inefficient Bureaucracy," Working Papers 611, IGIER (Innocenzo Gasparini Institute for Economic Research), Bocconi University 2017.

Grossman, Gene and Elhanan Helpman, "Quality Ladders in the Theory of Growth," Review of Economic Studies, 1991, $58(1), 43-61$.

Gutiérrez, Germán and Thomas Philippon, “Investment-less Growth: An Empirical Investigation," $2016 . \quad$ National Bureau of Economic Research Working Paper 22897.

_ and _ , "Declining Competition and Investment in the U.S.," 2017. National Bureau of Economic Research Working Paper 23583.

_ and _ , "How EU Markets Became More Competitive Than US Markets: A Study of Institutional Drift," 2019. NYU Working Paper.

Hall, Bronwyn, Adam Jaffe, and Manuel Trajtenberg, “The NBER Patent Citations Data File: Lessons, Insights and Methodological Tools," Working Paper 8498, National Bureau of Economic Research 2001.

Haltiwanger, John, Ron S. Jarmin, and Javier Miranda, “Who Creates Jobs? Small versus Large versus Young," The Review of Economics and Statistics, 2013, 95 (2), 347-361.

Hsieh, Chang-Tai and Peter J Klenow, "Misallocation and Manufacturing TFP in China and India," The Quarterly Journal of Economics, 2009, 124 (4), 1403-1448.

Imbens, Guido and Karthik Kalyanaraman, "Optimal Bandwidth Choice for the Regression Discontinuity Estimator," Review of Economic Studies, 2012, 79 (3), 933-959.

— and Thomas Lemieux, "Regression Discontinuity Designs: A Guide to Practice," Journal of Econometrics, 2008, 142 (2), 615-635.

Joh, Sung Wook and Ming Ming Chiu, “Loans to Distressed Firms: Political Connections, Related Lending, Business Group Affiliation and Bank Governance," in "Econometric Society 2004 Far Eastern Meetings" number 790 Econometric Society 2004

Johnson, Simon and Todd Mitton, "Cronyism and Capital Controls: Evidence from Malaysia," Journal of Financial Economics, 2003, 67 (2), 351-382.

Jones, Charles I, “R \& D-based models of economic growth," Journal of political Economy, 1995, 103 (4), $759-784$.

_ and Jihee Kim, “A Schumpeterian model of top income inequality,” Journal of Political Economy, 2018, 126 (5), 17851826.

Kaufmann, Daniel and Shang-Jin Wei, “Does" Grease Money" Speed Up the Wheels of Commerce?," 1999. National Bureau of Economic Research \#7093.

Khwaja, Asim Ijaz and Atif Mian, "Do Lenders Favor Politically Connected Firms? Rent Provision in an Emerging Financial Market," Quarterly Journal of Economics, 2005, 120 (4), 1371-1411.

Klette, Tor Jakob and Samuel Kortum, "Innovating Firms and Aggregate Innovation," Journal of Political Economy, 2004, 112 (5), 986-1018.

Kleven, Henrik, Camille Landais, and Jakob Egholt Sogaard, “Children and Gender Inequality: Evidence from Denmark," Working Paper 24219, National Bureau of Economic Research January 2018.

Kogan, Leonid, Dimitris Papanikolaou, Amit Seru, and Noah Stoffman, "Technological Innovation, Resource Allocation, and Growth," Working Paper 17769, National Bureau of Economic Research 2012.

Kroszner, Randall S. and Thomas Stratmann, "Interest-group Competition and the Organization of Congress: Theory and Evidence from Financial Services' Political Action Committees," American Economic Review, 1998, pp. 1163-1187.

Krusell, Per and Jose-Victor Rios-Rull, "Vested Interests in a Positive Theory of Stagnation and Growth," Review of Economic Studies, 1996, 63 (2), 301-329.

Lanjouw, Jean O. and Mark Schankerman, "Patent Quality and Research Productivity: Measuring Innovation with Multiple Indicators," Economic Journal, 2004, 114 (495), 441-465.

Lee, David S, "Randomized Experiments from Non-random Selection in U.S. House Elections," Journal of Econometrics, 2008, 142 (2), 675-697.

Lentz, Rasmus and Dale Mortensen, “An Empirical Model of Growth through Product Innovation," Econometrica, 2008, 76 (6), 1317-1373. 
Lerner, Josh, “The Importance of Patent Scope: An Empirical Analysis," RAND Journal of Economics, 1994, 25 (2), $319-333$.

Leuz, Christian and Felix Oberholzer-Gee, "Political Relationships, Global Financing, and Corporate Transparency: Evidence from Indonesia," Journal of Financial Economics, 2006, 81 (2), 411-439.

Loecker, Jan De and Jan Eeckhout, “Global Market Power,” NBER Working Papers 24768, National Bureau of Economic Research, Inc June 2018.

Lotti, Francesca and Giovanni Marin, "Matching of PATSTAT applications to AIDA firms: discussion of the methodology and results," Questioni di Economia e Finanza (Occasional Papers) 166, Bank of Italy, Economic Research and International Relations Area June 2013.

Lucas, Robert and Benjamin Moll, "Knowledge growth and the allocation of time," Journal of Political Economy, 2014,122 (1), 1-51.

Mattozzi, Andrea and Antonio Merlo, “Political Careers or Career Politicians?,” Journal of Public Economics, April 2008, 92 (3-4), 597-608.

Moser, Petra, Joerg Ohmstedt, and Paul Rhode, "Patent Citations and the Size of the Inventive Step - Evidence from Hybrid Corn," Working Paper 21443, NBER July 2015.

Mukoyama, Toshihiko and Latchezar Popov, "The Political Economy of Entry Barriers," Review of Economic Dynamics, 2014, 17 (3), 383-416.

Murphy, Kevin M., Andrei Shleifer, and Robert W. Vishny, "The Allocation of Talent: Implications for Growth," Quarterly Journal of Economics, 1991, 106 (2), 503-530.

Pakes, Ariel, "Patents as Options: Some Estimates of the Value of Holding European Patent Stocks," Econometrica, 1986, 54 (4), 755-784.

_ and Mark Schankerman, "Estimates of the Value of Patent Rights in European Countries During the Post-1950 Period," Economic Journal, 1986, 96 (384), 1052-1076.

Pellegrino, Bruno and Luigi Zingales, “Diagnosing the Italian Disease," Unpublished manuscript, September, $2014,14$.

Perla, Jesse and Christopher Tonetti, "Equilibrium imitation and growth," Journal of Political Economy, 2014,122 (1), 52-76.

Restuccia, Diego and Richard Rogerson, "Policy Distortions and Aggregate Productivity with Heterogeneous Establishments," Review of Economic Dynamics, 2008, 11 (4), 707 - 720.

Romer, Paul M, “Endogenous technological change," Journal of political Economy, 1990, 98 (5, Part 2), S71-S102.

Schoenherr, David, "Political Connections and Allocative Distortions," 2015. Institute of Global Finance Working Paper No. 5.

Shleifer, Andrei and Robert W Vishny, "Politicians and Firms," Quarterly Journal of Economics, 1994, 109 (4), $995-1025$.

_ and _ , The Grabbing Hand: Government Pathologies and Their Cures, Harvard University Press, 2002.

Soto, Hernando De, The Other Path, Harper \& Row New York, 1989.

Syverson, Chad, "Macroeconomics and Market Power: Facts, Potential Explanations, and Open Questions," Brookings Institution Report, January 2019. Accessed January 21, 2019. https://www.brookings.edu/research/macroeconomicsand-market-power-facts-potential-explanations-and-open-questions/.

Thoma, Grid, Salvatore Torrisi, Alfonso Gambardella, Dominique Guellec, Bronwyn H Hall, and Dietmar Harhoff, "Harmonizing and Combining Large Datasets - An Application to Firm-Level Patent and Accounting Data," Working Paper 15851, National Bureau of Economic Research March 2010.

Trajtenberg, Manuel, “A Penny for Your Quotes: Patent Citations and the Value of Innovations," RAND Journal of Economics, 1990, 21 (1), 172-187.

Vannucci, Alberto, "The Controversial Legacy of "Mani Pulite": A Critical Analysis of Italian Corruption and AntiCorruption Policies," Bulletin of Italian Politics, 2009, 1 (2), 233-264.

Zingales, L., A Capitalism for the People: Recapturing the Lost Genius of American Prosperity, Basic Books, 2012. 


\section{Online Appendix}

\section{Ufuk Akcigit, Salome Baslandze, Francesca Lotti}

April 11, 2020

\section{A Model Extension: Endogenizing Politician's Compensation}

Our benchmark model in the main text has focused on the static gains and dynamic losses. To keep these aspects tractable, we kept the determination of the politician's compensation exogenous. However, it is fairly straightforward to incorporate a Nash bargaining framework that would provide some additional insights. To this end, let us assume that politicians have different political powers $\phi \in(0,1)$, in line with their hierarchies. A politician with a political power $\phi$ is able to remove red tape by the same fraction $\phi$, thus the firm has to pay $(1+(1-\phi) \tau) w l$ for hiring $l$ workers (our benchmark model corresponds to $\phi=1$ ). This implies that a firm with a politician with power $\phi$ earns the following gross profit:

$$
\frac{\pi q}{1+(1-\phi) \tau}
$$

Denote the bargaining power of the politician by $\gamma$ and assume his/her outside value is simply $\eta(\phi)$, where $\eta^{\prime}(\phi)>0$. For simplicity, we also assume that the firm's outside option is to operate without a politician, hence it is $V_{-1}(q)$. Once the firm and the politician decide to match together, they stay together until the firm is replaced by another firm. It is convenient to formulate the problem in terms of the lump-sum compensation of the politician, which we denote by $\bar{w} \bar{w}^{p}$. We denote the dynamic value of being connected to a $\phi$-power politician (including politician's compensation) by $V_{1}^{\phi}$ and of not being connected by $V_{-1}$. Then the Nash bargaining problem is simply

$$
\begin{aligned}
\bar{w}^{p}(\phi) & \equiv \arg \max _{\bar{w}^{p}(\phi)}\left[V_{1}^{\phi}(q)-V_{-1}(q)-\bar{w}^{p}(\phi)\right]^{1-\gamma}\left[\bar{w}^{p}(\phi)-\eta(\phi)\right]^{\gamma} \\
& =\gamma \pi q\left(\frac{1}{[1+(1-\phi) \tau][r+\tilde{p}(\phi)]}-\frac{1}{[1+\tau][r+p]}\right)+(1-\gamma) \eta(\phi),
\end{aligned}
$$

where $\tilde{p}(\phi)$ is creative destruction rate faced by a firm connected with $\phi$-power politician, while $p$ is creative destruction rate faced by a non-connected firm. Note that by connecting to a politician with $\phi$, the incumbent manages to generate a cost advantage equal to $\phi \tau$. Hence, the quality threshold for the creative destruction to take place becomes $\lambda^{*}(\phi)=\phi \tau$.

This time, the rate at which a connected incumbent gets replaced is

$$
\tilde{p}(\phi)=p[\alpha+(1-\alpha) \operatorname{Pr}(\lambda>\phi \tau)]
$$

which implies $\tilde{p}^{\prime}(\phi)<0$. This implies that a firm that is connected to a more powerful politician is more likely to survive.

Next, we interpret the compensation of the politician as a function of its political power. The compensation $\bar{w}^{p}(\phi)$ increases in $\phi$ through three channels evident from equation (13): first, a more powerful (large $\phi)$ politician brings higher static profits due to lower wedges $((1-\phi) \tau)$ that the 
firm is required to pay. Second, a more powerful politician leads to lower replacement rate of the incumbent $(\tilde{p}(\phi))$. Finally, a more powerful politician has a better outside option, which allows him/her to extract a bigger fraction of the joint surplus. We conclude this section with the following implication. Politician's compensation $\bar{w}^{p}(\phi)$ increases in his/her political power $\phi$.

\section{B Data Construction}

This section provides more details on the steps undertaken during the data and variables construction.

\section{B.1 Dataset \#1: Social Security Data (INPS)}

The Italian SS data contains rich information on the universe of private-sector firms and their workers making social security contributions at INPS. At the individual level, we calculate an individual weekly wage - weekly gross labor income (including bonuses and overtime) as total yearly labor income, divided by number of weeks worked. We classify a worker as a white-collar if s/he is a manager, executive, professional, or an office worker (qualifica1 variable from UniEMENS equal to $2,3,7,9$, or P).

At the firm level, we describe a construction of three variables from INPS - employment, average weekly pay, and age. To construct yearly employment at the firm level ${ }^{39}$ - a variable firm Size we count the number of workers present in a firm in March. ${ }^{40}$ Some observations may be zeros, especially when firm is just starting or before it exits the business. We define employment growth at time $t$ as employment growth to the next period:

$$
g L_{i t}=2 \frac{L_{i t+1}-L_{i t}}{L_{i t+1}+L_{i t}}
$$

where $g L_{i t}$ stands for growth rate and $L_{i t}$ for employment. This measure follows Davis et al. (1998) and is bounded between -2 and 2 and reduces impact of outliers - which is especially important at the entry and exit of a firm.

At the firm level, Average weekly pay refers to the average weekly pay (in thousands of 2014 Euros) of workers who are present in March. A firm's Age is calculated from the first year when it gives a formal notice of operations to the INPS office intending to have an employee on the payroll.

\section{B.2 Dataset \#2: Firm Financials Data (Cerved)}

We use the following main company accounts variables from Cerved: a firm's total assets, intangible assets, value added, and profits. In addition, we compute labor productivity, $L P$, and total factor productivity, TFP.

\footnotetext{
${ }^{39}$ Note that firm-level employment variable in Cerved data is of very poor quality, so INPS data is crucial to construct a complete firm-level dataset.

${ }^{40}$ This is consistent with data construction by (Haltiwanger et al., 2013) using the U.S. Census data. Alternatively, one can look at average monthly employment in a year, but the measures are very similar.
} 
$V A$ is the yearly value added of a firm - revenue less the cost of intermediates. We replace with missing any negative value added (valore_aggiunto_operativo). Profits is value added less operating expenses, depreciation, and financial costs. Assets (attivo) is the total assets of a firm. Intangibles is intangible fixed assets. For tangible assets (immob_mat) and intangible fixed assets (immob_immat), we replace missings with zeros when possible. In most cases, Cerved data does not distinguish between missing values and zeros: observations whose value is less than 1 (in 1000) and observations that are truly missing in the report will both appear as missing. This is the case with tangible and intangible fixed assets variables. We impute with 0.5 (in 1000) the value of intangible assets if value of tangible assets is not missing, and vice versa for tangible assets. We verify these imputations with another simple imputation of missing values in the panel of firms - by simply imputing the missing value with latest non-missing observation. If such an imputation is too far off from the initial imputation of 0.5 , we revert back to the missing value.

$L P$ - labor productivity - is defined as value added per employee. We calculate a firm's total factor productivity, TFP, using a standard Cobb-Douglas specification: $Y=z K^{\alpha} L^{1-\alpha}$. Output $(Y)$ is measured as value added, capital $(K)$ is measured as total assets, labor $(L)$ is employment, and labor share $(1-\alpha)$ is the average industry-level labor share from the data. This gives us $z-$ our TFP measure.

Corresponding growth rates of the above variables at time $t$ are calculated as a growth from $t$ to $t+1$. All nominal variables are deflated with GDP deflator (2014 is the base year). In the analysis, we winsorize all these variables at top and bottom 1 percent.

\section{B.3 Dataset \#3: Patent Data (PATSTAT)}

We use EPO PATSTAT to obtain information on patenting activities of Italian firms. This section describes the matching procedure of EPO PATSTAT to our firm-level data, as well as the construction of our patent-based innovation measures.

First, we identify the sample of EPO patents applied for by Italian firms. Focusing on the period of 1990-2014, we identify 84,085 EPO patent applications filed by Italian companies. Some of those applications represent variants of the same patent and belong to the same patent family. Applicants may seek for protection for their inventions in multiple national offices, resulting in multiple applications that effectively represent the same invention. Hence, the relevant count is a count of unique patent families: we have 71,240 EPO patent families. In what follows, when it does not incur ambiguity, we will refer to patent families as just patents.

Second, we need to match patent records with our firm-level datasets. Unfortunately, patent data does not provide firm fiscal codes, which we could use to directly match PATSTAT records to Cerved data. Hence, we turn to company name cleaning routines to help to standardize company names in PATSTAT, and then match those names to fiscal codes. We proceed in the following three steps. We start by using an extensive patent-firm fiscal code match conducted by Unioncamere-Dintec. The name cleaning by Unioncamere is very precise, as it combines standard name cleaning routines with extensive manual checks to maximize patent matches for the period of 2000-2016. We extend the Unioncamere matches backwards by applying the Unioncamere "dictionary" from 2000-2016 to the period 1990-1999. Combined, this procedure results in up to $90 \%$ of patent matches. We further 
increase the matching rate (especially for the 90's) by using name cleaning routines from Lotti and Marin (2013) and the matched sample of patents from Thoma et al. (2010). Final matches result in a 93\% matching rate of all EPO patents for the period of 1990-2014. We identify 13,904 unique companies who file for patents. To the best of our knowledge, this is by far the most comprehensive match of Italian patent records to Italian firms spanning the longest time period.

Third, for all patents, we extract information on their technology classification (IPC - international patent classification), application date, grant status, number of claims, and backward and forward citations. We take the application date of a patent to be the earliest application date of all patents in the same patent family.

This data allows us to construct various measures of a firm's patenting activity considering different measures of patent qualities.

1. Clearly, whether a patent is granted or not is one type of patent quality measure. Hence, for each year, we construct a simple count of all patents and of all granted patents of a firm in a year.

2. The number of claims is another quality measure often used in the literature to proxy for patent breadth (Lerner, 1994; Lanjouw and Schankerman, 2004); for each year, we construct claims-weighted patent counts of a firm.

3. We also consider patent family size as another proxy for patent quality, as it indicates the extent of the geographical protection that and applicant is seeking. Hence, another measure of firm's inventive activity in a year is family-size-weighted patent counts in a year.

4. The number of citations a patent receives has traditionally been used as a measure of the economic and technological significance of a patent (see Pakes, 1986; Pakes and Schankerman, 1986; Trajtenberg, 1990; Hall et al., 2001; Kogan et al., 2012; Abrams et al., 2013; Moser et al., 2015). Our main measure of a firm's inventive activity is citations-weighted patent counts. We consider different variations when constructing this measure. First, citations received clearly suffer from a truncation problem - the fact that later patents have less time to get cited. To reduce this problem, we also consider a 5-year citations measure - the number of citations received by patent within 5 years from its application date. Second, our data allows us to see whether citations reported in a patent application originate from the applicant, were introduced during the prior art search at the time of application, or were introduced by an examiner. In the data, about one third of all citations made originate from the applicants themselves. Since this may be a closer proxy for the impact of a patent, we also consider a citations measure that just counts citations made by applicants. In all these cases, we construct family-to-family citations and we also count citations originating not only from the Italian, but all EPO patents.

Online Appendix Table 1 presents the correlation matrix for different quality measures defined at the patent level. Though all measures are positively correlated, in many cases, the correlation is not very strong, indicating that these measures entail information on different aspects of patent quality. We show summary statistics of those measures in Online Appendix Table A.2. 
Appendix Table A.1: Cross-correlations of Various Patent Quality Measures

\begin{tabular}{lcccccc}
\hline \hline \multicolumn{1}{c}{ Variables } & Grant & Fam. size & Claims & Cits & 5-yr cits & Cits, applicant \\
\hline Grant & 1.000 & & & & & \\
Family size & 0.410 & 1.000 & & & & \\
Claims & 0.313 & 0.106 & 1.000 & & & \\
Citations & 0.207 & 0.362 & 0.163 & 1.000 & & \\
5-yr citations & 0.151 & 0.293 & 0.154 & 0.750 & 1.000 & \\
Cits, applicant & 0.144 & 0.305 & 0.121 & 0.878 & 0.593 & 1.000 \\
5-yr cits, applicant & 0.097 & 0.251 & 0.122 & 0.592 & 0.813 & 0.637 \\
\hline \hline
\end{tabular}

Notes: Table presents a correlation matrix of different measures of patent qualities. Grant- dummy for whether patent has been granted; Family size - number of different patent applications within one patent family ID; Claims - number of patent claims; Citations - number of citations received; 5-yr citations - number of citations received within 5 years from the application date; Cits, applicant - number of citations received, excluding non-applicant citations (made by examiners or else); 5-yr cits, applicant - number of applicant-citations received within 5 years from application date.

Appendix Table A.2: Statistics on Patent Quality for Italian Patents (1990-2014)

\begin{tabular}{lc}
\hline Variable & Average \\
\hline Patent family size & 5.43 \\
Grant dummy & 0.54 \\
Number of claims & 10.43 \\
Citations received & 4.94 \\
Citations received in 5 yrs & 2.00 \\
Applicant citations & 1.71 \\
Applicant citations in 5 yrs & 0.63 \\
\hline
\end{tabular}

Notes: Table provides summary statistics for the universe of EPO patents applied by Italian firms in the 1990-2014 time period. Observation is a patent family - one or more patent applications that are the variants of the same patent. Sample contains 66,176 patent families.

\section{B.3.1 Dataset \#4: Registry of Local Politicians (RLP)}

The following are the steps undertaken to clean and make use of RLP data.

Step 1. First, to link individual politicians to SS data on private-sector employees, we need to assign fiscal codes (similar to social security numbers in the U.S.) to politicians. In Italy, the assignment of a fiscal code follows a specific rule that deterministically assigns a fiscal code using an individual's demographic information - name, surname, date of birth, place of birth, and gender. We develop an algorithm following this rule, and use a detailed demographic information from RLP to assign fiscal codes to each politician. 
Step 2. We determine which parties are the majority or minority based on political affiliations of politicians in RLP. The data provides either the party or coalition to which a politician is affiliated. For example, a typical example of an observation would be an entry "A | B" meaning that politician belongs to a list/coalition consisting of two parties A and B, which together participate in an election in that area. To define majorities, we first clean individual party names and then define major parties at local level.

- Cleaning party names:

Cleaning political party/coalition names in the data turned out to be a tedious task. The first challenge is misspellings and abbreviations of party names. The second is that political parties sometimes change their names, merge, split, form coalitions, etc. We tackle these issues by developing a name cleaning algorithm, based on information from extensive online searches and manual checks.

More specifically, in the example above with the "A | B" entry, we parse this entry into two separate party names, "A" and "B", clean each of those names separately, and then combine those names again. To clean names, we first compile a list of full names and abbreviations of parties/coalitions at all levels - municipality, province, regional or national - from Wikipedia articles. This represents a basic dictionary that helps to spot multiple forms of the same party/coalition name in the data. Next, we develop a name cleaning algorithm, where we standardize commonly used words and special characters, correct for word misspellings and shortcuts. Using this name standardization and dictionary-based approach gets us a long way in cleaning the data. Furthermore, we iteratively improve the algorithm by manually verifying and updating special cases.

- Defining majority parties/coalitions in RLP: Next, we define parties/coalitions that represent majorities at the regional/provincial/municipal level in a given year. We start by defining two variants of majority party variable at the location-year level. The first definition uses the political affiliation of a president/mayor. Second definition uses most frequent political affiliation of all politicians found in RLP. ${ }^{41}$

Specifically, we define following variables at $j$-location and $t$-year level:

Main party $(R L P)_{j t}$ - party (coalition) of a regional president/provincial president/mayor in year $t$ in a $j$ region/province/municipality, respectively. ${ }^{42}$

\#1 Party $(R L P)_{j t}$ - most frequent party (coalition) affiliation of politicians in a region/province/ municipality.

Since the winning candidate is generally also assured the majority of seats, the first and second definitions should be equivalent. However, there is one main reason for why, in many

\footnotetext{
${ }^{41}$ For the benchmark definition, we prefer defining majority using sample of councilmen only. In effect, president's/mayor's elections determine party composition in the councils. Hence, to determine a majority - party that has the largest representation, one needs to look at party affiliations of council members. Indeed, councilmen represent majority of politicians in RLP and about $15 \%$ of politicians in RLP are not elected.

${ }^{42}$ If affiliation is missing (in less than $3 \%$ of cases), we use an affiliation of council president. If those are still missing, we use affiliation of a vice-president/vice-mayor or a council vice-president.
} 
cases, those definitions provide different information in RLP. Consider this example: suppose, a winning candidate belongs to a party "B" and is supported by a coalition consisting of parties "A", "B", and "C". In such a case, RLP could report the candidate's party affiliation as either "A | B | C", "B", or "Z", where "Z" is some name of a coalition. ${ }^{43}$ Often, the third variant appears. Similarly, other politicians may have an affiliation reported in one of those ways (often, the second variant appears for an ordinary council member). Hence, we combine information from both variables - an affiliation reported by a president/mayor (Main party $\left.(R L P)_{j t}\right)$ and most frequent affiliation reported by all politicians (\#1 Party $(R L P)_{j t}$ ) to define the majority party/coalition in the most accurate fashion. Importantly, we will complement these definitions with further information from the Elections data, which we discuss below.

Using this data on majority parties, we can define whether individual belongs to the majority or the minority. We postpone further discussion after we describe the Elections data below.

Step 3. We define the following variables using political position attributes in RLP.

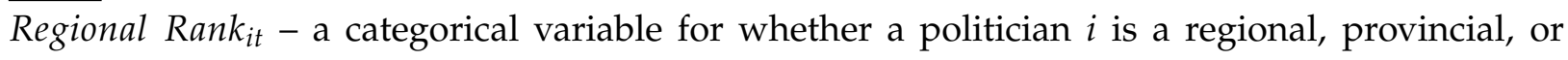
municipal politician at time $t$. In a few cases, when a politician has multiple observations in RLP at different position levels within a year, we keep the observation with the highest position level held in that year.

Hierarchical $\operatorname{Rank}_{i t}$ - a categorical variable for the position level (within a Regional Rank $k_{i t}$ ) of a politician $i$ at time $t$. In the first category, we group together the key positions of a municipality's mayor or vice mayor; provincial/regional president or a vice/president; as well as the important positions of president/vice-president of the local councils. The second category includes so called "assessore" that represent town councilors - executive position holders similar to local ministers. The third category is for regular council members. ${ }^{44}$

\section{B.3.2 Dataset \#5: Elections Data}

Our newly constructed, detailed dataset on local elections at the regional, provincial, and municipal levels serves two purposes. First, using information on vote shares in the election, we identify marginally contested elections. The details are described were Section 6.1. Second, we use this data to construct another variable on majority parties at the local level, and combine it with the RLP definitions of majority parties (Main party $(R L P)_{j t}$ and \#1 Party $(R L P)_{j t}$ explained above). This gives us confidence in the accuracy of our definition of local majorities as it taps the information from multiple sources.

- Defining majority parties/coalitions in the Elections data: For each election, we define a coalition as a set of parties supporting the same candidate (it may be just one party or multiple). Then, we define a coalition that gets most seats and define a coalition that supports a winning candidate (mayor or president). Because of the existence of a majority premium for the winning

\footnotetext{
${ }^{43}$ Often, for example, coalition may be listed as "Centro Destra" (center-right), or "Lista Civica" (civil list), or using other official name of a coalition, like "Polo per le Liberta" instead of listing its members "Forza Italia", "Alleanza Nazionale" or others.

${ }^{44}$ Data also includes other positions of "questore/commissario" - a super-intendent or commissioner. But these are temporary positions that appear on rare occasions, hence we do not report statistics on them.
} 
candidate, these two definitions should be equivalent. Indeed, these definitions are the same in all instances except for the rare cases, which account for well under $1 \%$ of observations. Hence, we define a variable:

Main party (Elections $)_{j t}$ - the party or coalition that gets the most seats in an election in region/province/ municipality $j$ at time $t$. It is equivalent to a party/coalition of a winning regional president/province president/municipality mayor in $j$ at time $t$.

\section{B.3.3 Combining Dataset \#4 and Dataset \#5 and Defining Individual Majority Affiliation}

Next we describe construction of Majority Affiliation for each politician from RLP. For that, we combine information on local majority parties/coalitions derived from RLP - Main party $(R L P)_{j t}$ and \#1 Party $(R L P)_{j t}$, and from the Elections data - Main party (Elections) ${ }_{j t}{ }^{45}$ There are two challenges when defining majority affiliation for individual politicians.

The first challenge has been already mentioned in Online Appendix B.3.1. Since, for any politician, RLP may report an affiliation with just one party (in our previous example, "B"), or a coalition ("A $|\mathrm{B}| \mathrm{C}$ "), or a coalition name "Z", there may be some noise in defining majorities just based on this data. In those cases, when, for example, mayor reports " $Z$ ", we would not be able to classify politicians reporting " $\mathrm{A}$ ", "B" or " $\mathrm{C}$ " as belonging to mayor's coalition. Hence, it is very useful to complement this data with information from the Elections data. The main advantage of the Elections data is that we observe all party names (" $\mathrm{A}$ ", "B", and " $\mathrm{C}$ " separately) that form a coalition, and we also often observe an official coalition name (" $Z$ "), if this exists. Hence, when defining majority affiliation at the individual level, we compare individual affiliation with both majority definitions from RLP and majority definition from the Elections data. This gives us confidence that majority affiliations can be defined as cleanly as possible. Extensive manual checks confirm that this definition significantly improves upon the definition based on RLP only.

The second challenge concerns politicians at the municipal level: in small municipalities, many politicians are affiliated with local political lists/coalitions - so called, civil lists, "lista civica", that may unite various party members. As an example, in an election held in the municipality of Cecima, there were two coalitions "Lista Civica con Voi per Voi" and "Lista Civica per Cecima". However, in RLP, both of them were reported as "Lista Civica" for short. If then both of those lists got at least one seat after the election, it would not be possible to understand whether the "Lista Civica" affiliation reported for a politician in RLP that of the winning list or not. We call such cases (elections that have multiple "Lista Civica" coalitions that got at least one seat in the council) elections with ambiguous "Lista Civica" names. Such cases are quite prevalent and represent half of all elections at the municipal level. In these ambiguous cases, if a winning party is "Lista Civica" and a politician reports "Lista Civica", we treat individual majority affiliation as missing. This results in more than 600 thousand missing values from up to 3 million individual-level observations at the municipal level. For some of those missing cases, however, we can be certain that individuals belong to local majorities. This happens for individuals holding key positions (the highest Hierarchical rank). This

\footnotetext{
${ }^{45}$ Notice that the Elections data is an unbalanced panel data with time gaps in between of elections. We impute most recent election outcomes (up to 4 years) to fill in those time gaps.
} 
decreases the number of missing observations in the Majority affiliation.

\section{B.4 The Matched Firm-level Data (Combining Dataset \#1 - Dataset \#5)}

\section{B.4.1 Matching INPS with Politicians Data (Combining Dataset \#1 with Datasets \#4 and \#5)}

We merge Politicians Data with INPS worker records using individual fiscal codes over time. This allows us to identify those local politicians that are employed in private firms, while also holding political office. Online Appendix Table A.3 shows summary statistics for the matched politicianworkers sample (in the years when they are both employed in a firm and work as politicians). We see that, among all local politicians, about one third $(162,417)$ have ever taken a private job while also in office. Clearly, the overwhelming majority of connections are through politicians at the municipal level. This is both because majority of politicians are municipality politicians and because, proportionally, municipality-level politicians work in private sector more than other politicians. It is also interesting to look at their education levels (this is a self-reported education level from RLP). Relative to the full sample of politicians, worker-politicians, on average, have slightly lower education levels (relatively more high-school graduates than university graduates, when compared to the whole sample). The share of politicians with majority affiliation is just slightly higher among worker-politicians. In addition, by comparing with other private-sector workers, politicians are employed disproportionally more on white-collar jobs or managerial positions and have significantly higher wages.

\section{B.4.2 Matching INPS with the Firm Financials and Patent Data (Combining Dataset \#1 with Datasets \#2 and \#3)}

We match firm-level data from INPS with Cerved using firms' fiscal codes. Many firm observations in INPS data do not match to Cerved, as can be seen from Table 4 - these are mainly small or shortlived firms not filing balance sheet information, sole-proprietorships, or household producers. On the other hand, for about $16 \%$ of observations from Cerved, firm fiscal codes were not possible to match to INPS. This means those firms did not make any INPS social security contributions for their workers - they might be employing only contractors or workers in agriculture. Finally, we merge this data with firms' patenting information from Dataset \#3. Only about $4 \%$ of patents did not get matched with INPS firms. In the data, over 12 thousand firms filed a patent at least once. 


\begin{tabular}{|c|c|c|}
\hline VARIABLES & & \\
\hline Observations & 825,105 & \\
\hline Distinct politicians & 162,417 & \\
\hline Years & $1993-2014$ & \\
\hline \multirow[t]{5}{*}{ Job in the firm: } & Top management & $2.86 \%$ \\
\hline & Middle management & $6.66 \%$ \\
\hline & Other white-collar job & $55 \%$ \\
\hline & Blue collar job & $33 \%$ \\
\hline & Trainee & $1.25 \%$ \\
\hline \multirow[t]{4}{*}{ Education: } & $<$ high school & $28.57 \%$ \\
\hline & high school & $53.09 \%$ \\
\hline & University & $18.29 \%$ \\
\hline & Post-graduate & $0.05 \%$ \\
\hline Average weekly pay & & 829 \\
\hline \multicolumn{3}{|l|}{ Political VARiables } \\
\hline \multirow[t]{3}{*}{ Regional Rank: } & Region & $0.4 \%$ \\
\hline & Province & $2.1 \%$ \\
\hline & Municipality & $97.5 \%$ \\
\hline \multirow[t]{3}{*}{ Hierarchical Rank: } & Mayor, President, Vice-mayor, Vice-president & $8.63 \%$ \\
\hline & Executive councilor & $17.79 \%$ \\
\hline & Council member & $73.58 \%$ \\
\hline Majority Affiliation: & Majority & $73 \%$ \\
\hline
\end{tabular}

Notes: Summary statistics for the sample of politicians who work in the private sector while holding office. The table is an extended version of Table 3 but on a sample of politicians who match to INPS. Nominal variables are deflated with GDP deflator with a base year in 2014. 
Appendix Figure A.1: Share of High-Rank Connected Large Firms

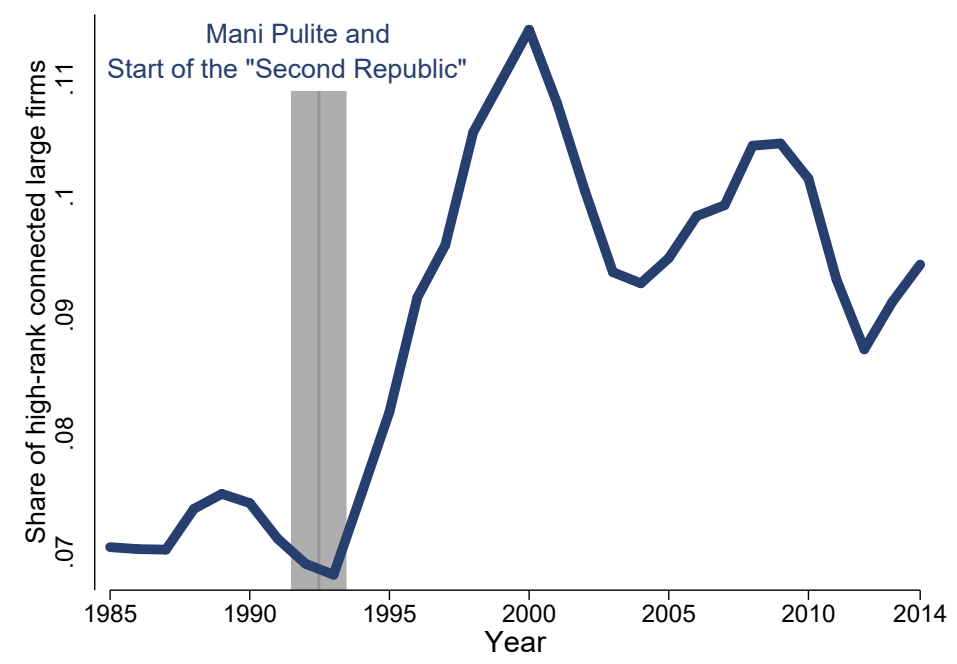

Notes: This figure plots the average share of firms that are politically connected with high-rank politicians among large firms with more than 100 employees over time. See Section 4.2 for the definition of high-rank connection. 


\section{B.5 Industry-Level Bureaucracy and Government Dependence Indices}

\section{Bureaucracy Index and Political Connections}

We build on Pellegrino and Zingales (2014) and develop our own industry-level "bureaucracy index" that measures the level of regulatory or bureaucratic burden, based on newspaper articles from Factiva - an online search engine that searches newspaper articles.

We look at newspaper articles from four large news providers and count the number of articles that contain keywords that proxy for government intervention or bureaucracy level that sectors are facing. ${ }^{46}$ Factiva groups newspaper articles into 58 sectors that roughly correspond to 2-digit NACE Rev 2 industry classification. We focus on articles starting from 1991 and experiment with alternative lists of keywords. List 1 consists of "regulation*", "regulated", "regulator", "bureaucracy", "bureaucratic", "deregulation*", "deregulated", "paperwork", "red tape", "license*" and plural forms of these words. List 2 adds additional words: "authority", "authorities", "liberaliz", "reform*", "Agency", "Agencies", "Commission", "Commissions", "policy maker*", "policymaker*", "government", "official form" ${ }^{*}$, "official procedure*." The * character denotes that variations of these words were also included. We calculate the Bureaucracy Index 1 (2) of sector $i$ as:

Bureaucracy Index $1(2)_{i}=\frac{\text { [All articles related to } i] \cap[\text { All articles with keywords from List 1(2)] }}{\text { All articles related to } i}$.

This measure is simply the share of newspaper articles in a sector that have certain keywords that are related to bureaucracy/regulation. Figure A.2 shows a strong and positive relationship between industry's Bureaucracy Indices and the share of firms that are politically connected. ${ }^{47}$ Table A.4 reports Bureaucracy Indices and connection intensities for all sectors available in Factiva. ${ }^{48}$

Appendix Figure A.2: Bureaucracy and Connections across Industries

$\begin{array}{ll}\text { (a) Bureaucracy Index } 1 \text { and connections } & \text { (b) Bureaucracy Index } 2 \text { and connections }\end{array}$
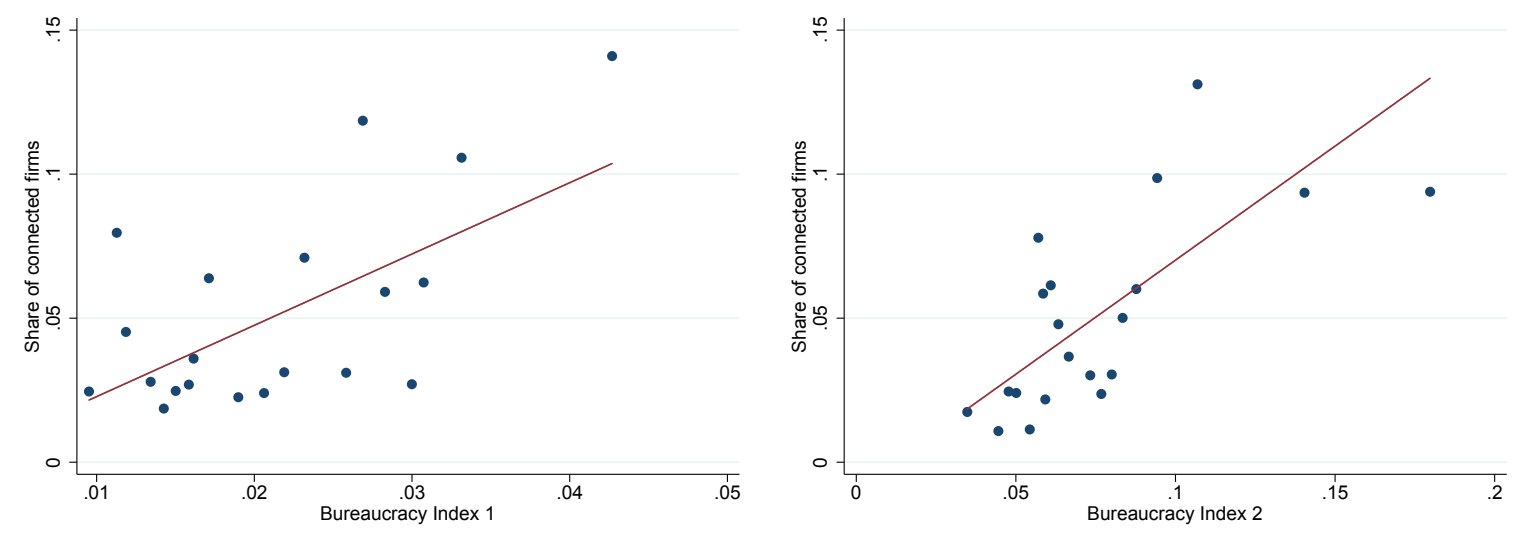

Notes: The binscatter plots with linear fits of the share of firms connected with politicians against the Bureaucracy Index for all sectors available in Factiva News search. Sector-level Bureaucracy Index is defined in equation 15 and is the share of newspaper articles in a sector that have certain keywords related to bureaucracy or regulation. Panel (a) uses the benchmark Bureaucracy Index from the main text, while panel (b) uses Bureaucracy Index 2.

\footnotetext{
${ }^{46}$ These news providers are Bloomberg, Dow Jones Adviser, Financial Times, and The Wall Street Journal. Using international newspapers alleviates concerns of endogeneity and reverse causality, as opposed to looking at Italian news.

${ }^{47}$ For this exercise, we aggregate industry classification from INPS (ATECO 2007) to the 58 sectors reported in Factiva.

${ }^{48}$ These correlations are stronger if consider majority-level or high-rank connections instead.
} 


\section{Appendix Table A.4: Connections and Bureacracy Index across Industries}

\begin{tabular}{|c|c|c|c|c|c|}
\hline Code & Industry description & $\begin{array}{c}\text { Connection } \\
\text { intensity }\end{array}$ & $\begin{array}{c}\text { High-rank } \\
\text { connection } \\
\text { intensity }\end{array}$ & $\begin{array}{l}\text { Bureaucracy } \\
\text { Index } 1\end{array}$ & $\begin{array}{c}\text { Bureaucracy } \\
\text { Index } 2\end{array}$ \\
\hline E36 & Water Utilities & 0.254 & 0.065 & 0.046 & 0.159 \\
\hline K64 & Banking/Credit or Investment/Securities & 0.222 & 0.075 & 0.027 & 0.110 \\
\hline $\mathrm{D}$ & Electricity/Gas Utilities & 0.155 & 0.032 & 0.033 & 0.191 \\
\hline $\mathrm{C} 12$ & Tobacco Products & 0.146 & 0.005 & 0.028 & 0.092 \\
\hline $\mathrm{C} 21$ & Pharmaceuticals & 0.139 & 0.024 & 0.031 & 0.087 \\
\hline $\mathrm{C} 24$ & Primary Metals & 0.119 & 0.026 & 0.011 & 0.057 \\
\hline J61 & Telecommunication Services & 0.114 & 0.040 & 0.031 & 0.095 \\
\hline B & Mining/Quarrying & 0.101 & 0.008 & 0.011 & 0.057 \\
\hline $\mathrm{C} 29$ & Motor Vehicles or Motor Vehicle Parts & 0.099 & 0.008 & 0.017 & 0.062 \\
\hline C11 & Beverages/Drinks & 0.083 & 0.005 & 0.023 & 0.059 \\
\hline C19 & Downstream Operations & 0.080 & 0.015 & 0.012 & 0.071 \\
\hline E38 & Waste Treatment/Disposal & 0.060 & 0.005 & 0.013 & 0.085 \\
\hline $\mathrm{C} 26$ & Computer Hardware/Consumer Electronics & 0.059 & 0.005 & 0.023 & 0.060 \\
\hline $\mathrm{C} 22$ & Rubber Products or Plastics Products & 0.057 & 0.009 & 0.018 & 0.058 \\
\hline $\mathrm{C} 20$ & Chemicals & 0.057 & 0.006 & 0.026 & 0.081 \\
\hline $\mathrm{C} 28$ & Machinery & 0.051 & 0.005 & 0.015 & 0.051 \\
\hline A & Agriculture & 0.049 & 0.009 & 0.011 & 0.063 \\
\hline $\mathrm{C} 27$ & Batteries/Electric Lighting Eqpm/Electrical Components & 0.047 & 0.005 & 0.021 & 0.064 \\
\hline F42 & Heavy Construction Not Sewer Construction & 0.041 & 0.005 & 0.022 & 0.104 \\
\hline $\mathrm{N}$ & Rental/Leasing/Recruitment Services/Admin/Support Serv & 0.040 & 0.004 & 0.016 & 0.082 \\
\hline J58 & Publishing & 0.039 & 0.007 & 0.031 & 0.076 \\
\hline $\mathrm{C} 17$ & Paper/Pulp & 0.039 & 0.004 & 0.022 & 0.047 \\
\hline $\mathrm{H}$ & Transportation/Logistics or Postal Service & 0.036 & 0.005 & 0.020 & 0.096 \\
\hline $\mathrm{C} 23$ & Building Materials/Products or Glass/Glass Products & 0.036 & 0.003 & 0.017 & 0.059 \\
\hline $\mathrm{J} 62$ & Computer Services & 0.034 & 0.004 & 0.016 & 0.071 \\
\hline E37 & Sewer Construction or Wastewater Treatment & 0.033 & 0.003 & 0.016 & 0.169 \\
\hline C30 & Aerospace/Defense or Shipbuilding or Railroads & 0.032 & 0.005 & 0.016 & 0.079 \\
\hline C33 & Machinery Repair/Maintenance/Aircraft Maintenance Serv & 0.028 & 0.002 & 0.040 & 0.076 \\
\hline $\mathrm{C} 13$ & Textiles & 0.026 & 0.002 & 0.030 & 0.061 \\
\hline $\mathrm{R}$ & Theaters/Entertainment Venues/Libraries/Archives & 0.024 & 0.003 & 0.035 & 0.090 \\
\hline F41 & Building Construction & 0.022 & 0.001 & 0.014 & 0.059 \\
\hline J59 & TV Program/Sound/Music Recording/Publishing & 0.022 & 0.001 & 0.021 & 0.059 \\
\hline J63 & Online Service Providers & 0.019 & 0.002 & 0.025 & 0.077 \\
\hline $\mathrm{C} 15$ & Leather Goods & 0.018 & 0.002 & 0.011 & 0.028 \\
\hline C31 & Furniture & 0.018 & 0.001 & 0.015 & 0.037 \\
\hline J60 & Broadcasting & 0.018 & 0.001 & 0.029 & 0.086 \\
\hline I55 & Lodgings & 0.017 & 0.001 & 0.027 & 0.073 \\
\hline $\mathrm{C} 16$ & Wood Products & 0.016 & 0.001 & 0.014 & 0.044 \\
\hline $\mathrm{C} 25$ & Metal Products & 0.016 & 0.001 & 0.008 & 0.048 \\
\hline $\mathrm{C} 32$ & Jewelry/Musical Instruments/Sport Goods/Games & 0.016 & 0.001 & 0.030 & 0.065 \\
\hline C18 & Printing & 0.015 & 0.002 & 0.014 & 0.039 \\
\hline M & Legal and Professional & 0.015 & 0.002 & 0.027 & 0.145 \\
\hline $\mathrm{C} 10$ & Food Products & 0.014 & 0.001 & 0.022 & 0.064 \\
\hline G46 & Wholesalers Non-Auto/Auto Part Wholesale & 0.014 & 0.001 & 0.016 & 0.055 \\
\hline $\mathrm{C} 14$ & Clothing & 0.013 & 0.002 & 0.028 & 0.057 \\
\hline K & Financial Services & 0.011 & 0.001 & 0.031 & 0.118 \\
\hline L68 & Real Estate & 0.011 & 0.000 & 0.011 & 0.048 \\
\hline G45 & Motor Vehicle Dealing/Repair/Maintenance/Auto Stores & 0.009 & 0.000 & 0.018 & 0.053 \\
\hline F43 & Special Trade Contractors or Building Refurbishment & 0.009 & 0.000 & 0.010 & 0.044 \\
\hline G47 & Retail Non-Auto Parts/Tire Stores Not Auto Dealing & 0.007 & 0.000 & 0.013 & 0.046 \\
\hline $\mathrm{I} 56$ & Bars/Public Houses or Restaurants/Cafes & 0.005 & 0.000 & 0.015 & 0.051 \\
\hline E39 & Waste Management/Recycling Services & 0.003 & 0.000 & 0.020 & 0.080 \\
\hline
\end{tabular}

Notes: Table reports measures of connections and the bureaucracy indices across industries. Industry codes are based on classifications from the Factiva News search and the codes correspond to NACE Rev 2 classification. Column 3 reports the average share of connected firms in an industry. Column 4 reports the average share of high-rank connected firms in an industry. Columns 5 and 6 report Bureaucracy Index 1 and Index 2, respectively. The indices show the average share of newspaper articles about a sector from Factiva News search that mention government regulation- or bureaucracy-related words. Industry-level Bureaucracy Index 1 is our benchmark index defined in Section 3, while Bureaucracy Index 2 is defined in Section C. 


\section{Government Dependence Index and Political Connections}

We define industry-level indices of government dependence to proxy for the importance of government demand and procurement contracts for the firms. For this purpose, we use a 2-digit input-output table issued by the Italian National Statistical Institute (Istat) in 2010. Denote by $Y_{j}$ total output of an industry $j$. Then $Y_{j}=F_{j}+I_{j}$, where $F_{j}$ denotes industry's output used as final consumption, while $I_{j}$ denotes industry's output used as an intermediate input. Our Government Dependence Indices then measure the share of industry's output - by type of use - demanded by the public sector, i.e. public administration, education, health, and waste management services. Specifically,

$$
\text { Government Dependence Index } 1=\frac{F_{j}^{P}}{F_{j}} \quad \text { Government Dependence Index } 2=\frac{I_{j}^{P}}{I_{j}} \text {, }
$$

where superscript $P$ denotes output demanded by the public sector. Government Dependence Index 2 is similar to the index defined in Cingano and Pinotti (2013). Figure A.3 shows that none of these measures of government dependence correlate with the share of firms that are politically connected. These correlations are essentially zero also if we look at majority-level or high-rank connections instead.

Appendix Figure A.3: Government Dependence and Connections across Industries

(a) Government Dependence Index 1 and connections

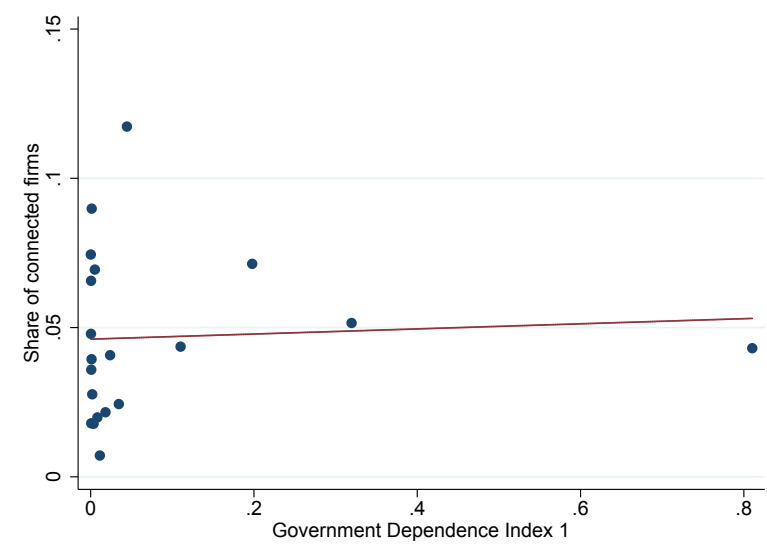

(b) Government Dependence Index 2 and connections

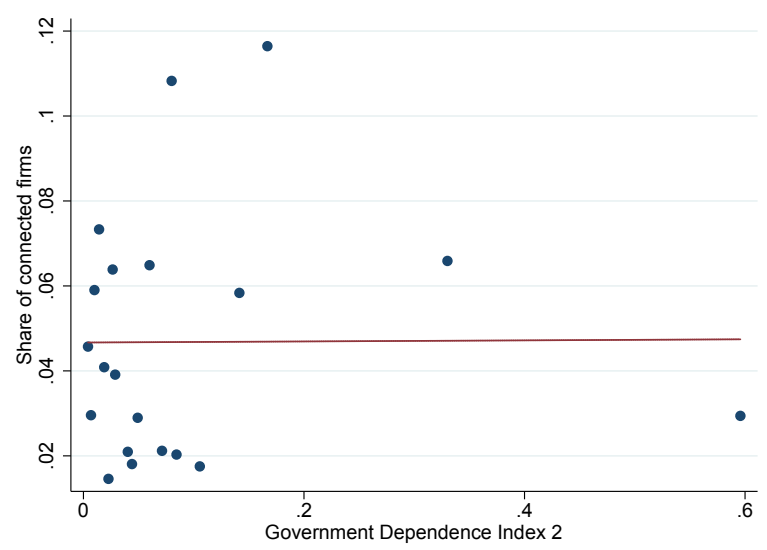

Notes: The binscatter plots with linear fits of the share of firms connected with politicians against the Government Dependence Index for all 2-digit sectors from Istat. Industry-level Government Dependence Indices are defined in equation 16 and are based on input-output tables from Istat in 2010. Correspondingly, an industry's share of connected firms is calculated as an average for 2009-2011 period. Panel (a) uses Index 1 for the final-use output, while panel (b) uses Index 2 for the intermediate-use output. 


\title{
C Robustness and Additional Empirical Results
}

\author{
Appendix Figure B.1: LeAdership PARAdox - REVISITED
}

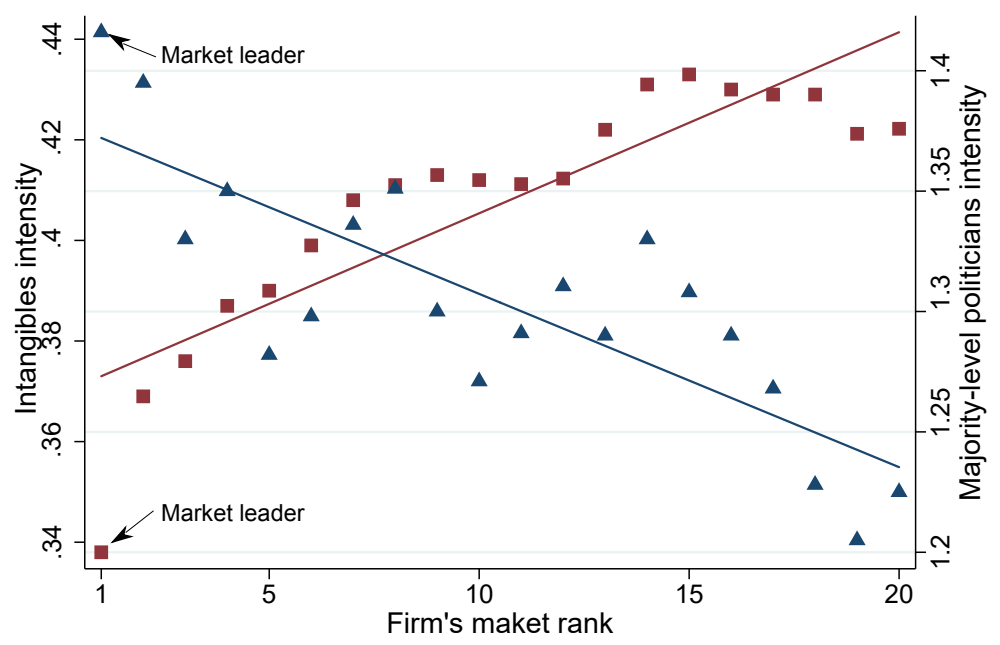

- Intangibles intensity $\quad \Delta$ Majority-party politicians intensity

Notes: Figure plots politician intensity and innovation intensity over a firm's market rank for top 20 firms in the markets. Market is defined at (6-digit) industry $\times$ region $\times$ year level. Markets in which top 1 firm holds less than 10\% share are excluded. Politician intensity (blue triangles) is the number of majority-member politicians employed in a firm normalized by 100 white-collar employees. Innovation intensity (red squares) is intangible assets over value added. Both outcome variables are adjusted for industry, region, and year fixed effects. The blue and red lines depict regression lines from regressing politician intensity and innovation intensity, respectively, on market rank controlling for industry, region, and year fixed effects.

Appendix Table B.1: Market Rank, Innovation, and Political Connection

\begin{tabular}{lcccc}
\hline \hline & $\begin{array}{c}\text { Politicians } \\
\text { intensity }\end{array}$ & $\begin{array}{c}\text { Majority politicians } \\
\text { intensity }\end{array}$ & $\begin{array}{c}\text { Intangibles } \\
\text { intensity }\end{array}$ & $\begin{array}{c}\text { Patents } \\
\text { intensity }\end{array}$ \\
\hline Rank 1 & $0.298^{* * *}$ & $0.125^{* * *}$ & $-3.485^{* * *}$ & $-18.71^{* * *}$ \\
& $(0.0181)$ & $(0.0129)$ & $(0.227)$ & $(0.798)$ \\
Rank 2 & $0.240^{* * *}$ & $0.116^{* * *}$ & $-1.443^{* * *}$ & $-16.81^{* * *}$ \\
& $(0.0191)$ & $(0.0136)$ & $(0.239)$ & $(0.972)$ \\
Rank 3 & $0.204^{* * *}$ & $0.0734^{* * *}$ & $-0.804^{* * *}$ & $-15.39^{* * *}$ \\
& $(0.0202)$ & $(0.0143)$ & $(0.253)$ & $(1.080)$ \\
Rank 4 & $0.179^{* * *}$ & $0.0792^{* * *}$ & $-0.442^{*}$ & $-13.15^{* * *}$ \\
& $(0.0212)$ & $(0.0150)$ & $(0.265)$ & $(1.234)$ \\
Rank 5 & $0.163^{* * *}$ & $0.0525^{* * *}$ & 0.0955 & $-13.67^{* * *}$ \\
& $(0.0221)$ & $(0.0157)$ & $(0.277)$ & $(1.392)$ \\
Log age & $0.0377^{* * *}$ & $0.0249^{* * *}$ & $-5.178^{* * *}$ & $-7.186^{* * *}$ \\
& $(0.00331)$ & $(0.00235)$ & $(0.0413)$ & $(0.302)$ \\
\hline Year FE & YES & YES & YES & YES \\
Region FE & YES & YES & YES & YES \\
Industry FE & YES & YES & YES & YES \\
$N$ & 5441271 & 5441271 & 4962755 & 23409 \\
\hline \hline
\end{tabular}

Notes: Firm-level OLS regressions of political connection and innovation intensity over firm's market rank. Market is defined at (6-digit) industry $\times$ region $\times$ year level. Rank $n$ is a dummy equal to one if a firm is ranked $n^{\prime}$ th in the market in that year based on its employment level. Omitted group pools firms that are ranked 6 and above. Dependent variables: column 1 - Politicians intensity is the number of politicians employed over 100 white-collar workers; columns 2 - Majority politicians intensity is the number of majority-party politicians employed over 100 white-collar workers; columns 3 - Intangibles intensity is intangibles over firm value added; columns 4 - Patents intensity is the number of patents (conditional on patenting) over 100 white-collar workers. All regressions control for year, region, and year dummies. ${ }^{*} p<0.1,{ }^{* *} p<0.05,{ }^{* * *} p<0.01$. Similar to Figures 5 and B.1, this table shows that the largest market leaders are more politician intensive but less innovation intensive. In addition, age has a strong effect for both connections and innovation intensities. 


\section{Appendix Figure B.2: Market Rank, Innovation, and Political Connection, with an Alternative Defi- nition of Market Rank}

(a) Politician and Patent Intensities

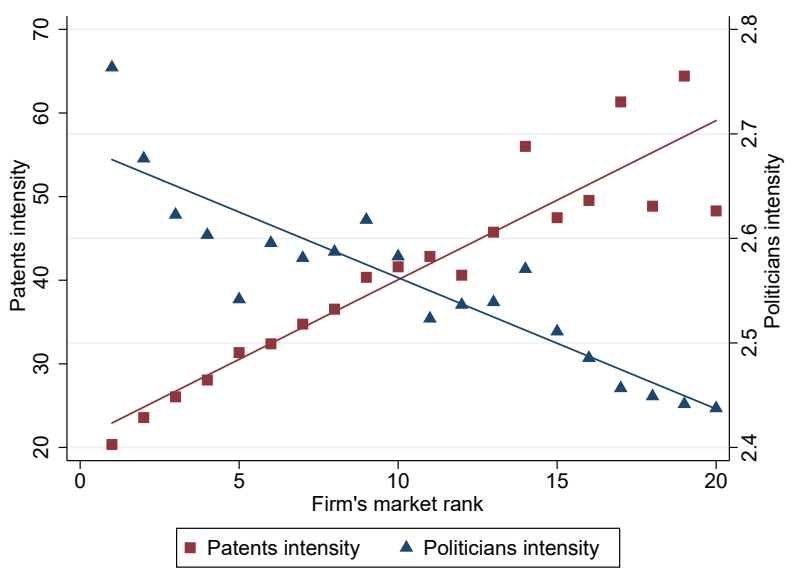

(b) Majority-level Politician and Intangible Intensities

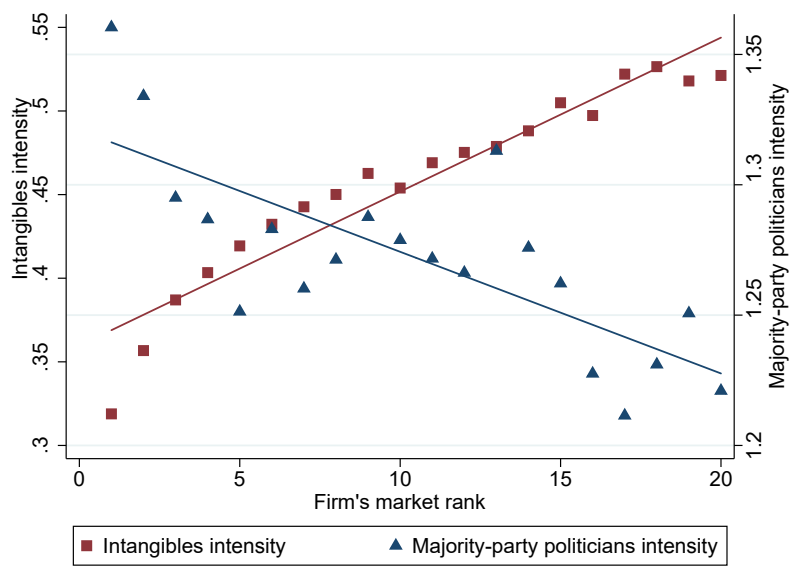

Notes: Figure repeats main plots from Figures 5 and B.1 but with an alternative definition of market rank based on firms' value added. Market is defined at (6-digit) industry $\times$ region $\times$ year level. Markets in which the top 1 firm holds less than $10 \%$ share are dropped. In Panel (a), politician intensity (blue triangles) is the number of politicians employed in a firm normalized by 100 white-collar employees. Innovation intensity (red squares) is the number of patent applications in a year normalized by 100 white-collar employees (conditional on patenting). In Panel (b), politician intensity (blue triangles) is the number of majority-member politicians employed in a firm normalized by 100 white-collar employees. Innovation intensity (red squares) is intangible assets over value added. All outcome variables are adjusted for industry, region, and year fixed effects. The blue and red lines depict regression lines from regressing politician intensity and innovation intensity, respectively, on market rank controlling for industry, region, and year fixed effects. Market leaders are less innovation-intensive and more politician-intensive relative to their competitors.

\section{Appendix Figure B.3: Market Rank, Innovation, and Political Connection, with Quality-adjusted Patent Intensity}

(a) Citations-adjusted Patent Intensity

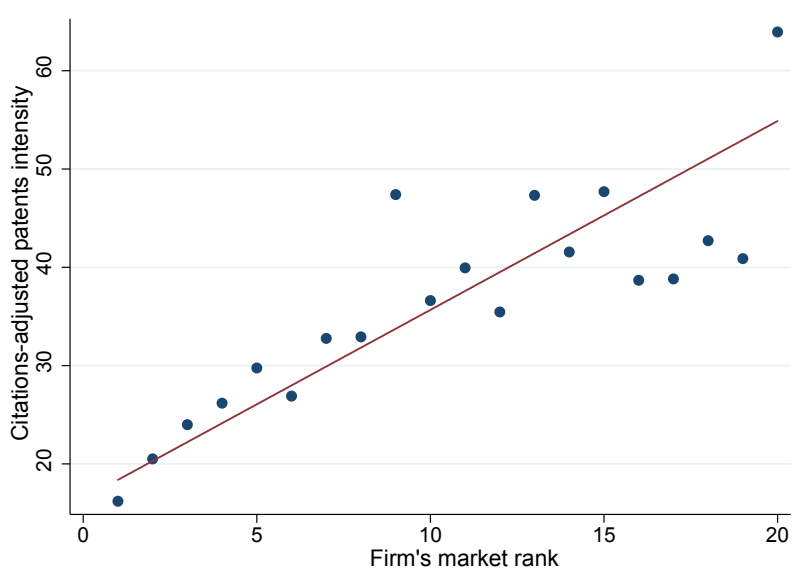

(b) Family-size-adjusted Patent Intensity

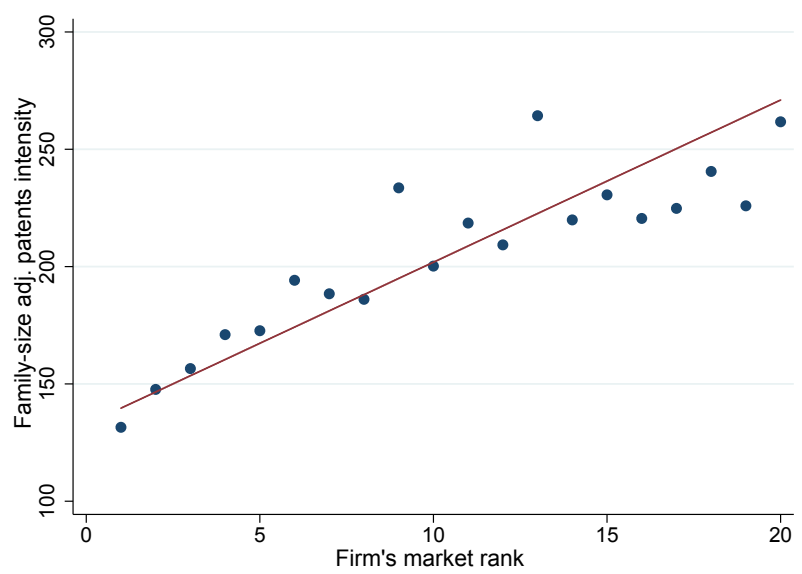

Notes: Figure plots average outcome variable over firm's market rank for top 20 firms in the markets. Market is defined at (6-digit) industry $\times$ region $\times$ year level. Market rank is defined by a firm's employment level. Markets in which top 1 firm holds less than $10 \%$ share are dropped. Outcome variables are demeaned with industry, year, and region fixed effects. The red line depicts a regression line from regressing firm's outcome on market rank, controlling for industry, region, and year fixed effects. In Panel (a) the outcome is 5-year citations-adjusted patent counts per 100 white-collar workers; Panel (b) considers patent family size-adjusted patent counts per 100 white-collar workers. Market leaders produce lower quality-adjusted innovation, when compared to their competitors. 
Appendix Table B.2: Growth in Size versus Productivity

\begin{tabular}{|c|c|c|c|c|}
\hline \multicolumn{5}{|c|}{ - Panel A. Growth in Size - } \\
\hline $\begin{array}{r}\text { Dependent variable- } \\
\text { Growth in: }\end{array}$ & Employment & Value added & Profits & Employment, white-collar \\
\hline \multirow[t]{2}{*}{ Connection Dummy } & $0.0432^{* * *}$ & $0.0148^{* * *}$ & $0.0284^{* * *}$ & $0.0312^{* * *}$ \\
\hline & $(0.0012)$ & $(0.0016)$ & $(0.0135)$ & $(0.106)$ \\
\hline Age, Size, Assets & Yes & Yes & Yes & Yes \\
\hline Firm FE & Yes & Yes & Yes & Yes \\
\hline Observations & 6585740 & 5710338 & 5983604 & 5237358 \\
\hline \multicolumn{5}{|c|}{ - Panel B. Growth in productivity - } \\
\hline $\begin{array}{r}\text { Dependent variable - } \\
\text { Growth in: }\end{array}$ & LP & TFP & Intangibles & Patents \\
\hline \multirow[t]{2}{*}{ Connection Dummy } & $-0.0305^{* * *}$ & $-0.0209^{* * *}$ & $-0.0510^{* * *}$ & -0.0042 \\
\hline & $(0.0018)$ & $(0.0014)$ & $(0.0112)$ & $(0.0038)$ \\
\hline Age, Size, Assets & Yes & Yes & Yes & Yes \\
\hline Firm FE & Yes & Yes & Yes & Yes \\
\hline Observations & 5623077 & 5291979 & 5538995 & 73180 \\
\hline
\end{tabular}

Notes: Table summarizes a positive association of firm-level political connections with the next-period growth in size (Panel A) and a negative association of connections with the next-period growth in productivity of a firm (Panel B). Dependent variables for the growth in size in Panel A are employment, value added, profits, and white-collar employment growth. Dependent variables for the growth in productivity in Panel B are labor productivity, TFP, share of intangibles (intangibles over value added), and patents growth. Since patenting is a slow-moving process, we look at the average (annualized) 3-year patent growth of firms.

\section{Appendix Figure B.4: Distribution of Elections by Margins of Victory}

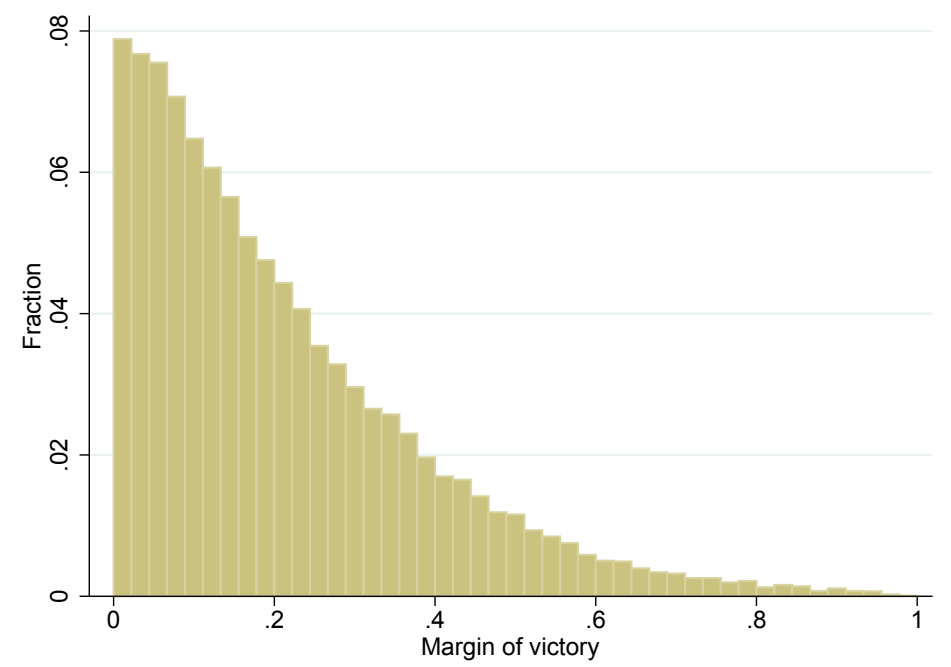

Notes: Histogram plotting distribution of elections by their respective margins of victory. Margin of victory is equal to the difference between the share of votes received by a winning candidate minus the share of votes by a runner-up. 
Appendix Figure B.5: Marginal Elections within 2\% Margin by Provinces (municipality \& province)

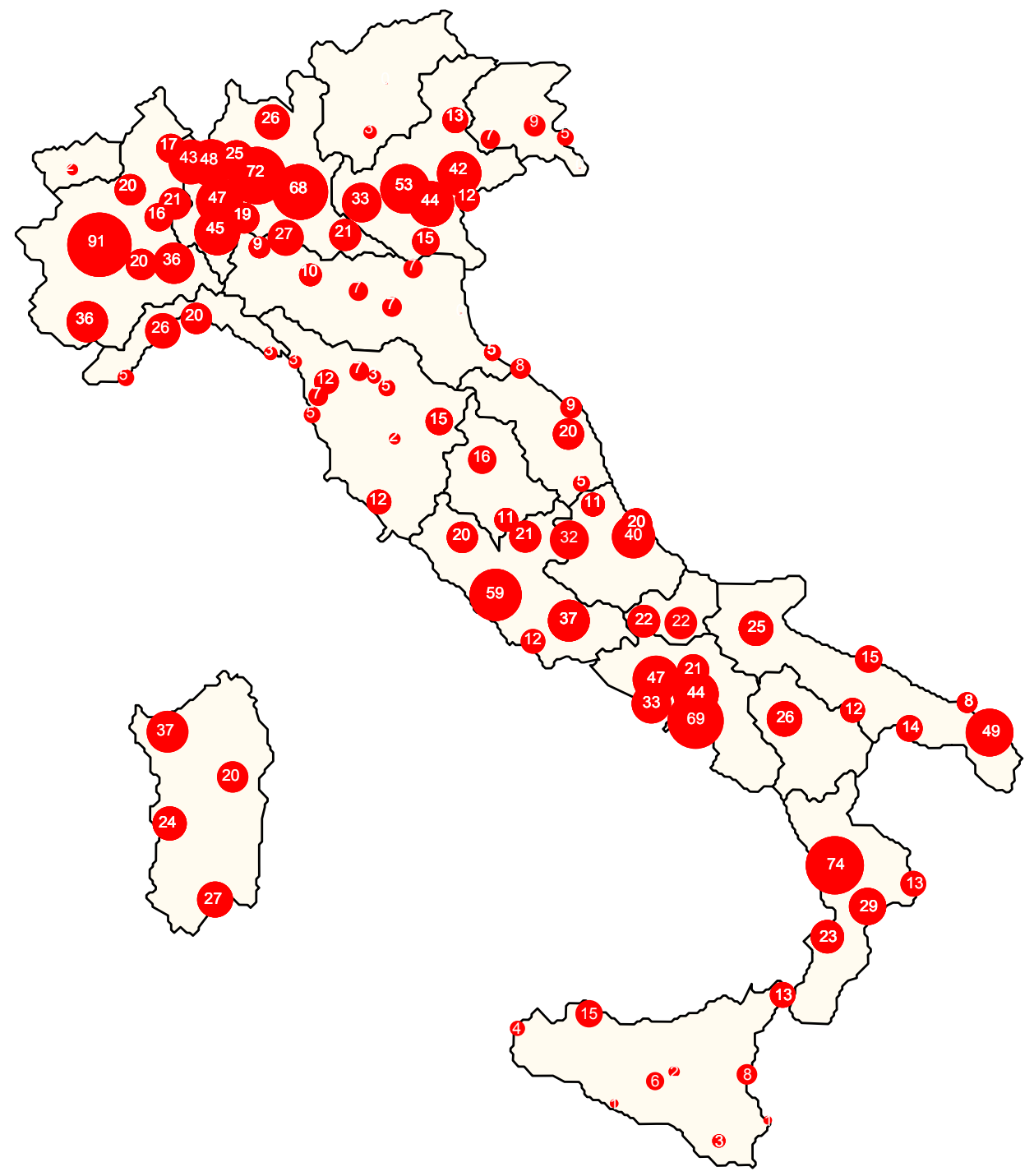

Notes: The map displays the number of municipal and province-level marginal elections, decided within a $2 \%$ victory margin. Each circle depicts the location of the main city in a province, and number of total marginal elections in 19932014 in a corresponding province in that circle. Victory margin is defined as the difference between share of votes of the winning candidate and the share of votes of the closest competitor. 
Appendix Figure B.6: Employment and Labor Productivity Growth after Election. 20\% Margin of Victory Sample.

(a) EMPLOYMENT GROWTH AFTER ELECTION $(T \rightarrow T+1)$

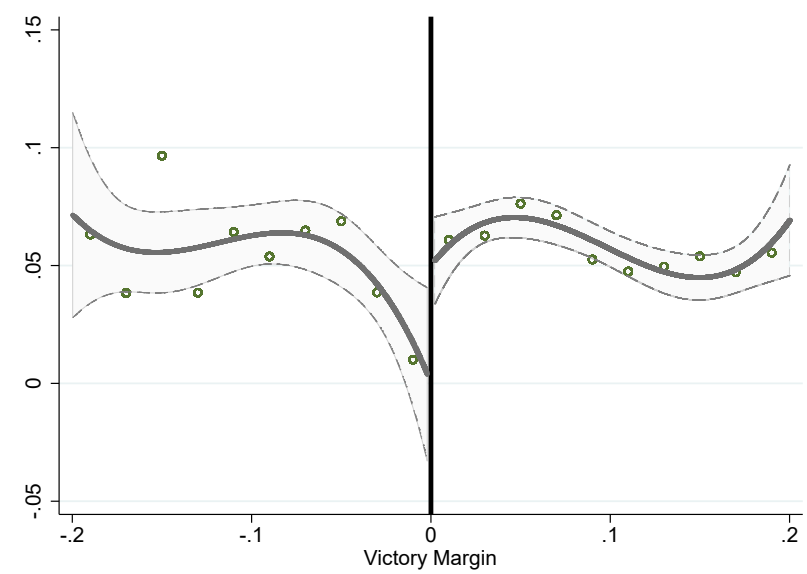

(b) LP GROWTH AFTER ELECTION $(T \rightarrow T+1)$

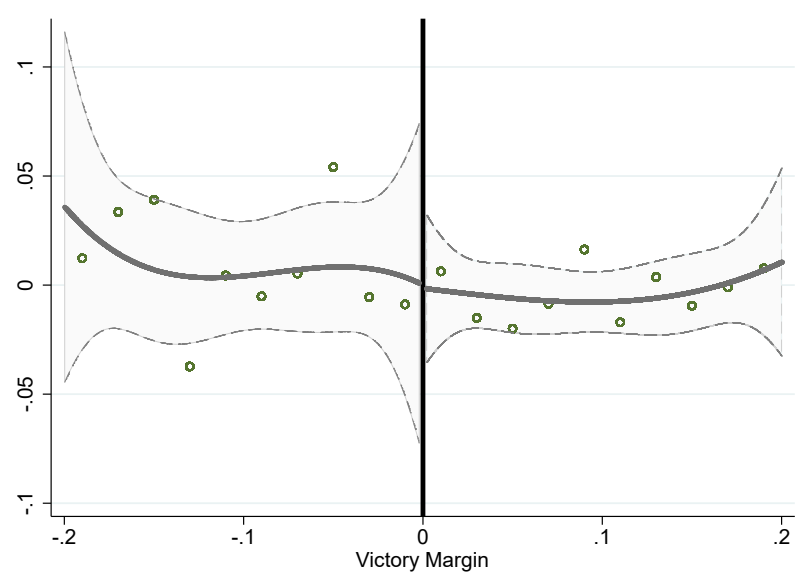

Notes: Figure plots a firm's growth from $T$ to $T+1$ against margin of victory at time $T$ for the sample of elections within a $5 \%$ margin of victory. Positive margins of victory denote firms that have been connected at time $T-1$ with a politician from a party that won an election at time $T$ with the corresponding margin of victory. Likewise, negative margins of victory depict firms that are connected with losing politicians. For visibility, we divide the $x$-axis into 0.01 -wide intervals of the margin of victory at time $T$ and each point denotes the average outcome for firms in that interval. The solid lines represent predicted third order polynomial fits from a regression that includes third order polynomial in the margin of victory, a dummy $\operatorname{Win}_{i T-1}$, and an interaction of the dummy with the polynomial (a regression in equation 11 that excludes additional controls). The dashed lines represent $90 \%$ confidence intervals. Outcome variable in Panel (a) is employment growth, while in Panel (b) is labor productivity growth. Figures are normalized such that outcome variables for marginal losers at the threshold are equal to zero.

Appendix Table B.3: Politicians' Within-Firm Within-Group Wage Premium

\begin{tabular}{l|cccc}
\hline & \multicolumn{2}{|c}{ MUNICIPALITY LEVEL POLITICIANS } & \multicolumn{2}{c}{ PROVINCE LEVEL POLITICIANS } \\
& Female & Male & Female & Male \\
Blue-collar & 1.06 & 1.08 & 1.15 & 1.04 \\
White-collar & 1.10 & 1.10 & 1.19 & 1.19 \\
\hline \hline & \multicolumn{2}{|c}{ REGIONAL LEVEL } & POLITICIANS & \multicolumn{2}{c}{ HIGH-RANK } & POLITICIANS \\
& Female & Male & Female & Male \\
Blue-collar &. &. & 1.09 & 1.08 \\
White-collar & 2.08 & 1.57 & 1.25 & 1.18 \\
\hline
\end{tabular}

Notes: Table shows politicians' within-firm wage premium, by type of job and gender. Premium in each cell is defined as the weekly wage paid to politicians, divided by the average weekly wage paid to non-politicians within the same firm, conditional on the same type of job and gender. Four different panels present wage premiums calculated for politicians at the municipal level, provincial level, regional level, and high-rank politicians, respectively. Cells are empty if the number of observations in that cell is less than 100 . 